\title{
Estimates of $\mathrm{CO}_{2}$ fluxes over the city of Cape Town, South Africa, through Bayesian inverse modelling
}

\author{
Alecia Nickless $^{1,2}$, Peter J. Rayner ${ }^{3}$, Francois Engelbrecht ${ }^{4,5}$, Ernst-Günther Brunke ${ }^{6}$, Birgit Erni ${ }^{1,7}$, and \\ Robert J. Scholes ${ }^{8}$ \\ ${ }^{1}$ Department of Statistical Sciences, University of Cape Town, Cape Town, 7701, South Africa \\ ${ }^{2}$ Nuffield Department of Primary Care Health Sciences, University of Oxford, Oxford, OX2 6GG, UK \\ ${ }^{3}$ School of Earth Sciences, University of Melbourne, Melbourne, VIC 3010, Australia \\ ${ }^{4}$ CSIR Natural Resources and the Environment - Climate Studies, Modelling and Environmental Health, \\ P.O. Box 395, Pretoria, 0001, South Africa \\ ${ }^{5}$ Unit for Environmental Sciences and Management, North-West University, Potchefstroom, 2520, South Africa \\ ${ }^{6}$ South African Weather Service c/o CSIR, P.O. Box 320, Stellenbosch, 7599, South Africa \\ ${ }^{7}$ Centre for Statistics in Ecology, the Environment and Conservation, University of Cape Town, \\ Cape Town, 7701, South Africa \\ ${ }^{8}$ Global Change Institute, University of the Witwatersrand, Johannesburg, 2050, South Africa
}

Correspondence: Alecia Nickless (alecia.nickless@phc.ox.ac.uk)

Received: 28 June 2017 - Discussion started: 25 July 2017

Revised: 25 February 2018 - Accepted: 7 March 2018 - Published: 9 April 2018

\begin{abstract}
We present a city-scale inversion over Cape Town, South Africa. Measurement sites for atmospheric $\mathrm{CO}_{2}$ concentrations were installed at Robben Island and Hangklip lighthouses, located downwind and upwind of the metropolis. Prior estimates of the fossil fuel fluxes were obtained from a bespoke inventory analysis where emissions were spatially and temporally disaggregated and uncertainty estimates determined by means of error propagation techniques. Net ecosystem exchange (NEE) fluxes from biogenic processes were obtained from the land atmosphere exchange model CABLE (Community Atmosphere Biosphere Land Exchange). Uncertainty estimates were based on the estimates of net primary productivity. CABLE was dynamically coupled to the regional climate model CCAM (Conformal Cubic Atmospheric Model), which provided the climate inputs required to drive the Lagrangian particle dispersion model. The Bayesian inversion framework included a control vector where fossil fuel and NEE fluxes were solved for separately.

Due to the large prior uncertainty prescribed to the NEE fluxes, the current inversion framework was unable to adequately distinguish between the fossil fuel and NEE fluxes, but the inversion was able to obtain improved estimates of the
\end{abstract}

total fluxes within pixels and across the domain. The median of the uncertainty reductions of the total weekly flux estimates for the inversion domain of Cape Town was $28 \%$, but reach as high as $50 \%$. At the pixel level, uncertainty reductions of the total weekly flux reached up to $98 \%$, but these large uncertainty reductions were for NEE-dominated pixels. Improved corrections to the fossil fuel fluxes would be possible if the uncertainty around the prior NEE fluxes could be reduced. In order for this inversion framework to be operationalised for monitoring, reporting, and verification (MRV) of emissions from Cape Town, the NEE component of the $\mathrm{CO}_{2}$ budget needs to be better understood. Additional measurements of $\Delta^{14} \mathrm{C}$ and $\delta^{13} \mathrm{C}$ isotope measurements would be a beneficial component of an atmospheric monitoring programme aimed at MRV of $\mathrm{CO}_{2}$ for any city which has significant biogenic influence, allowing improved separation of contributions from NEE and fossil fuel fluxes to the observed $\mathrm{CO}_{2}$ concentration. 


\section{Introduction}

Cities are under pressure to reduce their carbon dioxide emissions. In the last 10 years (2006 to 2015), the mean annual increase in carbon dioxide $\left(\mathrm{CO}_{2}\right)$ concentrations in the global atmosphere has been $2.11 \mathrm{ppm}$ per year (Dlugokencky and Tans, 2016) (NOAA/ESRL, 2016), a sharper rise in $\mathrm{CO}_{2}$ emissions than the preceding decades (IPCC, 2014). Approximately $76 \%$ of current anthropogenic greenhouse gas emissions are comprised of $\mathrm{CO}_{2}$ contributions (IPCC 2014). While cities cover a mere $2 \%$ of the global land surface area, they are responsible for $70 \%$ of anthropogenic greenhouse gas emissions (UN-Habitat, 2011) and between 71 and $76 \%$ of $\mathrm{CO}_{2}$ emissions from global final energy use (Seto et al., 2014). Annual urban $\mathrm{CO}_{2}$ emissions are more than double the net terrestrial or ocean carbon sinks (Le Quéré et al., 2013).

South Africa is the single largest emitter of $\mathrm{CO}_{2}$ on the continent of Africa and the 13th largest emitter in the world (Boden et al., 2011). South African cities are home to 63\% of the present population (Statistics South Africa, 2011), and by 2030 this is predicted to be $71 \%$. The population of Cape Town (CT) has been rising at $2.5 \%$ per annum over the past two decades and currently is nearly 4 million (City of Cape Town, 2011). Cities are seen as having the greatest potential to provide solutions for emissions reduction and climate change mitigation (Seto et al., 2014; Wu et al., 2016). By reducing the $\mathrm{CO}_{2}$ impact of cities, cities play a pivotal role in decreasing their own climate vulnerability. But there are also additional co-benefits which include improving air quality, energy access, public health, city liveability, and developing the economy and job creation through advances in green technology (Seto et al., 2014).

Formal climate action plans are developed by governments and city managers whereby the road map for implementing greener policies is provided, such as encouraging and developing public transport which makes use of low emission technologies, mass and rapid transport systems, and building retrofits (Sugar and Kennedy, 2013; Erickson and Tempest, 2014). Many cities are taking it on themselves to respond to the climate crisis, reacting to limited international and national policy progress (Hutyra et al., 2014). But to determine whether the plans implemented are having the anticipated effect of lowering $\mathrm{CO}_{2}$ emissions, monitoring is required. Monitoring, reporting, and verification (MRV) is a concept which is fundamental to most market and policy-based mechanisms in climate economics (Bellassen and Stephan, 2015). In order for emission reduction strategies to be properly implemented and assessed, an MRV approach should be adopted so that emission reduction claims can be validated in a consistent and reliable manner. Currently, the primary source of this information for cities is by means of emissions inventories. This relies on the collection of activity data to provide an inventory of emissions from different sectors or specific point sources. These inventories are not perfect rep- resentations of $\mathrm{CO}_{2}$ emissions. They are heavily dependent on accurate reporting, emission factors, and assumptions regarding temporal or spatial disaggregation of emissions (Andres et al., 2012), where errors associated with these emission estimates increase with higher spatial and temporal resolutions (Andres et al., 2014). As the importance of these inventories increases due to the need to quantify emissions and assess emission targets, it has become necessary to verify the accuracy of these estimates (NRC, 2010). Adequate MRV implementation requires transparency, quality, and comparability of information, with narrow uncertainty estimates ( $\mathrm{Wu}$ et al., 2016). Currently, uncertainties associated with urban emissions far exceed emission reduction goals, and therefore verification remains challenging. The large amount of uncertainty is due to factors such as incomplete data, inconsistency in reporting between different institutions or facilities, fugitive emissions from point sources such as those caused by gas leaks, and methodology which is rarely checked against scientific standards and procedures (Hutyra et al., 2014). A way of verifying inventory data for a city, and reducing uncertainty of inventory estimates, is by means of the Bayesian atmospheric inversion technique. This method aims to take advantage of continuous measurement of $\mathrm{CO}_{2}$ concentrations from a network of atmospheric monitoring sites located in and around a city. By attempting to model the $\mathrm{CO}_{2}$ concentrations at these sites, the inversion is able to provide corrections to the inventory of $\mathrm{CO}_{2}$ emissions from the city, so that the mismatch between the modelled and observed concentrations is reduced.

Several regional or mesoscale atmospheric inversions have been published (Lauvaux et al., 2008, 2009, 2012; Schuh et al., 2013), and more recently city-scale inversion studies have been conducted in Europe and North America (Strong et al., 2011; Duren and Miller, 2012; McKain et al., 2012; Brioude et al., 2013; Kort et al., 2013; Lauvaux et al., 2013; Bréon et al., 2015; Turnbull et al., 2015; Boon et al., 2016; Oda et al. , 2017). These top-down approaches make use of an atmospheric transport model to relate observations of $\mathrm{CO}_{2}$ concentrations in the atmosphere to the $\mathrm{CO}_{2}$ fluxes from the domain of interest (Lauvaux et al., 2012). This method applies corrections to the inventory data, which enters the inversion calculation by means of the prior estimates. This paper reports the results for an atmospheric inversion for CT, South Africa.

Making use of point measurements of $\mathrm{CO}_{2}$ concentrations means that the effects of all fluxes of $\mathrm{CO}_{2}$ are observed as an aggregated total. It is challenging to separate out these aggregated $\mathrm{CO}_{2}$ fluxes into different components of the total $\mathrm{CO}_{2}$ budget without additional measurements, such as $\Delta^{14} \mathrm{C}$ (Turnbull et al., 2015) and $\delta^{13} \mathrm{C}$ isotope measurements (Newman et al., 2016), or without high confidence in the spatial and temporal patterns of fluxes (Shiga et al., 2014). Even when additional measurements of $\mathrm{CO}_{2}$ mole fractions are available, at the current point in time, background atmospheric conditions are not sufficiently characterised to use 
isotope tracers to discriminate between fossil fuel and biogenic fluxes (Turnbull et al., 2015). To conduct a Bayesian atmospheric inversion at the city scale, a detailed $\mathrm{CO}_{2}$ inventory analysis is required, where all the main contributors to the anthropogenic $\mathrm{CO}_{2}$ budget are considered. Apart from their use in an atmospheric inversion, better understanding of the underlying processes at the urban scale and improved quantification of $\mathrm{CO}_{2}$ emissions provide information contributing towards the policy decisions made by urban practitioners, help to improve understanding of urban dynamics, and inform future scenarios (Hutyra et al., 2014). An example of this is the detailed street-level inventory analysis undertaken in the Hestia Project for US cities Indianapolis, Los Angeles, Phoenix, and Salt Lake City (Gurney et al., 2012; Davis et al., 2017). Preceding these inventories was the Vulcan inventory, which covers the contiguous US (Gurney et al., 2009). These detailed inventories have made possible atmospheric inversion exercises, as well as other top-down methods for obtaining urban $\mathrm{CO}_{2}$ flux estimates, for these cities (Strong et al., 2011; Brioude et al., 2013; Bréon et al., 2015; Lauvaux et al., 2016). Such a detailed inventory analysis is not available for any South African city, and therefore a detailed spatially and temporally disaggregated inventory analysis of direct $\mathrm{CO}_{2}$ emissions was undertaken for CT specifically for the use of this atmospheric inversion exercise (Nickless et al., 2015a).

Atmospheric inversions have various sources of uncertainty, which include atmospheric transport modelling errors (particularly at night when the planetary boundary layer is shallow) (Geels et al., 2007), incorrect characterisation of prior flux estimates and their uncertainties (which includes errors in the inventory analysis) (Bréon et al., 2015; Lauvaux et al., 2016), atmospheric measurement errors (Gerbig et al., 2003), representation errors due to the comparison of a concentration measurement at a point with a modelled concentration representative of a surface grid box (Gerbig et al., 2003), and aggregation errors which occur as fluxes from various sources are coerced into homogeneous grid cells (Kaminski et al., 2001). In the case of cities, atmospheric transport modelling is further complicated by smallscale turbulence, highly heterogeneous surface characteristics, and urban heat island effects (Hutyra et al., 2014; Bréon et al., 2015).

Therefore, careful consideration of the atmospheric transport model (or models) is required for an atmospheric inversion. The atmospheric transport modelling in this study was provided by the Conformal Cubic Atmospheric Model (CCAM) (McGregor and Dix, 2008) at the resolution of $1 \mathrm{~km} \times 1 \mathrm{~km}$. CCAM, at a slightly coarser resolution, has already been used for a regional network design study over South Africa, making use of a similar Bayesian inversion framework (Nickless et al., 2015b), and has been verified over South Africa and over the CT target region at a spatial resolution of up to $1 \mathrm{~km} \times 1 \mathrm{~km}$ (Roux, 2009; Engelbrecht et al., 2009, 2011).
High-resolution inversions are required to quantify emissions down to the sector or point source level. Lauvaux et al. (2016) performed an ultra high-resolution inversion where sector-specific anthropogenic emissions were considered, but ignored biogenic fluxes. This was possible due to the selection of the dormant period for the inversion, when fluxes due the biosphere would have been at a minimum. When considering longer periods, or for cities in regions which may not have a dormant vegetation period, this assumption will not be valid, particularly for a medium-sized city, where natural processes can be a significant contributor to the carbon budget. Such would be the case for South African cities, such as CT and Johannesburg, where large national parks and other natural areas are located near or within city limits and within city vegetation growth is non-negligible. CT is also surrounded by a large agricultural sector consisting of vineyards and fruit orchards. Ironically, there are features of cities which allow for better plant growth. For example, the urban heat island effect leads to a longer growing season for plants, and reduced wind within cities leads to less plant stress resulting in better plant growth (Buyantuyev and $\mathrm{Wu}, 2012$ ). In addition, nitrogen deposition within cities leads to increased nutrient availability, and particularly in arid regions, cities cause augmented water availability for plants (Hutyra et al., 2014). If allowed growing space, plants can make a significant contribution to the carbon budget of a city.

Therefore, for a city like CT, biogenic fluxes cannot be ignored and are usually estimated by means of a land surface exchange model within atmospheric inversion studies (Bréon et al., 2015; Staufer et al., 2016). Bréon et al. (2015) and Staufer et al. (2016) made use of the C-TESSEL land atmosphere scheme which is used in the ECMWF forecasting system. In this study we have made use of the CABLE (Community Atmosphere Biosphere Land Exchange) model to represent the biogenic $\mathrm{CO}_{2}$ fluxes in the $\mathrm{CO}_{2}$ budget (Kowalczyk et al., 2006). CABLE had the same spatial and temporal resolution as the meteorology. The average weekly fluxes for each pixel were calculated and used as the prior biogenic fluxes.

We present a Bayesian inversion framework used to obtain estimates of $\mathrm{CO}_{2}$ fluxes over CT and present the results of the reference atmospheric inversion for a 16-month period from March 2012 until June 2013. The domain considered was a $100 \mathrm{~km} \times 100 \mathrm{~km}$ region with CT at the centre. The spatial resolution of the atmospheric transport model was set at $1 \mathrm{~km} \times 1 \mathrm{~km}$, and the spatial resolution of the surface fluxes was made to match this resolution. Fluxes were solved for at a weekly time step, separately for day and night. Fossil fuel and biogenic fluxes were solved for separately, and fossil fuel fluxes were separated into week and weekend fluxes. 


\section{Methods}

\subsection{Bayesian inverse modelling approach}

The Bayesian synthesis inversion method, as described by Tarantola (2005) and Enting (2002), was used to solve for the fluxes in this study. This method has been described for global inversions (Bousquet et al., 1999; Kaminski et al., 1999; Rayner et al., 1999; Gurney et al., 2002; Peylin et al., 2002; Gurney et al., 2003; Law et al., 2003; Baker et al., 2006; Rayner et al., 2008; Ciais et al., 2010) and for many of the recent city-scale inversions (Lauvaux et al., 2016; Bréon et al., 2015). The observed concentration $(c)$ at a measurement station at a given time can be expressed as the sum of different contributions from the surface fluxes, from the domain boundaries, and from the initial concentration at the site. Concentrations at the measurement site can be modelled as

$\boldsymbol{c}_{\bmod }=\mathbf{H} \boldsymbol{s}$,

where $\boldsymbol{c}_{\text {mod }}$ are the modelled concentrations and $\boldsymbol{s}$ are various sources, where sources are any part of the domain which can provide a positive or negative contribution of $\mathrm{CO}_{2} . \mathrm{H}$ is the Jacobian matrix representing the first derivative of the modelled concentration at the observational site and dated with respect to the coefficients of the source components (Enting, 2002). It provides the sensitivity of each observation to each of the unknown sources, where the sources can be either fluxes or concentrations of $\mathrm{CO}_{2}$. Estimates of the unknown sources can be obtained by minimising the following cost function with respect to $s$ :

$$
\begin{aligned}
J(s)= & \frac{1}{2}\left(\left(\boldsymbol{c}_{\mathrm{mod}}-\boldsymbol{c}\right)^{T} \mathbf{C}_{c}^{-1}\left(\boldsymbol{c}_{\mathrm{mod}}-\boldsymbol{c}\right) /\right. \\
& \left.+\left(\boldsymbol{s}-\boldsymbol{s}_{0}\right)^{T} \mathbf{C}_{\boldsymbol{s}_{0}}^{-1}\left(\boldsymbol{s}-\boldsymbol{s}_{0}\right)\right)
\end{aligned}
$$

where $s$ is the control vector of unknown surface fluxes and boundary concentrations we wish to solve for, $\boldsymbol{s}_{0}$ is the vector of prior flux and boundary concentration estimates, $\mathbf{C}_{c}$ is the uncertainty covariance matrix of the observations, and $\mathbf{C}_{\boldsymbol{s}_{0}}$ is the uncertainty covariance matrix of the fluxes and boundary concentrations (Tarantola, 2005).

The solution to this minimisation problem is

$$
\boldsymbol{s}=\boldsymbol{s}_{0}+\mathbf{C}_{\boldsymbol{s}_{0}} \mathbf{H}^{T}\left(\mathbf{H C}_{\boldsymbol{s}_{0}} \mathbf{H}^{T}+\mathbf{C}_{c}\right)^{-1}\left(\boldsymbol{c}-\mathbf{H} \boldsymbol{s}_{0}\right),
$$

and the posterior covariance matrix can be determined as follows (Tarantola, 2005):

$$
\begin{aligned}
\mathbf{C}_{s} & =\left(\mathbf{H}^{T} \mathbf{C}_{c}^{-1} \mathbf{H}+\mathbf{C}_{\boldsymbol{s}_{0}}^{-1}\right)^{-1} \\
& =\mathbf{C}_{\boldsymbol{s}_{0}}-\mathbf{C}_{\boldsymbol{s}_{0}} \mathbf{H}^{T}\left(\mathbf{H C}_{\boldsymbol{s}_{0}} \mathbf{H}^{T}+\mathbf{C}_{c}\right)^{-1} \mathbf{H C}_{\boldsymbol{s}_{0}} .
\end{aligned}
$$

\subsection{Control vector $-s$}

The control vector, $\boldsymbol{s}$, can be broken up into different components. The total $\mathrm{CO}_{2}$ flux from a single surface pixel for a given week is made up of the following individual fluxes:

$$
\begin{aligned}
\boldsymbol{s}_{\mathrm{ff} ; i}= & \boldsymbol{s}_{\mathrm{ff} \text { week day; } i}+\boldsymbol{s}_{\mathrm{ff} \text { week night } ; i} \\
& +\boldsymbol{s}_{\mathrm{ff} \mathrm{weekend} \mathrm{day} ; i}+\boldsymbol{s}_{\mathrm{ff} \text { weekend night } ; i} \\
& +\boldsymbol{s}_{\mathrm{NEE} \mathrm{day;} i}+\boldsymbol{s}_{\mathrm{NEE} \mathrm{night} ; i},
\end{aligned}
$$

where $\boldsymbol{s}_{\mathrm{sf} ; i}$ is the total weekly surface flux from the $i$ th pixel, $\boldsymbol{s}_{\mathrm{ff}}$ week day; $i$ is the total fossil fuel flux during the day during the working week, $\boldsymbol{s}_{\mathrm{ff}}$ week night; $i$ is the total night-time fossil

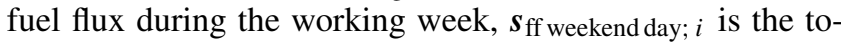
tal weekend daytime fossil fuel flux, $\boldsymbol{s}_{\mathrm{ff}}$ weekend night; $i$ is the total weekend night-time fossil fuel flux, and $s_{\mathrm{NEE} \text { day; } i}$ and $\boldsymbol{s}_{\text {NEE night; } i}$ are the total day- and night-time biogenic fluxes for the full week from the $i$ th pixel. The inversion solves for each of these separate fluxes. There are $101 \times 101=10201$ surface pixels. Over the 16-month period from March 2012 to June 2013, separate monthly inversions are carried out for all months with sufficient valid concentration observations a total of 13 inversions. Each monthly inversion solves for four weekly fluxes. Therefore a monthly inversion solves for $10201 \times 6 \times 4=244824$ surface fluxes.

The mean day and night-time concentrations at each of the four domain boundaries for each week are the last components of the control vector. The inversion solves for $4 \times 2 \times 4=32$ boundary concentrations (four boundaries, day/night, 4 weeks). We solved for weekly concentrations at the boundaries as we expected these concentrations to show small changes on synoptic timescales, particularly inflow from the ocean boundaries. We avoided solving for too short a period so that the percentile filtering technique (see Sect. 2.8) would never discard all measurements for a period. The maximum standard deviation in the hourly background $\mathrm{CO}_{2}$ concentrations for a week was $0.8 \mathrm{ppm}$.

As a sensitivity analysis, presented in a follow-up paper (Nickless et al., 2018), we examined two alternative compositions of the control vector. We considered solving for a mean weekly flux for each month. In this case for a surface pixel we solved for two biogenic mean weekly fluxes (day and night) and four fossil fuel mean weekly fluxes (day and night working week, day and night weekend). We also considered a separate inversion for each week. In this case only the concentration measurements for 1 week were used and the individual weekly fluxes (two biogenic and four fossil fuel) were solved for, and this was repeated for each of the 4 weeks in the month. The benefit of these two alternative control vectors is that the resulting dimensions of the $\mathbf{C}_{\boldsymbol{s}_{0}}$ matrix are much smaller compared with the reference case we present in this paper. 


\subsection{Concentration measurements - $c$}

Two $\mathrm{CO}_{2}$ monitoring sites were established at Robben Island and Hangklip lighthouses. Due to the dominant wind directions in CT (Fawcett et al., 2007), either from the south or north-west, the location of the Robben Island and Hangklip stations were well suited for observing contributions from the area of interest, particularly from CT. The Hangklip site observed mainly background air, but occasionally viewed the biogenic-influenced continental air. Robben Island often observed air with enhancements from CT. The location of these sites in relation to the domain are shown in Fig. 1. The average wind speed and direction across the domain, as modelled by CCAM, are shown in Sect. 1.3 in the Supplement.

Each site was equipped with a Picarro cavity ring-down spectroscopy (CRDS) (Picarro G2301) instrument. This instrument measures $\mathrm{CO}_{2}$, methane $\left(\mathrm{CH}_{4}\right)$, and water vapour $\left(\mathrm{H}_{2} \mathrm{O}\right)$ simultaneously, every $5 \mathrm{~s}$, producing a precision of better than 0.05 parts-per-million volume (ppmv) for $\mathrm{CO}_{2}$, 0.07 parts-per-billion volume (ppbv) for $\mathrm{CH}_{4}$, and $100 \mathrm{ppmv}$ for $\mathrm{H}_{2} \mathrm{O}$. This instrument maintains high linearity, precision, and accuracy over changing environmental conditions, requiring only minimal calibration, and is recognised as one of the highest precision instruments for measurement of the top three greenhouse gases (Crosson, 2008).

The inlet of the measurement tube at each site was located at the top of the lighthouse and had a Gelman filter to prevent contamination of the instrument through aerosols or water droplets. The inlet tube led to a VICI rotary valve which directed the sampled air stream to the Picarro instrument. Approximately every 4 days the rotary valve switched to a calibration line which allowed the flow of calibration gas through the instrument for a period of half an hour.

The Robben Island lighthouse is an $18 \mathrm{~m}$ tall circular masonry tower, and the height of the focal plane of the light is $47 \mathrm{~m}$ above the high water level. The location of the lighthouse is $33^{\circ} 48^{\prime} 52.20^{\prime \prime} \mathrm{S}$ and $18^{\circ} 22^{\prime} 29.25^{\prime \prime} \mathrm{E}$. The Hangklip lighthouse is a $22 \mathrm{~m}$ tall concrete tower, where the focal plane of the light is $34 \mathrm{~m}$ above the high water level. It is located at $34^{\circ} 23^{\prime} 11.40^{\prime \prime} \mathrm{S}$ and $18^{\circ} 49^{\prime} 42.30^{\prime \prime} \mathrm{E}$. It is located on the tip of False Bay, opposite to Cape Point.

\subsection{System meteorology}

CCAM is the variable-resolution global atmospheric model developed by the Commonwealth Scientific and Industrial Research Organisation (CSIRO) (McGregor, 1996; McGregor and Dix, 2001; McGregor, 2005a, b; McGregor and Dix, 2008). It employs a semi-implicit semi-Lagrangian method to solve the hydrostatic primitive equations. The Geophysical Fluid Dynamics Laboratory (GFDL) parameterisations for long-wave and short-wave radiation are used (Lacis and Hansen, 1974; Schwarzkopf and Fels, 1991), with interactive cloud distributions determined by the liquid and ice water scheme of Rotstayn (1997). Total-variation-diminishing ver- tical advection is applied to solve for the advective process in the vertical. A stability-dependent boundary layer scheme based on Monin-Obukhov similarity theory is employed (McGregor, 1993), together with the non-local treatment of the boundary layer scheme as described in Holtslag and Boville (1993). A canopy scheme is included, as described by Kowalczyk et al. (1994), with six layers for soil temperatures and soil moisture (solving Richard's equation) and three layers for snow. The cumulus convection scheme uses a mass-flux closure (McGregor, 2003) and includes downdrafts, entrainment, and detrainment. Gravity wave drag is parameterised following Chouinard et al. (1986).

CCAM may be applied in stretched-grid mode to function as a regional climate model, thereby providing a flexible framework for downscaling reanalysis data or global circulation model simulations to high resolution over an area of interest. Stretched grids are obtained using the Schmidt (1977) transformation. A multiple-nudging approach was followed to downscale the $250 \mathrm{~km}$ resolution National Centres for Environmental Prediction (NCEP) reanalysis data (Kalnay et al., 1996) to a resolution of $60 \mathrm{~km}$ over southern Africa, $8 \mathrm{~km}$ over the south-western Cape, and subsequently $1 \mathrm{~km}$ over the study area. The $8 \mathrm{~km}$ resolution domain stretched over an area of about $1300 \times 1300 \mathrm{~km}^{2}$, whilst the $1 \mathrm{~km}$ resolution domain centred over False Bay stretched over an area of about $160 \times 160 \mathrm{~km}^{2}$. Output was stored at a time resolution of $1 \mathrm{~h}$. CCAM was spectrally nudged with the synoptic-scale forcing reanalysis data at 6-hourly intervals for the period 1979-2013 using a scale-selective Gaussian filter (Thatcher and McGregor, 2009, 2010). This forcing was applied from $900 \mathrm{hPa}$ higher up into the atmosphere. Seasurface temperatures from the NCEP dataset were used as lower boundary forcing.

To justify the use of CCAM to provide modelled winds and other climatological variables, we rely on previous studies which have used this model for atmospheric transport modelling in our target area (Whittlestone et al., 2009) and studies which have validated CCAM at various spatial resolutions (Engelbrecht et al., 2009; Roux, 2009; Engelbrecht et al., 2011, 2013, 2015). In particular, CCAM has been able to satisfactorily recreate present-day rainfall totals and the rainfall seasonal cycle, as well as circulation patterns over South Africa (Engelbrecht et al., 2009), and has been able to simulate with some success mid-tropospheric closed lows and extreme rainfall events (Engelbrecht et al., 2015). CCAM has been validated over the Stellenbosch wine-producing area, which falls within the domain of this inversion, with respect to temperature, relative humidity, and wind speed at six different stations within this region (Roux, 2009). Those stations located within the high-resolution focus area of the stretched-grid obtained root mean square errors of $0.64 \mathrm{~m} \mathrm{~s}^{-1}$ or lower and correlations close to 1 between the modelled and observed wind speeds. Validating the wind product from CCAM further in a rigorous manner is beyond the scope of this paper. 


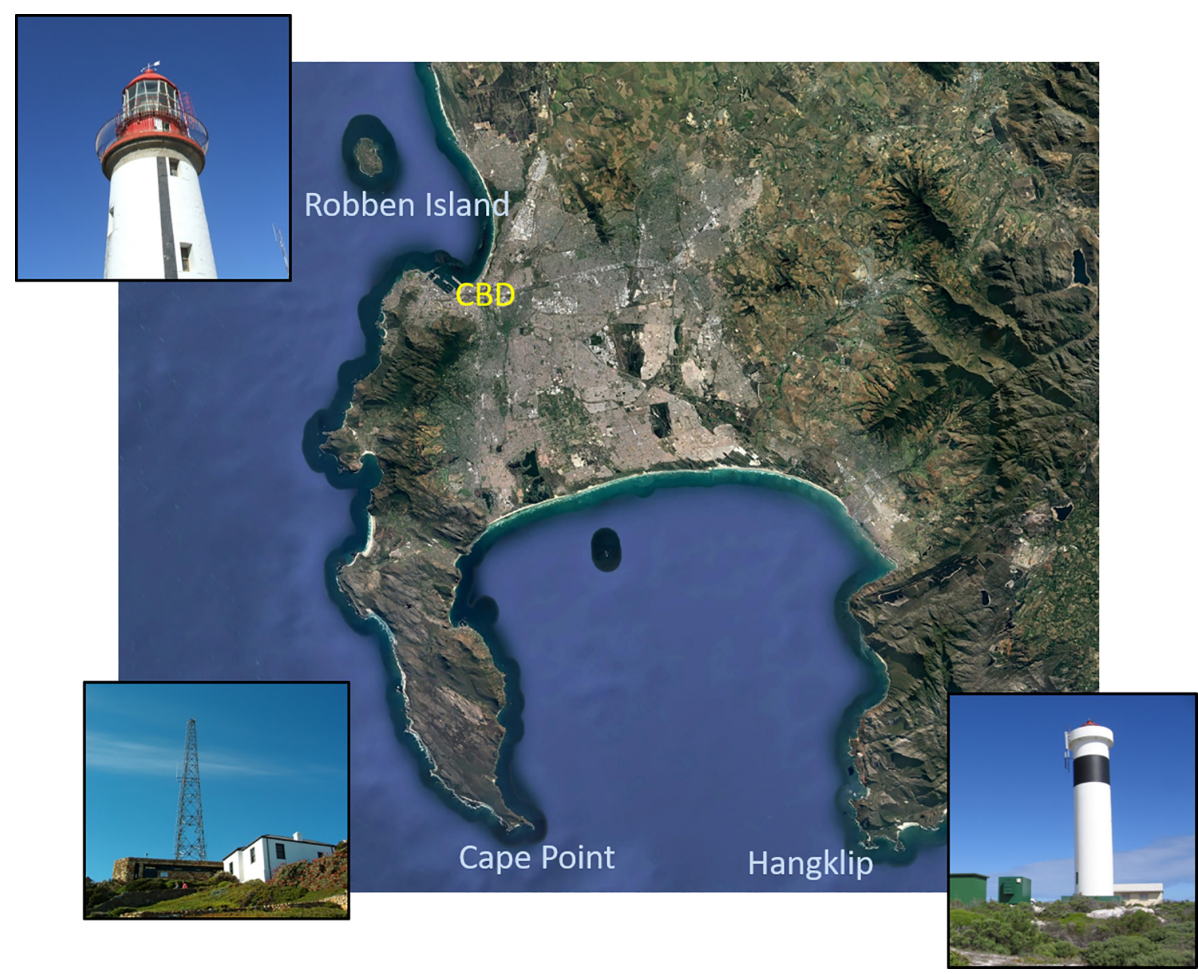

Figure 1. Google Earth image of the domain, where Cape Town is located at the centre. The corner coordinates of the full domain are $33^{\circ} 29^{\prime} 42.00^{\prime \prime} \mathrm{S} 18^{\circ} 11^{\prime} 42.00^{\prime \prime} \mathrm{E}$ (top left), $33^{\circ} 29^{\prime} 42.00^{\prime \prime} \mathrm{S} ; 1^{\circ} 12^{\prime} 18.00^{\prime \prime} \mathrm{E}$ (top right); $34^{\circ} 30^{\prime} 18.00^{\prime \prime} \mathrm{S}, 18^{\circ} 11^{\prime} 42.00^{\prime \prime} \mathrm{E}$ (bottom left); and $34^{\circ} 30^{\prime} 18.00^{\prime \prime} \mathrm{S}, 19^{\circ} 12^{\prime} 18.00^{\prime \prime} \mathrm{E}$ (bottom left). The locations of the measurement sites and the Cape Point GAW station background site are indicated together with images of these sites (photo credits: Ernst Brunke and Alecia Nickless). CBD is the central business district.

\subsection{Jacobian matrix - H}

In order to generate the Jacobian matrix, $\mathbf{H}$, for the inversion procedure, which maps the surface fluxes and boundary inflows to the concentrations observed at the receptor sites, a Lagrangian particle dispersion model (LPDM) was run in backward mode. An LPDM simulates the release of a large number of particles from arbitrary receptors and records the location of the particles at fixed time steps (Uliasz, 1993, 1994). The model implemented in this study was developed by Marek Uliasz (1993), which will be referred to as LPDM. LPDM is driven by the hourly three-dimensional fields of mean winds $(u, v, w)$, potential temperature, and turbulent kinetic energy (TKE), which were obtained from the CCAM model. When LPDM is run backward in time, in receptororientated mode, the particle counts can be used to generate $\mathbf{H}$ for a given receptor site, as described in Ziehn et al. (2014) and Nickless et al. (2015b), following Seibert and Frank (2004).

The Jacobian for a 4-week period during each month of the study was generated by allowing the LPDM model to run in backward mode over a full 2-month period. Particle counts were extracted for the 4 weeks of interest. Particles were released every $20 \mathrm{~s}$ and each particle's position was recorded at $1 \mathrm{~min}$ intervals. Particles that were near the surface were allocated to a surface grid box, corresponding to the surface pixels of the atmospheric transport model, and the total particle count within each of these boxes was determined. These counts depended on the dimensions and position of the surface grid boxes. The particle counts were used to calculate the source-receptor $(s-r)$ relationship. We followed Seibert and Frank (2004) to convert the particle counts into the elements of the Jacobian matrix. As described in Ziehn et al. (2014), we modified the approach of Seibert and Frank (2004) to account for the particle counts which were produced by our LPDM as opposed to the mass concentrations which were output by the atmospheric transport model in their study. The resulting $s-r$ relationship between the measurement site and source $i$ at time interval $n$, which provide the elements of the matrix $\mathbf{H}$, is

$\frac{\partial \overline{c_{\mathrm{sf}}}}{\partial s_{\text {in }}}=\frac{\Delta T \mathrm{~g}}{\Delta P} \overline{\left(\frac{N_{\text {in }}}{N_{\text {tot }}}\right)} \frac{44}{12} \times 10^{3}$,

where $\overline{c_{\mathrm{sf}}}$ is a volume mixing ratio (receptor) expressed in ppm and $s_{i n}$ is a mass-flux density (source), $N_{i n}$ the number of particles in the receptor surface grid from source pixel $i$ released at time interval $n, \Delta T$ is the length of the time interval, $\Delta P$ is the pressure difference in the surface layer, $\mathrm{g}$ is the acceleration due to gravity, and $N_{\text {tot }}$ the total number of particles released during a given time interval. 
In this inversion setup weekly fluxes of $\mathrm{CO}_{2}$ were separated into day and night-time contributions, into fossil fuel and net ecosystem exchange (NEE) contributions, and, in the case of fossil fuels, into working week and weekend contributions. Therefore, to obtain the NEE contributions the particle count $N_{\text {in }}$ was the sum over one week $(\Delta T=1$ week; day/night). For fossil fuel fluxes, the particle count was separated into the contribution from the working week and from the weekend, separately for day and night.

The surface layer height was set to $50 \mathrm{~m}$ which corresponds to approximately $595 \mathrm{~Pa}(\Delta P)$. If we assume wellmixed conditions, then the $s-r$ relationship should be independent of the thickness of the surface layer, as long as the layer is not too deep, as the particle count will be adjusted proportional to the volume of the grid box. Under stable conditions, this may not be the case (Seibert and Frank, 2004). The spatial resolution of the surface flux grid boxes was set to be the same as that of the high-resolution subregion of the atmospheric transport model, resulting in a gridded domain consisting of $101 \times 101$ grid boxes (a resolution of approximately $0.01^{\circ} \times 0.01^{\circ}$ or $\left.1 \mathrm{~km} \times 1 \mathrm{~km}\right)$.

The fluxes from the surface pixels are expressed in $\mathrm{kg}$ $\mathrm{CO}_{2} \mathrm{~m}^{-2}$ week $^{-1}$ and are transformed through $\mathbf{H}$ into contributions to the concentration at the measurement site in units of ppm. The inversion solves for the concentrations at the boundary of the domain. Ziehn et al. (2014) show that the Jacobian which provides the sensitivities of observed concentrations to boundary concentrations can be calculated as

$\frac{\partial \overline{s_{\mathrm{B}}}}{\partial c_{\mathrm{b}}}=\frac{N_{\mathrm{B}}}{N_{\text {tot }}}$,

where $\overline{s_{\mathrm{B}}}$ is the concentration at the domain boundary, $c_{\mathrm{b}}$ is the volume mixing ratio, $N_{\mathrm{B}}$ is the number of particles from the specific domain boundary, and $N_{\text {tot }}$ the total number of particles viewed at the receptor site from any of the domain boundaries. The contribution to the observed concentration at the receptor site can be written as

$\boldsymbol{c}_{\mathrm{b}}=\mathbf{H}_{\mathrm{B}} s_{\mathrm{B}}$,

where $\mathbf{H}_{\mathrm{B}}$ is the Jacobian with respect to the domain boundary concentrations, $s_{\mathrm{B}}$ the domain boundary concentrations, and $c_{\mathrm{b}}$ the contributions from the boundary to the observed concentration at the measurement site in units of ppm. The row elements of $\mathbf{H}_{\mathrm{B}}$ sum to one. Therefore the elements of $\boldsymbol{c}_{\mathrm{b}}$ represent a weighted average of the concentrations at the domain boundaries and provide a basis concentration to which the contributions from the surface fluxes are added. Each inversion solves for 4-weekly domain boundary concentrations for each cardinal direction, separated by day and night.

\subsection{Inventory of anthropogenic emissions}

An inventory analysis was conducted specifically for this atmospheric inversion exercise (Nickless et al., 2015a). The anthropogenic emissions were subdivided into those due to road transport, airport and harbour emissions, residential lighting and heating, and industrial point sources. Road transport emissions were derived from modelled values of vehicle kilometres for each section of the road network, modelled from observed vehicle count data. The vehicle kilometres were scaled for each hour of the day and reported separately for working week days and weekend days. Therefore the vehicle emissions for day and night are distinctive for the week/weekend and day night periods.

Airport emissions were derived from landing and takeoff cycles, as reported by Airports Company South Africa for each month. We used the IPCC-reported average emission factors for domestic and international fleets (IPCC, 2000), and these were used to convert the airport activity data into emissions of $\mathrm{CO}_{2}$. Emissions were expected to be concentrated between 06:00 and 22:00, and so the monthly emission was divided evenly between these hours. Harbour emissions were derived for port activity published by the South African Ports Authority for each month. Based on the gross tonnage of vessels which docked at the port during the month, emissions could be derived as described in DEFRA (2010). The monthly emissions were divided equally between all hours of the month, as it was assumed that harbour activities would be continuous.

Residential emissions for lighting and heating were derived from population count data obtained for each of the municipal wards in 2011 (Statistics South Africa, 2011). The population of CT was 3740025 , as reported in the 2011 census (Statistics South Africa, 2011). The South African government reports on the fuel used for domestic heating and lighting (South African Department of Energy, 2009). This was divided between the total population and then allocated to each ward depending on the population residing in that area. The fuel usage was scaled according to the proportion of fuel used for cooking, lighting, and heating, where $75 \%$ of the annual heating fuel usage was assumed to take place during the winter months (March to August). It was assumed that $75 \%$ of the annual energy consumed was used for heating, $20 \%$ for cooking and $5 \%$ for lighting.

CT provided monthly fuel usage by the largest industrial emitters. The reported fuel usage for the top fuel users were converted directly into $\mathrm{CO}_{2}$ emissions by multiplying these figures with the Defra greenhouse gas emission factors (DEFRA, 2013a). The fuel types that were considered included heavy fuel oil, coal, diesel, paraffin, and fuel gas, which were divided into liquid petroleum gas and refinery fuel gas. As no information was available about when the activity was occurring at these facilities, the emissions were divided equally between all hours of the month. 
Based on this inventory analysis, the percentage contribution of industrial point sources to the total fossil fuel emission for CT was $12.0,34.6 \%$ from vehicle road transport, $51.0 \%$ from the residential sector, and $2.4 \%$ from the airport and harbour transport. Residential emissions are a large contributor to the fossil fuel emission budget as well as one of the largest contributors to the uncertainties in the fossil fuel flux. This is due to the dependency that many people living in CT have on raw fossil fuel burning for heating and lighting. Emissions from power stations are a small component of the total fossil fuel flux from CT as the bulk of the direct emissions from power stations occur elsewhere in the country.

The total fossil fuel emissions for the domain were comparable with those from the EDGAR (Emission Database for Global Atmospheric Research) (v4.2) database (Nickless et al., 2015a). EDGAR is a global product on a $0.1^{\circ} \times 0.1^{\circ}$ grid, which provides the total anthropogenic emissions of $\mathrm{CO}_{2}$ as estimated from proxy data such as population counts and information on the road transport network (JanssensMaenhout et al., 2012). The total emissions estimated from our bespoke inventory analysis for 2012 were $22 \%$ higher relative to the emissions from EDGAR in 2010, where the emissions in our inventory tended to be concentrated over specific sources, such as oil refinery plants, whereas the EDGAR emissions were smoothed over the city region.

\subsection{Biogenic emissions}

CCAM was dynamically coupled to the land surface model CABLE, which allows for feedbacks between land surface and climate processes, such as leaf area feedback on maximal canopy conductance and latent heat fluxes (Zhang et al., 2013). This type of coupling has successfully been implemented in CSIRO's national earth system modelling scheme (Australian Community Climate and Earth System Simulator or ACCESS) and describes land-atmosphere exchanges of energy, carbon, and water using biogeochemical, vegetationdynamic, and disturbance processes (Law et al., 2012). Several studies have validated CABLE under different ecosystems and parameters using both global model simulations (e.g. Zhang et al., 2009; Wang et al., 2011) and site-level offline CABLE simulations (Exbrayat et al., 2013; Zhang et al., 2013).

The model produces hourly estimates of NEE, which were aggregated into weekly (day and night) flux estimates in units of $\mathrm{kg} \mathrm{CO}_{2} \mathrm{~m}^{-2}$ week ${ }^{-1}$, and used as the prior estimate of biogenic fluxes over the land surface. The spatial resolution of these prior NEE fluxes were kept at a $0.01^{\circ} \times 0.01^{\circ}$ resolution.

In terms of natural vegetation, the target domain is dominated by the fynbos biome. This biome is biodiverse, with many endemic species, and covers a relatively small area in South Africa, but a significant area within the domain of the inversion. The fynbos biome is poorly represented by dynamic vegetation models (Moncrieff et al., 2015). The land atmosphere exchange model CABLE was selected to couple with CCAM due to its use and development in regions of Australia which share similar characteristics to the savanna biome in South Africa, which has a coverage of over $50 \%$. Its ability to simulate respiration and photosynthesis in the fynbos region is largely untested. In addition to the natural vegetation, a large agricultural sector is within the proximity of $\mathrm{CT}$, consisting predominantly of vineyards and fruit orchards. The CT region experiences a Mediterranean climate with winter rainfall. Consequently, summers are hot and dry and winters are mild and wet. Therefore significant NEE fluxes take place during both winter and summer periods. The NEE in this region is limited by the amount of water availability, whereas temperatures are usually sufficiently high enough not to limit plant production and respiration.

The $\mathrm{CO}_{2}$ fluxes over the ocean were obtained from Gregor and Monteiro (2013). This study characterised the seasonal cycle of air-sea fluxes of $\mathrm{CO}_{2}$ in the southern Benguela upwelling system off the South African west coast. A time series of $p \mathrm{CO}_{2}$, derived from total alkalinity and dissolved inorganic carbon and scatterometer-based wind, was obtained from six monthly cross-shelf cruises in the St. Helena Bay region during 2010. Daily $\mathrm{CO}_{2}$ fluxes were derived from these $p \mathrm{CO}_{2}$. These fluxes were applied as prior estimates to the ocean surface grids within the domain. Therefore, an assumption was made that ocean $\mathrm{CO}_{2}$ fluxes are relatively homogeneous in space near the south-western coast of South Africa, but the inversion was given the ability to differentially adjust each of the ocean sources in the posterior estimates.

\subsection{Domain boundary concentrations}

The existence of the Cape Point Global Atmospheric Watch (GAW) station made CT an ideal candidate for a city-scale inversion exercise (South African Weather Service, 2014). The Cape Point station is located approximately $60 \mathrm{~km}$ south of CT within a nature reserve, situated on the southern-most tip of the Cape Peninsula at a latitude of $34^{\circ} 21^{\prime} 12.0^{\prime \prime} \mathrm{S}$ and longitude of $18^{\circ} 29^{\prime} 25.2^{\prime \prime} \mathrm{E}$. The inlet is located on top of the $30 \mathrm{~m}$ measurement tower, which is located on a cliff $230 \mathrm{~m}$ above sea level. The station observes background measurements of $\mathrm{CO}_{2}$ when observing maritime air advected directly from the south-western Atlantic Ocean. This is an extensive region stretching from $20^{\circ}$ (subequatorial) to $80^{\circ}$ (Antarctic region) (Brunke et al., 2004). Therefore, maritime measurements at Cape Point from the Southern Ocean are well representative of the background $\mathrm{CO}_{2}$ signal influencing the Cape Peninsula. The background signal at Cape Point, obtained from a percentile filtering technique (Brunke et al., 2004), was used as the prior estimate of the concentrations at each of the four domain boundaries. The percentile filtering technique removes data influenced by the continent or anthropogenic emissions. Two 11-day moving percentiles, which are adjustable by tuneable factors, control the upper and lower threshold limits. This results in 
a subset of background measurements from Cape Point represented by a narrow concentration band contained within these limits. This filter, when applied to the Cape Point $\mathrm{CO}_{2}$ measurements, selects approximately $75 \%$ of the data. The percentile-filtering technique has been shown to compare well with the more robust method of using contemporaneous radon $\left({ }^{222} \mathrm{Rn}\right)$ measurements to differentiate between marine and continental air.

This site provides a long-term record of background $\mathrm{CO}_{2}$ concentrations for the area. These continuous measurements of the background $\mathrm{CO}_{2}$ levels meant that we were not dependent on the atmospheric transport model to produce estimates of $\mathrm{CO}_{2}$ concentrations at the domain boundary, which are prone to large errors (Lauvaux et al., 2016). Due to the prevailing wind directions across the domain the "gradient approach" for solving for $\mathrm{CO}_{2}$ was not appropriate. This gradient approach relies on the observed wind direction and wind speed to obtain a subset of the concentration measurements when the air flow is from one measurement site directly to another. The differential in the concentrations is modelled by the inversion (Lauvaux et al., 2013; Bréon et al., 2015; Staufer et al., 2016). Plots provided in Sect. 1.3 in the Supplement show the average wind speed and direction for the domain for each month. In general, the wind direction was not favourable to the gradient approach and, with only two measurement sites, would have left little information to constrain the surface fluxes. When the wind is blowing from the south-easterly direction, air from the Hangklip site curves northwards towards the interior and away from CT. When the Robben Island site is observing marine air on its way into the CT area from the Atlantic side, such as June 2013, the wind changes for the north-westerly direction once it passes over CT to a more northerly direction, missing the Hangklip site.

The mean weekly background concentrations, separate for day and night, were determined from the percentile filtered measurements at the site and were used as the prior domain boundary concentrations for each of the four cardinal directions. The inversion was then allowed to make small adjustments to these concentrations. The prior variance assigned to the boundary concentrations was equal to the variance of the measured hourly concentrations for that period. As the variability in the background $\mathrm{CO}_{2}$ in the Southern Hemisphere is small, much smaller than for the Northern Hemisphere, this resulted in a tight constraint on the prior background $\mathrm{CO}_{2}$ concentrations. Large adjustments by the inversion to the far-field domain boundary concentrations were not expected. The daytime weekly background concentrations are shown in Fig. 2. The standard deviation in the hourly background $\mathrm{CO}_{2}$ concentrations ranged between 0.32 and $0.90 \mathrm{ppm}$, with a mean of $0.62 \mathrm{ppm}$.

The boundaries of the domain were deliberately set to be far from the measurement sites so that contributions to the $\mathrm{CO}_{2}$ concentration at a measurement site were dominated by the surface fluxes within the domain rather than by the domain boundary concentrations.

\subsection{Prior covariance matrix $-\mathrm{C}_{s_{0}}$}

The uncertainty covariance matrix, $\mathbf{C}_{\boldsymbol{s}_{0}}$, of the prior fluxes and domain boundary concentrations $s_{0}$ determines in part how much freedom the inversion has to adjust these fluxes based on the observed concentrations $c$. If the off-diagonal prior covariance elements are significantly different from zero, then the estimate for a each flux will be more dependant on the prior estimates of the surrounding fluxes compared with an inversion where the covariances between the uncertainties in the prior fluxes were set to zero. In contrast, if the prior variances are large, the inversion is able to make large adjustments to flux estimates to obtain better agreement between the observed and modelled concentrations. The next two subsections explain how the original estimates of the uncertainties in the fluxes and observation errors were determined. The uncertainties in the prior fluxes were scaled by an additional factor of 2 to ensure goodness of fit of the covariance structure (see Sect. 1.2 in the Supplement).

\subsubsection{Fossil fuel emissions}

Error propagation techniques were used to estimate the uncertainties in the sector-specific fossil fuel emissions. This was described in Nickless et al. (2015a). An industrial point source flux $s_{0 ; \text { ff }}$ was derived from the equation

$s_{0 ; \mathrm{ff}}=A E$,

where $A$ is the activity data, usually fuel usage, and $E$ is the process-specific emission factor. The uncertainty in the flux was estimated from

$C_{\boldsymbol{s}_{0 ; \mathrm{ff}}}=\left|s_{0 ; \mathrm{ff}}\right|^{2} \times\left(\left(\frac{\delta A}{A}\right)^{2}+\left(\frac{\delta E}{E}\right)^{2}\right)$,

where $C_{\boldsymbol{s}_{0 ; f f}}$ is the uncertainty in the flux estimate expressed as a variance, $\delta A$ is the uncertainty in the activity data, and $\delta E$ is the uncertainty in the emission factor, expressed as standard deviations. DEFRA (2013b) provides estimates of uncertainty in the activity data and emission factors under various industrial processes for each fuel type.

For vehicle emissions, which relied on count data, Poisson errors were assumed and propagated together with the uncertainty in the conversion factors for the different vehicle types. For airport and harbour emissions, vessel counts were assumed to be correct, and therefore the uncertainty in the emissions contained within the emission factors for the different vessel types and activities. For aircraft, these errors are assumed to be $34 \%$ for the international fleet and $28 \%$ for the domestic fleet (IPCC, 2000). The error estimate for berth and manoeuvring activities of shipping vessels is reported to be between 20 and $30 \%$, and therefore a conservative estimate of $30 \%$ was used (DEFRA, 2010). For 


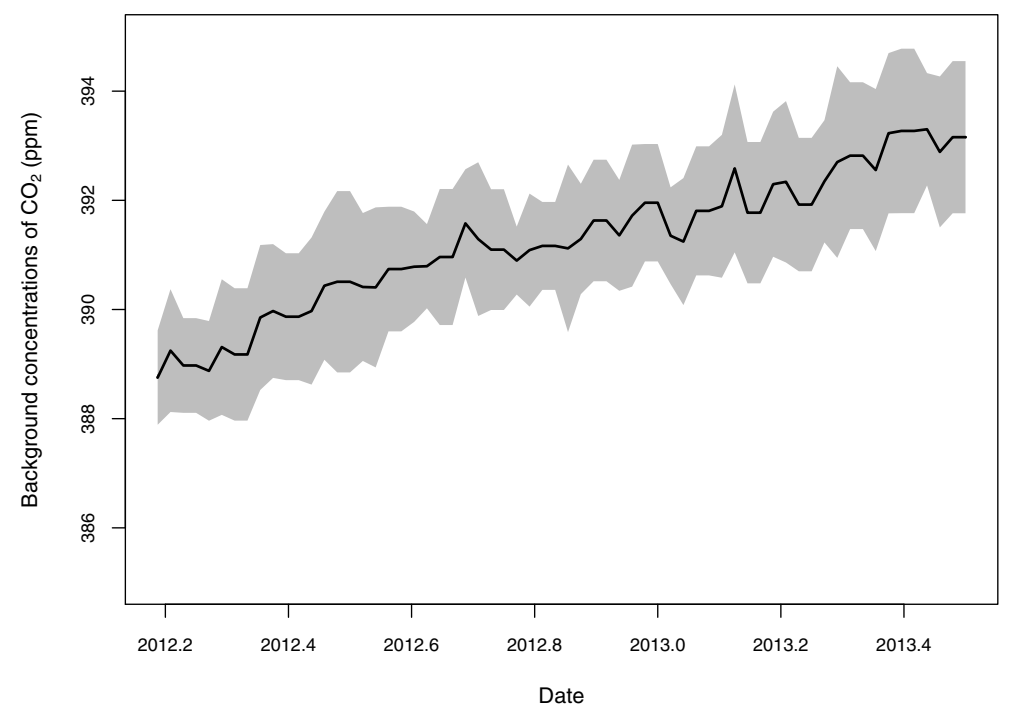

Figure 2. Weekly mean background concentrations of $\mathrm{CO}_{2}(\mathrm{ppm})$ as measured at Cape Point GAW station, with $95 \%$ confidence interval represented by the grey shaded area. The mean concentrations are calculated from percentile filtered observations, extracting only those observations considered to be representative of background conditions.

domestic heating and lighting, the estimates relied on population census, which had a reported omission rate of $15 \%$. There was no information available on the variability in fuel usage between households, and therefore the uncertainty in the domestic emissions was set at $30 \%$ as a relatively arbitrary, but conservative, level. Domestic emissions due to fossil fuel burning was a large contributor to the overall fossil fuel flux of the domain. As the percentage uncertainty assigned to these fluxes was large, uncertainties in the domestic emissions was a significant contributor to the overall uncertainty in the fossil fuel fluxes.

After accounting for the scaling of the uncertainty estimates to improve goodness of fit of the covariance structure, the resulting uncertainty estimates (expressed as standard deviations) ranged between 6.7 and $71.7 \%$ of the prior fossil fuel emission estimate, with a median percentage of 34.9 to $38.4 \%$, depending on the month. These values are in general more conservative compared with uncertainties that were determined by Bréon et al. (2015) for the Airparif inventory, which were set at $20 \%$ throughout. The spatial distribution of the fossil fuel fluxes during the month of March 2012 are mapped in Fig. 3. The daytime fossil fuel emissions have a mean of $0.006 \mathrm{~kg} \mathrm{CO}_{2} \mathrm{~m}^{-2}$ week $^{-1}$ and go up to $3.4 \mathrm{~kg} \mathrm{CO}_{2} \mathrm{~m}^{-2}$ week $^{-1}$. The mean went down to $0.004 \mathrm{~kg} \mathrm{CO}_{2} \mathrm{~m}^{-2}$ week $^{-1}$ during the summer months, when domestic heating and lighting fuel usage is lower. The largest fossil fuel emission estimated was located towards the north of the city and corresponded to a crude oil refinery. Most point estimates were located on the outskirts of the city, with a few located within the central peninsula area. The road network is apparent in the figure of the prior fossil fuel fluxes displaying the corresponding transport emissions and clearly illustrates the large contribution that road transport makes to the overall $\mathrm{CO}_{2}$ budget of $\mathrm{CT}$.

Since we solved for weekly, rather than daily, fluxes, we used a strong assumption that fossil fuel fluxes within the same week were $100 \%$ correlated. To allow the inversion to react to local conditions within a given week, no correlation was assumed between weekly fluxes. Since fossil fuel emissions were expected to be localised in space, we also assumed no spatial correlation between fossil fuel fluxes.

\subsubsection{Biogenic fluxes}

The uncertainty in the biogenic prior fluxes was set at the absolute value of the net primary productivity (NPP) as produced by CABLE. This is a large error relative to the prior estimate itself, but there is a great deal of uncertainty in both the productivity and respiration fluxes contributing to the NEE flux (Wang et al., 2011). The estimates of NEE are strongly dependent on the assumptions behind the model forms selected for different processes in the CABLE model. For example, the model forms used for the soil temperaturerespiration function and the soil moisture-respiration function have large impacts on the NEE estimates, with resulting NEE estimates differing by over $100 \%$ compared with measurements from flux towers (Exbrayat et al., 2013). The approach of assigning either the productivity or respiration component of NEE as the uncertainty has been used by Chevallier et al. (2010). We avoided assigning a fixed proportional uncertainty to the NEE estimates, particularly in semi-arid regions, such as those conditions found throughout South Africa, because small NEE fluxes can occur as a result of both large productivity and respiration fluxes. In the CT situation, this would lead to unrealistically low estimates of 

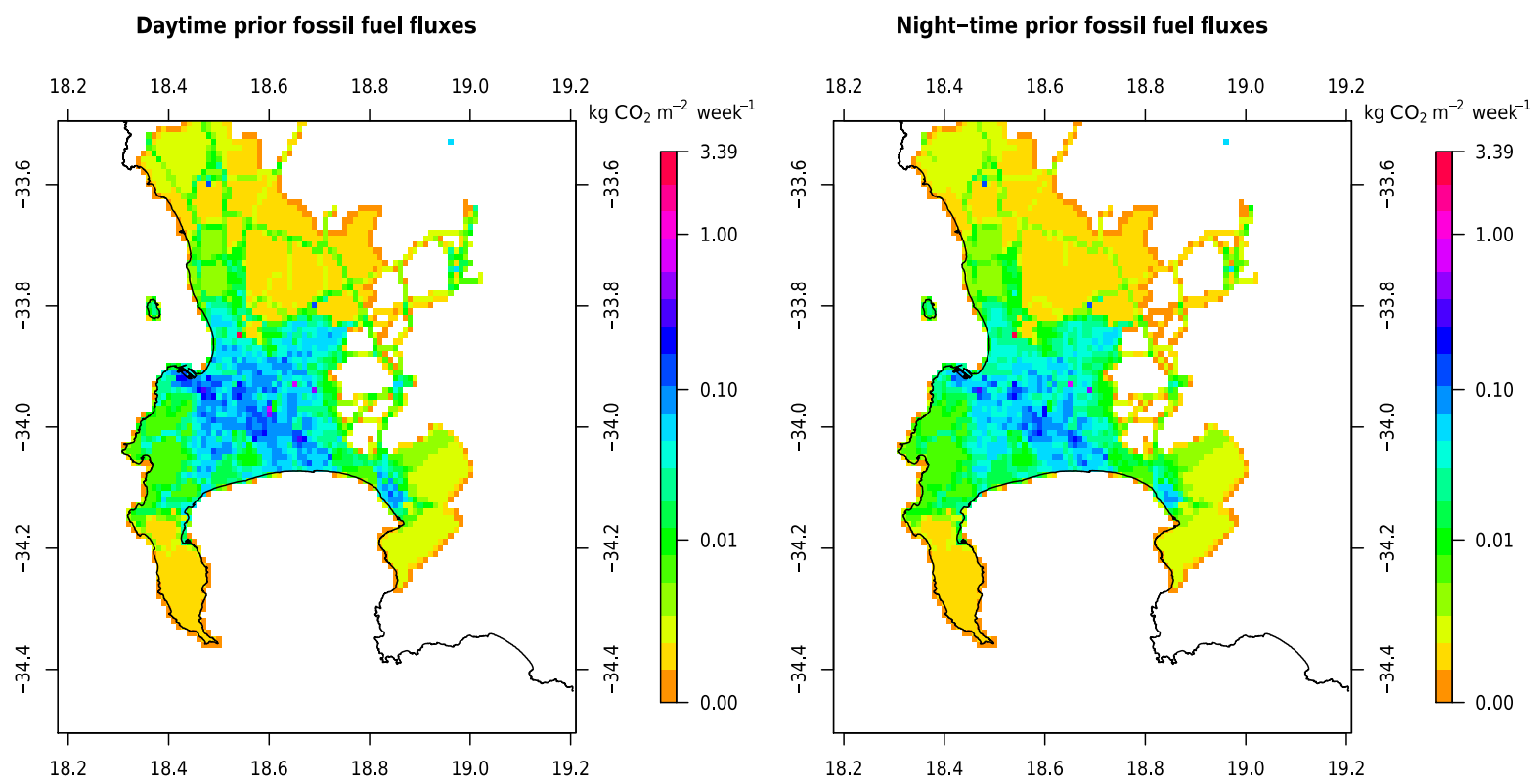

\section{Daytime prior fossil fuel flux uncertainties}

Night-time prior fossil fuel flux uncertainties
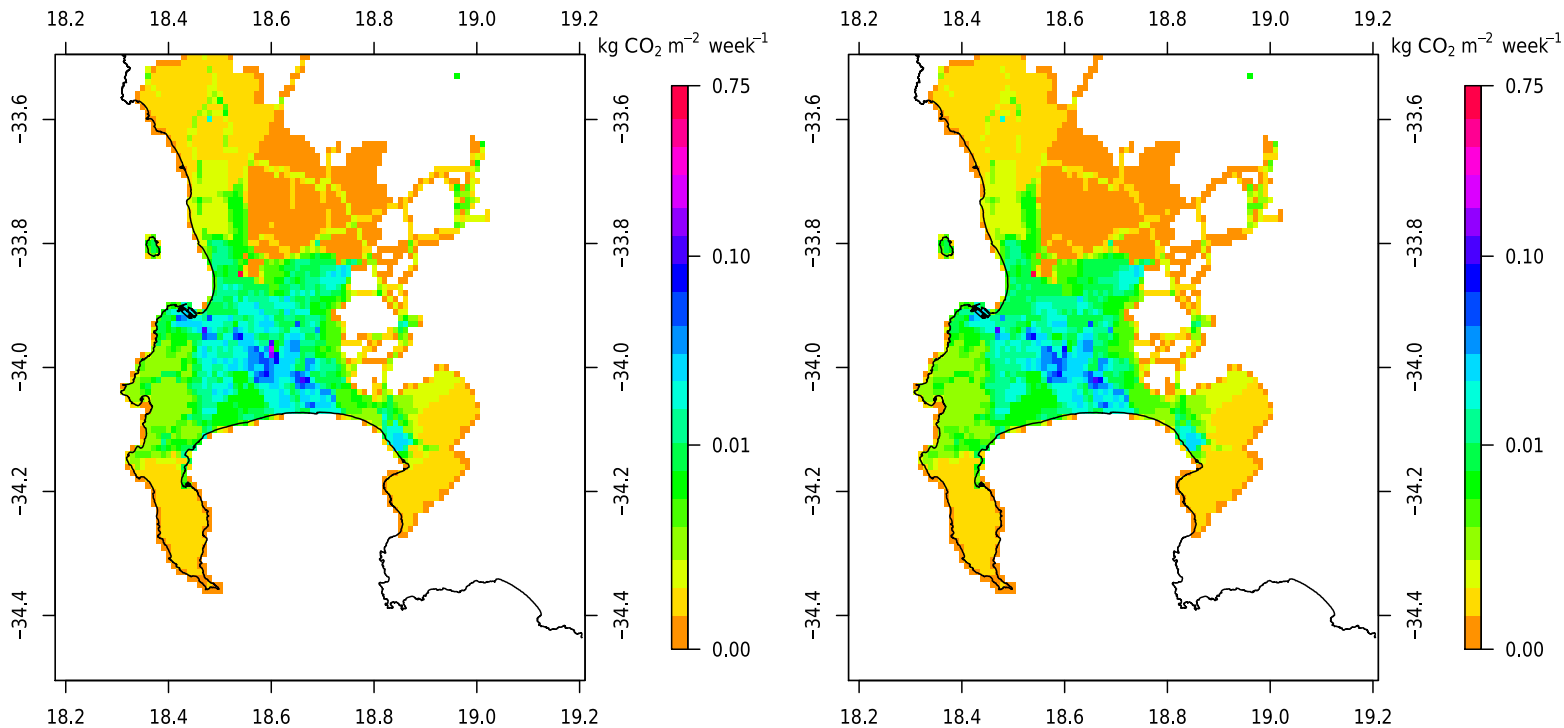

Figure 3. Prior estimates for day- and night-time fossil fuel fluxes $\left(\mathrm{kg} \mathrm{CO}_{2} \mathrm{~m}^{-2}\right.$ week $\left.{ }^{-1}\right)$ and the corresponding uncertainties, expressed as standard deviations $\left(\mathrm{kg} \mathrm{CO}_{2} \mathrm{~m}^{-2}\right.$ week $\left.^{-1}\right)$, for the month of March 2012. These estimates were derived from an inventory analysis for CT based on vehicle, aviation, and shipping vessel count data, population census data, and fuel usage at industrial point sources. White indicates regions where the fossil fuel flux and its uncertainty are set to zero. These prior estimates are provided at a resolution of $1 \mathrm{~km} \times 1 \mathrm{~km}$ and the extent of the grid is between 34.5 and $33.5^{\circ} \mathrm{S}$ and between 18.2 and $19.2^{\circ} \mathrm{E}$.

the uncertainty in NEE fluxes. This is different to the approach used by Bréon et al. (2015), where an uncertainty level of $70 \%$ was assigned to biogenic fluxes, but in their case absolute NEE estimates were usually large in summer and expected to be small in winter.

To estimate covariances between the uncertainties in the NEE fluxes, we assumed an isotropic Balgovind correlation model as used in Wu et al. (2013). This helps to ensure positive definiteness of the resulting covariance matrix. The off-diagonal covariance elements between $s_{\mathrm{NEE} ;} i$ and $s_{\mathrm{NEE} ;} j$ 

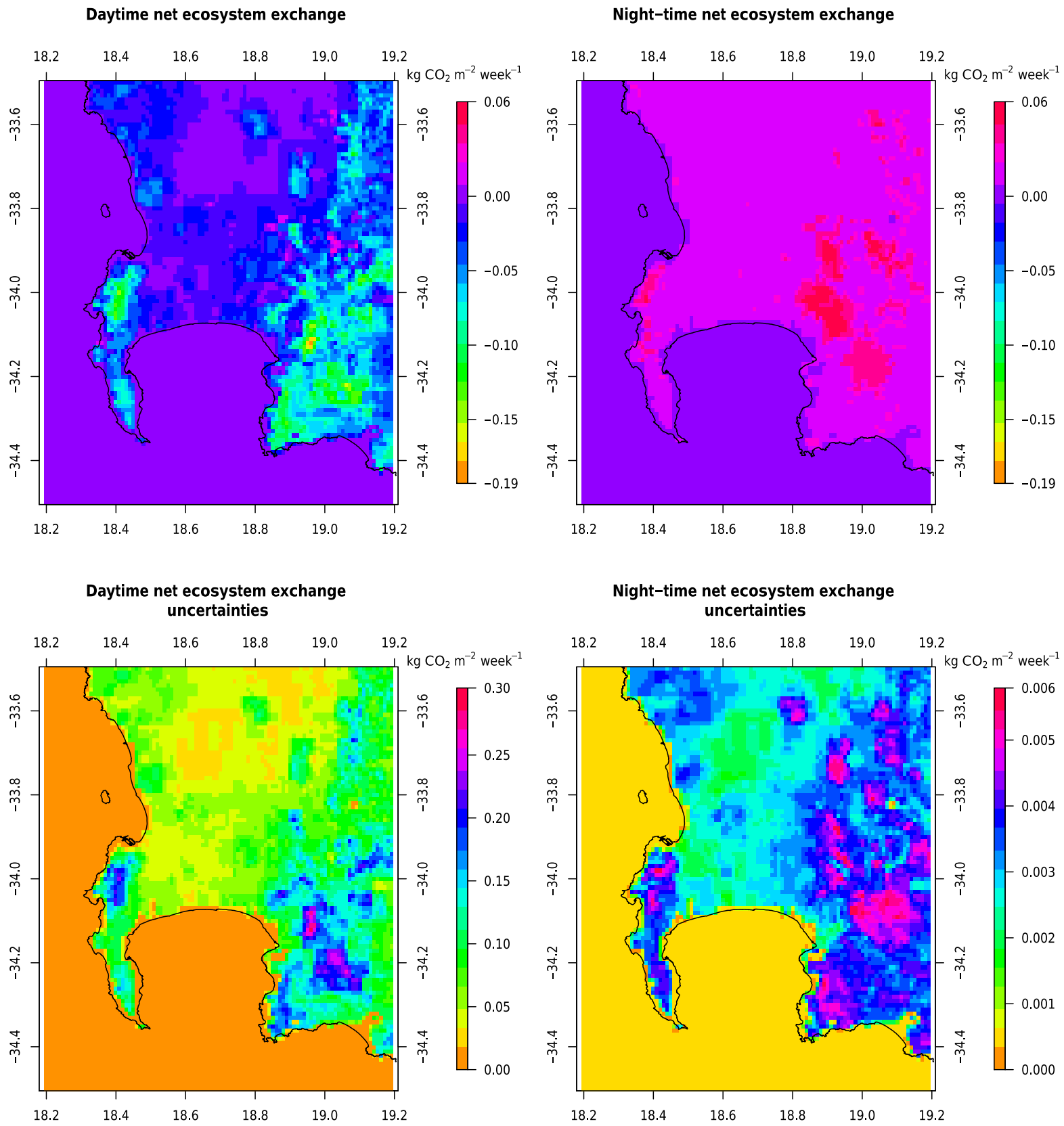

Figure 4. Prior estimates for day- and night-time NEE fluxes $\left(\mathrm{kg} \mathrm{CO}_{2} \mathrm{~m}^{-2}\right.$ week $\left.{ }^{-1}\right)$ and the corresponding uncertainties, expressed as standard deviations $\left(\mathrm{kg} \mathrm{CO}_{2} \mathrm{~m}^{-2}\right.$ week $\left.^{-1}\right)$, during the month of March 2012. The prior estimates were obtained from the CABLE landatmosphere exchange model at a spatial resolution of $1 \mathrm{~km} \times 1 \mathrm{~km}$. The extent of the grid is between 34.5 and $33.5^{\circ} \mathrm{S}$ and between 18.2 and $19.2^{\circ} \mathrm{E}$.

were calculated as

$$
\begin{aligned}
C_{s_{0 ; \mathrm{NEE}}}\left(s_{\mathrm{NEE} ; i}, s_{\mathrm{NEE} ; j}\right)= & \sqrt{C_{s_{0 ; \mathrm{NEE}}}\left(s_{\mathrm{NEE} ; i}\right)} \\
& \sqrt{C_{s_{0 ; \mathrm{NEE}}}\left(s_{\mathrm{NEE} ; j}\right)} \\
& \left(1+\frac{h}{L}\right) \exp \left(-\frac{h}{L}\right),
\end{aligned}
$$

where $s_{\mathrm{NEE} ; i}$ and $s_{\mathrm{NEE} ;} j$ are NEE fluxes in pixels $i$ and $j$, $C_{\boldsymbol{s}_{0 ; \mathrm{NEE}}}\left(s_{\mathrm{NEE} ; i}\right)$ and $C_{\boldsymbol{s}_{0 ; \mathrm{NEE}}}\left(s_{\mathrm{NEE} ; j}\right)$ are the corresponding variances in the NEE flux uncertainties in pixels $i$ and $j$, the characteristic correlation length $L$ was assumed to be $1 \mathrm{~km}$, and $h$ is the spatial distance between pixels $i$ and $j$. As for the fossil fuel fluxes, no correlation was assumed between weekly biogenic fluxes since the inversion setup is already assuming that biogenic fluxes within the same week were $100 \%$ correlated (i.e. constant over the week). 
Figure 4 shows the spatial distribution of the NEE fluxes and their uncertainties for the month of March 2012. Daytime NEE fluxes ranged between -0.19 and $0.04 \mathrm{~kg}$ $\mathrm{CO}_{2} \mathrm{~m}^{-2}$ week $^{-1}$, concentrated over areas such as the Cape Point Nature Reserve and Kogelberg Nature Reserve, located near the Hangklip lighthouse. At night the fluxes were between 0.0 and $0.06 \mathrm{~kg} \mathrm{CO}_{2} \mathrm{~m}^{-2}$ week ${ }^{-1}$. The uncertainties in the NEE daytime fluxes ranged between 0.00001 (over the ocean) and $0.30 \mathrm{~kg} \mathrm{CO}_{2} \mathrm{~m}^{-2}$ week $^{-1}$, whereas at night the uncertainties ranged between 0.000001 and $0.006 \mathrm{~kg} \mathrm{CO}_{2} \mathrm{~m}^{-2}$ week $^{-1}$. Uncertainties were smaller at night because night-time biogenic activity was mainly driven by respiration, and consequently the flux estimates were smaller as well as their uncertainties. Over the full measurement period, the estimates of NEE fluxes ranged between -0.22 and 0.004 during the summer to between -0.11 and $0.007 \mathrm{~kg} \mathrm{CO}_{2} \mathrm{~m}^{-2}$ week $^{-1}$ during mid-winter.

\subsection{Uncertainty covariance matrix of the observations $-\mathbf{C}_{c}$}

The uncertainties in the observations represented in $\mathbf{C}_{c}$ contain both the measurement error (which are known to be in the order of $0.3 \mathrm{ppm}$ ) (Bréon et al., 2015; Wu et al., 2016) and the error associated with modelling the concentrations. The modelling errors result from several sources, including errors within the atmospheric transport model and aggregation errors which are due to smoothing emission estimates from localised sources within the spatial grids (Kaminski et al., 2001).

Similar to the approach adopted in the optimal network design for South Africa (Nickless et al., 2015b), an error of $2 \mathrm{ppm}$ during the day and $4 \mathrm{ppm}$ at night was assigned to each observation, so that night-time observations carried less weight in the inversion. These values were assigned as baseline (i.e. minimum) errors and accounted for measurement errors, atmospheric transport modelling errors, aggregation errors, and representation errors.

These errors are smaller than those for city-scale inversions conducted in the Northern Hemisphere. We justify the use of these values in our application since we are dealing with a much smaller city compared with the megacity applications, such as Paris and Indianapolis. Measurements of background $\mathrm{CO}_{2}$ have shown that $\mathrm{CO}_{2}$ concentrations in the Southern Hemisphere have smaller standard deviations. For example, for the years 2012 to 2013 the standard deviation between the monthly $\mathrm{CO}_{2}$ means for Mauna Loa GAW station in the Northern Hemisphere was $2.3 \mathrm{ppm}$ (Tans and Keeling, 2016), whereas for the same time period at Cape Point the standard deviation between the monthly means was $1.6 \mathrm{ppm}$.

We accounted for additional sources of error in the atmospheric transport model. We took into consideration that errors in the modelled $\mathrm{CO}_{2}$ concentrations due to the transport model would be larger when the wind speed was lower
(Bréon et al., 2015), and this would be compounded at night when the planetary boundary layer height was lower and less stable (Feng et al., 2016). Additional error ranging between 0 and $1 \mathrm{ppm}$ was added to the daytime uncertainty of $2 \mathrm{ppm}$, linearly scaled depending on the wind speed, with $0 \mathrm{ppm}$ added when wind speeds were high $\left(20 \mathrm{~m} \mathrm{~s}^{-1}\right)$ and $1 \mathrm{ppm}$ added when the wind speed was close to zero. At night the additional uncertainty ranged between 0 and $4 \mathrm{ppm}$.

We also considered the standard deviation of the measured $\mathrm{CO}_{2}$ concentrations during each hour. It would be expected that the atmospheric transport model would be more likely to make errors during this period if there was a large amount of variability between the instantaneous measurements at the site. The variance of the observed $\mathrm{CO}_{2}$ concentrations that contributed towards the mean estimate of the $\mathrm{CO}_{2}$ concentration for that hour was added to the overall uncertainty. Therefore each hour had a customised observation error dependant on the prevailing conditions at the measurement site. Therefore the total observation error for hour $k$, as a variance, is given as

$C_{c}(k, k)=C_{c}$; base $^{2}+C_{c} ;$ wind $^{2}+C_{c ; \text { obs }}^{2}$,

where $C_{c}$; base is the baseline observation error of 2 ppm during the day and $4 \mathrm{ppm}$ during the night, $C_{c \text {; wind }}$ is the additional error due to the wind speed conditions which ranged between 0 and 1 , and $C_{c \text {; obs }}$ is the standard deviation of the observed concentrations within that hour. A time series of the customised observation errors is provided in Fig. 5. The final observation errors could reach up to 10 or $15 \mathrm{ppm}$ at night, reducing the weight of these measurements in the estimation of the prior fluxes.

Temporal correlation between the observation errors was accounted for in an analogous manner to which covariance terms were estimated for the NEE flux uncertainties. The characteristic correlation length $L$ was assumed to be $1 \mathrm{~h}$, and $h$ was the temporal distance between observations.

\subsection{Model assessment}

In order to assess the appropriateness of the uncertainty covariance matrices $\mathbf{C}_{c}$ and $\mathbf{C}_{\boldsymbol{s}_{0}}$, the $\chi^{2}$ statistic, as described in Tarantola (2005), can be employed to determine the minimum value of the statistic:

$\chi_{1}^{2}=\frac{1}{v}\left(\mathbf{H} \boldsymbol{s}_{0}-\boldsymbol{c}\right)^{T}\left(\mathbf{H C}_{\boldsymbol{s}_{0}} \mathbf{H}^{T}+\mathbf{C}_{c}\right)^{-1}\left(\mathbf{H} \boldsymbol{s}_{0}-\boldsymbol{c}\right)$,

where $v$ is the dimension of the data space, in this case the length of observations in the inversion.

The squared residuals from the inversion (squared differences between observed and modelled concentrations) should follow the $\chi^{2}$ distribution with degrees of freedom equal to the number of observations (Michalak et al., 2005; Tarantola, 2005). Dividing this statistic by the degrees of freedom should yield a $\chi_{1}^{2}$ distribution. Values lower than 1 indicate that the uncertainty is too large, and values greater 

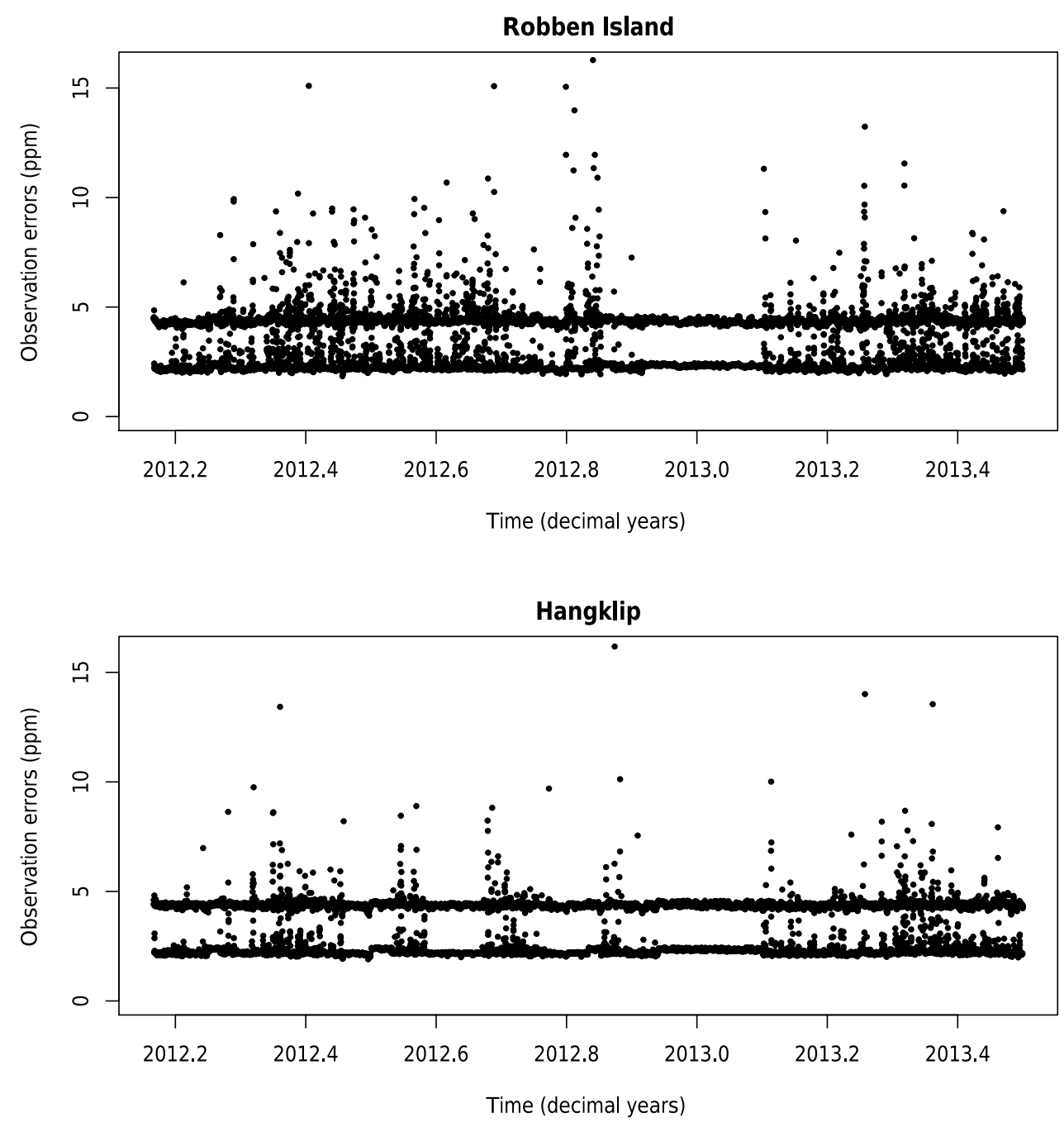

Figure 5. Time series of the customised observation errors (ppm) assigned to the $\mathrm{CO}_{2}$ concentration measurement for each hour at the Robben Island and Hangklip measurement sites. The errors consist of a baseline error (set as 2 ppm during the day and 4 ppm at night) and additional atmospheric model errors based on prevailing wind speed and the variation in the instantaneous $\mathrm{CO}_{2}$ observations within an hour. The two distinct sets of points for each site arises due to the night-time observation errors set to be larger than daytime observation errors.

than 1 indicate that the uncertainty prescribed is lower than it should be. The error in the assignment of the uncertainty could be in either $\mathbf{C}_{c}$ or $\mathbf{C}_{\boldsymbol{s}_{0}}$ (or both).

Sensitivity analyses carried out on the specification of the covariance matrices have indicated that these errors are most likely contained in $\mathbf{C}_{\boldsymbol{s}_{0}}$. These analyses are presented in a follow-up paper. In order to ensure the suitability of $\mathbf{C}_{\boldsymbol{s}_{0}}$, the prior variances were multiplied by a factor of 2 . This ensured that the $\chi_{1}^{2}$ statistic was close to a value of 1 for almost all months of the inversion. A single scaling factor was used to adjust all the prior flux variances. An alternative to a single value scaling factor will be considered in a subsequent paper.

Using the $\chi^{2}$ statistic to scale or estimate covariance parameters has been implemented by Lauvaux et al. (2016) and Michalak et al. (2005). Lauvaux et al. (2016) used the $\chi^{2}$ statistic to scale the elements of the observation error covariance matrix. An alternative to manually scaling the elements of either $\mathbf{C}_{s_{0}}$ or $\mathbf{C}_{c}$ is to use a hierarchical Bayesian approach to estimate hyperparameters for the covariance matrix, which are estimated based on the observed concentrations (Ganesan et al., 2014).

\section{Results}

In this paper we concentrate on the results of the reference inversion, as described in the previous section. We present sensitivity analyses elsewhere (Nickless et al., 2018). Additional information on the distribution and time series of the observed concentrations at Robben Island, Hangklip, and Cape Point over the 16-month period is provided in Sect. 1.1 in the Supplement. Information is also provided on the as- 
sessment of the goodness of fit of the prescribed covariance structures in Sect. 1.2 in the Supplement to justify the use of the scaling factor of 2 to increase the original estimates of the uncertainties in the prior fluxes to get the $\chi^{2}$ statistic closer to 1 . The average wind speed and direction, supplied as monthly maps of the wind fields across the domain, as modelled by CCAM are provided in Sect. 1.3.

\subsection{Modelled concentrations}

The time series of the prior and posterior modelled concentrations at Robben Island were compared with the observed concentrations (Fig. 6). The prior estimates tended to be in the correct range for $\mathrm{CO}_{2}$ concentration measurements, but could be higher or lower compared with the observations by as much as $100 \mathrm{ppm}$. It is possible to test whether our assumed uncertainties in the prior fluxes are consistent with the misfit between the prior modelled concentrations and observations. Michalak et al. (2005) pointed out that the covariances of the differences between the prior simulation and observations are given by the matrix $\mathbf{H C}_{\boldsymbol{s}_{0}} \mathbf{H}^{T}+\mathbf{C}_{c}$. This matrix accounts for both the uncertainty in the prior fluxes and in the observations. The square root of the diagonal elements of this matrix had a similar distribution to the absolute mismatches between the observations and prior modelled concentrations, showing that the setup is statistically consistent. The prior concentrations tended to spike at the same time as the observations, but these spikes were usually larger in the prior modelled concentrations.

As one would expect, the agreement between the posterior modelled concentrations and the observations was much stronger compared with the prior estimates. The posterior concentrations appeared to track the observed concentrations during localised "pollution" events. For example, in March to April 2012 all except one of the spikes in the observed $\mathrm{CO}_{2}$ concentration were replicated in the posterior concentrations. The agreement can be assessed by means of the intraclass correlation coefficient (ICC) (Shrout and Fleiss, 1979), which is a stronger condition than correlation. Values close to zero indicate poor agreement while values close to one indicate strong agreement. The ICC was low at 0.03 (95\% CI: 0.01 to 0.06 ) but still significant, between the observed and prior modelled concentrations, but went up to 0.59 (95\% CI: 0.57 to 0.61 ) between the observed and posterior modelled concentrations.

We define prior residuals as the difference between the observed and prior modelled concentrations and posterior residuals as the difference between the observed and posterior modelled concentrations. A time series plot of the prior and posterior residuals given in Fig. 6 indicates more clearly how large the misfits between the modelled and observed concentrations can get. The prior residuals could be large in either the positive or negative direction, up to $100 \mathrm{ppm}$ and occasionally out by as much as $200 \mathrm{ppm}$. The posterior residuals were much closer to the zero line, with the highest devia- tion equal to $33 \mathrm{ppm}$. The bias in the prior modelled concentrations was $-2.9 \mathrm{ppm}$. The standard deviation of the prior residuals was $21.4 \mathrm{ppm}$ (interquartile range between -9.1 and $3.7 \mathrm{ppm}$ ), indicating a large amount of spread in the residuals. The bias in the posterior modelled concentrations went down to $0.5 \mathrm{ppm}$ and the standard deviation of residuals reduced to $3.9 \mathrm{ppm}$ (interquartile range -1.5 and $1.5 \mathrm{ppm}$ ), showing a significant reduction in the misfit compared with the prior modelled concentrations. Compared with the standard deviation of the observed concentrations, which was $5.02 \mathrm{ppm}$, the standard deviation of the posterior residuals was lower by $1.1 \mathrm{ppm}$, indicating that the uncertainty in the posterior estimates of the concentrations was well below the expected variability around the observed concentrations.

The time series of the observed, prior, and posterior concentrations at Hangklip reveal a similar result compared with those for Robben Island (Fig. 7). The prior estimates could be much larger or smaller compared with the observed concentrations. The posterior concentration estimates matched much more closely with the observed concentrations compared with those for Robben Island. The ICC between the observed and prior modelled concentrations was similar to Robben Island at 0.03 (95\% CI: 0.003 to 0.05 ), but the agreement between the observed and posterior modelled concentrations was better with an ICC of 0.76 (95\% CI: 0.75 to 0.77). The prior residuals at the Hangklip site tended to be less extreme compared with those for Robben Island, with a maximum deviation of $117 \mathrm{ppm}$ in either direction (Fig. 7). The summary statistics of the residuals indicate that the mean bias in the prior estimates was $2.4 \mathrm{ppm}$ with standard deviation equal to 17.6 (interquartile range between -2.3 and $6.5 \mathrm{ppm}$ ). For the posterior residuals, the bias was reduced to $0.04 \mathrm{ppm}$ with standard deviation equal to 2.46 (interquartile range -1.1 to 0.8 ), which was lower by $1.4 \mathrm{ppm}$ compared with the standard deviation of the observed concentrations, which was 3.89 ppm.

The observed and modelled concentrations and their misfits are provided separately for day and night concentrations in Figs. 6 and 7. There is no notable difference in the degree of misfit between day and night at either site. The large improvement in the representativeness of the posterior concentrations in relation to the observed concentrations at both sites lends confidence to the reference inversion's ability to adjust the estimates of the fluxes to better match the true fluxes in the region.

The mean working week and weekend diurnal cycles in the observed, prior, and posterior modelled concentrations are shown for each site and for each month in Sect. 1.5 in the Supplement. Figure 8 provides the mean working week and weekend diurnal cycle over the full measurement period. For Robben Island, the mean concentrations for each hour indicate that the emissions are overestimated by the prior estimates. The posterior modelled concentrations are much closer to the observed concentrations, replicating the peak in concentrations to be between 08:00 and 09:00 in the 

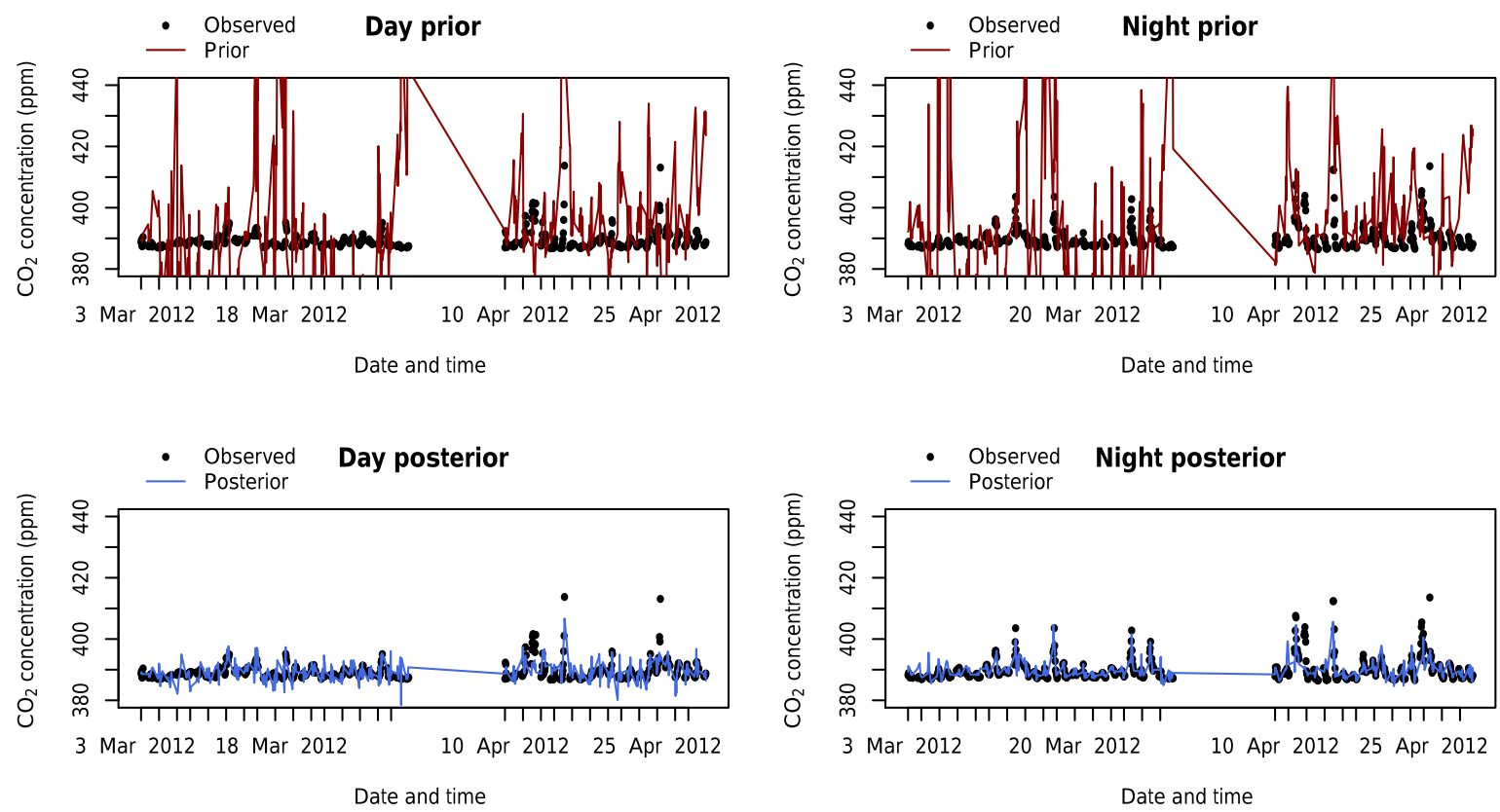

Day prior residuals
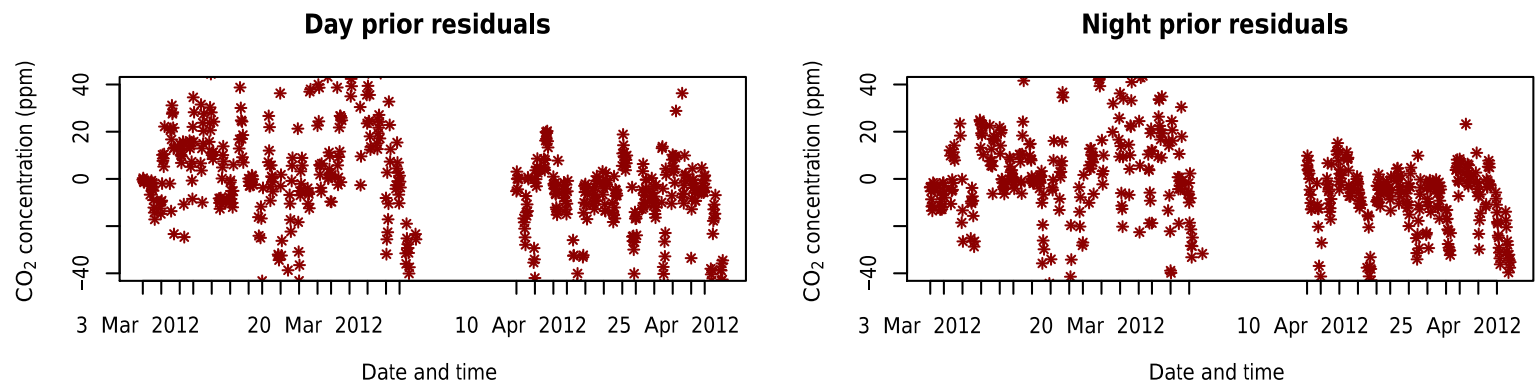

Day posterior residuals
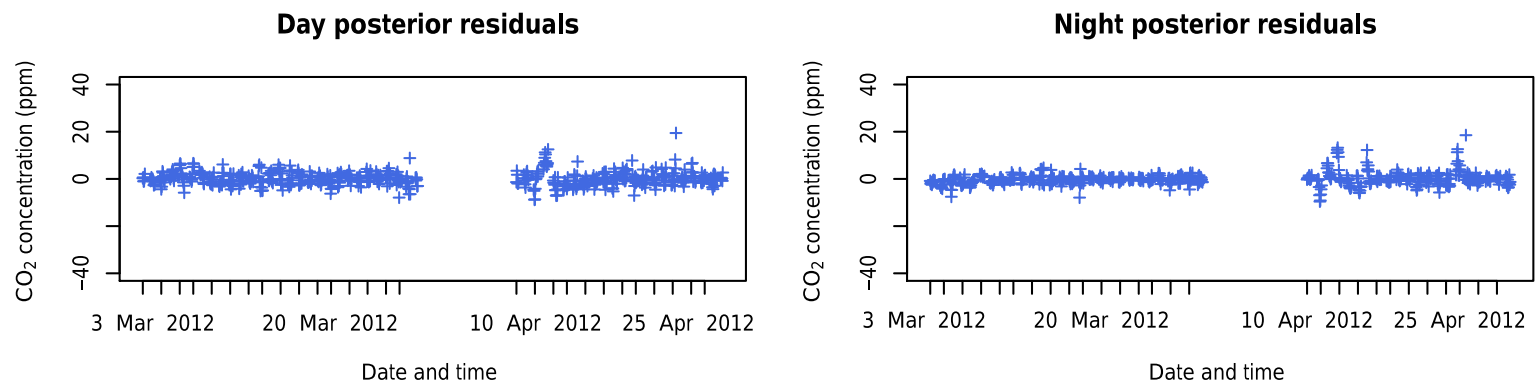

Figure 6. The top four panels provide a time series of the observed, prior, and posterior modelled concentrations at the Robben Island site. The time series is separated into day and night-time periods. The residuals between the observed and prior/posterior modelled concentrations, defined as the difference between the observed and modelled concentrations, are provided in the lower panel four panels. The first 2 months are presented here and remainder of the time series is presented in Sect. 1.4 in the Supplement.

morning and the trough in concentrations to occur between 15:00 and 18:00. Overall the cycle in the posterior concentrations is flatter compared with that of the observed concentrations. The observed concentrations during the week are usually slightly higher compared with those over the week- end. The posterior estimates show a smaller deviation between the week and weekend concentrations at each hour of the day, particularly around mid-morning, compared with the observed week and weekend concentrations. 


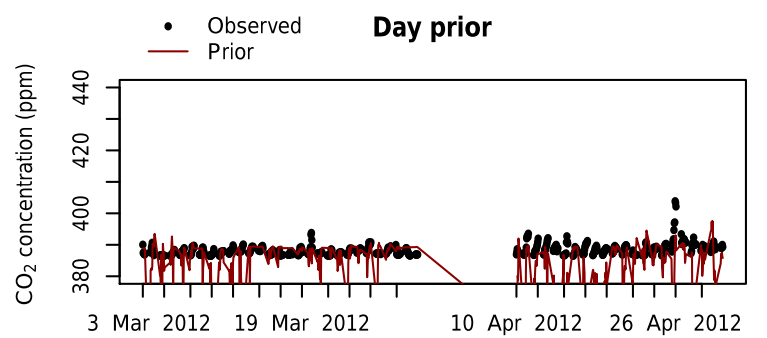

Date and time

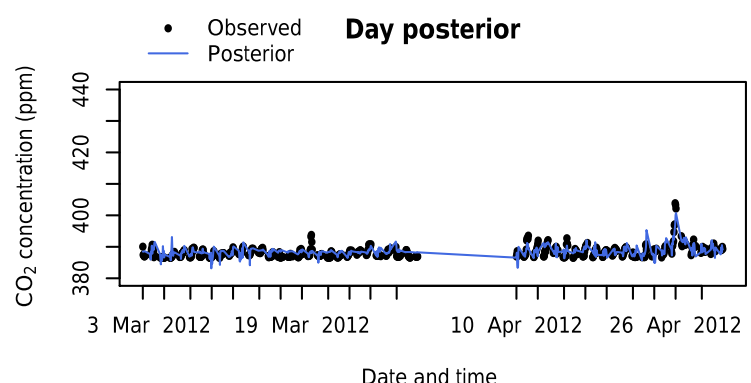

Day prior residuals

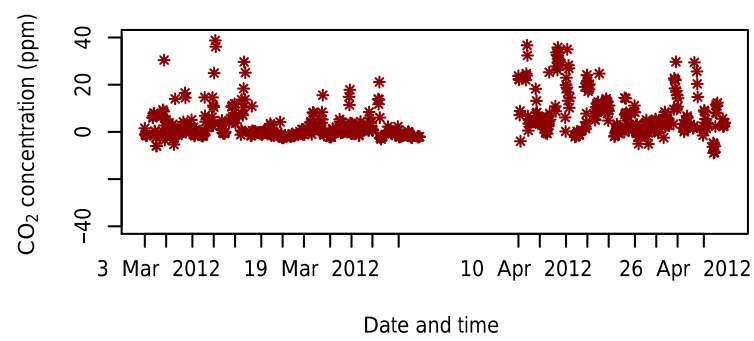

Day posterior residuals

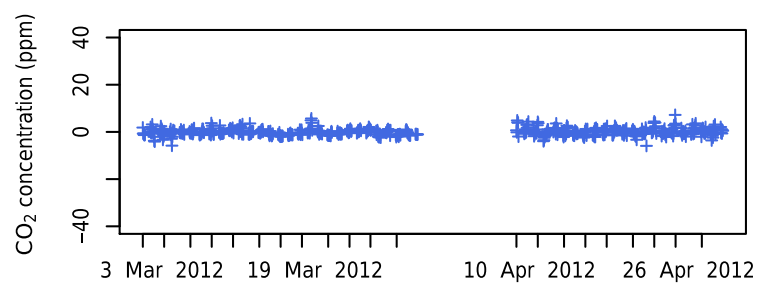

Date and time

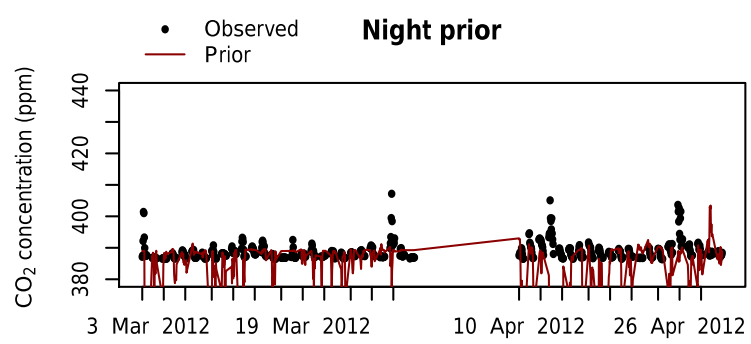

Date and time

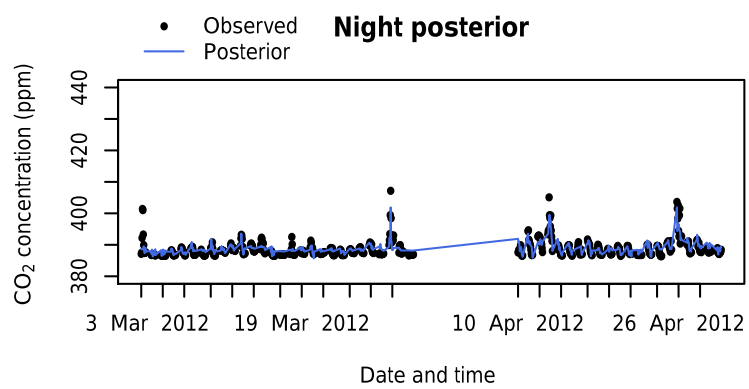

Night prior residuals

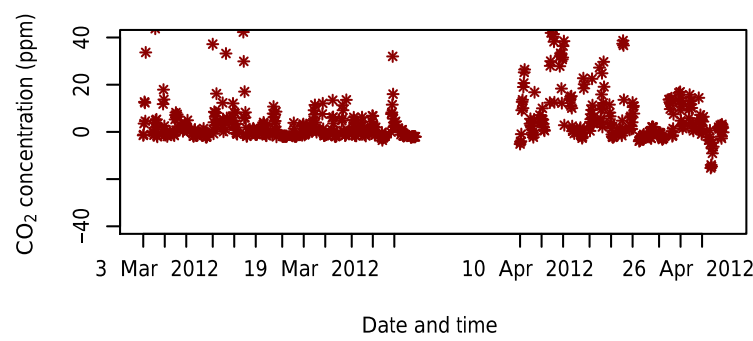

Night posterior residuals

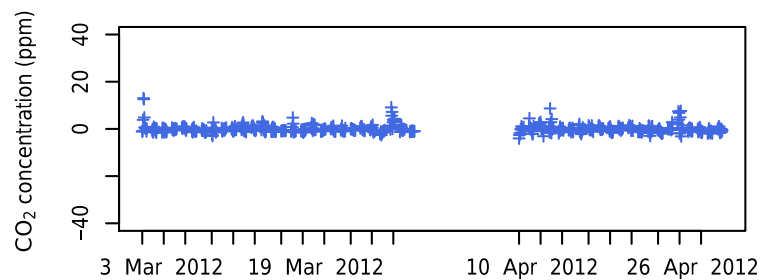

Date and time

Figure 7. The top four panels provide a time series of the observed, prior and posterior modelled concentrations at the Hangklip site. The time series is separated into day- and night-time periods. The residuals between the observed and prior/posterior modelled concentrations, defined as the difference between the observed and modelled concentrations, are provided in the lower panel four panels. The first 2 months are presented here and remainder of the time series is presented in Sect. 1.4 in the Supplement.

The prior estimates for the Hangklip measurement show the opposite bias compared with Robben Island, with prior modelled concentrations lower at each hour compared with the observed concentrations. The posterior modelled concentrations for Hangklip overlap closely with the observed con- centrations. When compared with Robben Island, there is slightly less separation between the working week and weekend concentrations at each hour. This should be expected as the concentrations observed at the Hangklip site are more dominated by biogenic sources compared with Robben Is- 
land. The closest fossil fuel sources are those from transport and domestic emissions. The main road through this area carries a large amount of commercial traffic during the week, and over the weekend the area is frequented by weekend residents and tourists, and therefore anthropogenic activity is not expected to be much lower over the weekend. The posterior concentrations show that the inversion was able to replicate the separation between the mean hourly working week and weekend concentrations shown by the observed concentrations for most hours of the day, particularly the difference between these concentrations occurring between the hours of 07:00 and 09:00.

The contributions by the fossil fuel and NEE fluxes to the modelled concentrations were determined. These are displayed in Figs. 9 and 10 for Robben Island and Hangklip, respectively, for March to June 2012. July 2012 to June 2013 are supplied in Sect. 1.6 in the Supplement. The prior contributions by these two fluxes were of similar magnitude at both sites, but with the fossil fuel fluxes increasing $\mathrm{CO}_{2}$ concentrations and the NEE fluxes reducing the concentration. After the inversion, the contributions of the posterior NEE fluxes to the modelled concentrations were much more modified by the inversion compared with those from the posterior fossil fuel fluxes. Moreover, the adjustments made to the NEE fluxes resulted in the contributions to the $\mathrm{CO}_{2}$ concentrations that were much more similar in magnitude to the fossil fuel fluxes, to the extent that the uptake of $\mathrm{CO}_{2}$ due to biogenic processes cancelled out the contributions made by the fossil fuel fluxes.

The inversion-corrected $\mathrm{CO}_{2}$ concentrations at the domain boundary are obtained from the posterior source estimates. Therefore these concentrations are extracted from the solution of $s$. Figure 11 provides a time series of the prior and posterior concentration estimates. The northern and eastern domain borders are terrestrial, whereas the ocean borders the south and west. For all four domain boundaries, across the total measurement period, the inversion has made only small innovations, with the posterior estimates remaining within the $95 \%$ confidence limits of the prior concentrations. Only the northern and eastern terrestrial boundaries showed some deviations from the priors between May and June 2012 and between March and April 2013. As these are the terrestrial boundaries of the domain, the concentrations here would be subject to influences from outside of the domain, and it would therefore be expected that the inversion would need to provide greater adjustments to these boundary concentrations. The ocean boundaries would be expected to have concentrations close to the background concentrations provided by the Cape Point measurement site.

\subsection{Weekly flux estimates}

We refer to the difference between the prior and posterior flux estimates as the innovations. The impact of the inversion on the flux estimates can be assessed through the size and direction of these innovations and through the reduction in the flux uncertainties. Figure 12 shows the innovations in the total flux estimates for each pixel in $\mathrm{kg} \mathrm{CO}_{2} \mathrm{~m}^{-2}$ week $^{-1}$ for the month of May 2012, as well as the percentage reduction in the flux uncertainty, the percentage reduction in the fossil fuel emissions, and change in NEE fluxes. The mean total weekly flux of a pixel was obtained by first deriving the total flux from the six fossil fuel and NEE flux estimates for that week, and then taking the mean of the four weekly fluxes obtained for the month. The innovations for the total flux were calculated as the difference between the total prior and total posterior weekly fluxes. Positive innovations indicate that the prior fluxes were too far in the positive direction and that the flux should be adjusted towards the negative direction, whereas negative innovations indicate that prior fluxes were too far in the negative direction and should be adjusted towards the positive direction. The uncertainties for the total flux in each pixel are represented by standard deviations which have been derived from the elements of the prior and posterior uncertainty covariance matrices of the fluxes. The figure displays the percentage uncertainty reduction within each pixel. The percentage reductions in the total fossil fuel flux are presented rather than the absolute changes from the prior to posterior flux estimates in each pixel, as these changes were small and the inversion generally resulted in a reduction in the fossil fuel flux estimate. The inversion had more freedom to make changes to the NEE estimates as the uncertainties prescribed were large relative to the prior NEE flux estimates, and therefore the absolute changes from prior to posterior are presented in $\mathrm{kg} \mathrm{CO}_{2} \mathrm{~m}^{-2}$ week $^{-1}$.

May falls within the winter rainfall season of the Western Cape region. The innovations indicate that the total flux for the pixel over the petrol refinery, which had the largest prior flux estimate, was overestimated by the prior $\left(9.43 \mathrm{~kg} \mathrm{CO}_{2} \mathrm{~m}^{-2}\right.$ week $\left.^{-1}\right)$ relative to the posterior estimate $\left(6.62 \mathrm{~kg} \mathrm{CO}_{2} \mathrm{~m}^{-2}\right.$ week $\left.^{-1}\right)$ by an amount of $2.81 \mathrm{~kg} \mathrm{CO} \mathrm{m}^{-2}$ week $^{-1}$ (Fig. 12). Innovations were generally small, ranging between -0.001 and $0.003 \mathrm{~kg} \mathrm{CO}_{2} \mathrm{~m}^{-2} \mathrm{week}^{-1}$. The area around the natural reserves, such as Cape Point and Kogelberg nature reserves, had innovations by the inversion that were close to zero or slightly negative, indicating that the amount of carbon uptake (i.e. negative NEE flux) in these regions was overestimated by the CABLE model. The largest negative innovation by the inversion was $-0.08 \mathrm{~kg} \mathrm{CO}_{2} \mathrm{~m}^{-2}$ week $^{-1}$, from -0.03 up to $0.04 \mathrm{~kg} \mathrm{CO}_{2} \mathrm{~m}^{-2}$ week $^{-1}$, over a pixel in the Cape Point $\mathrm{Na}-$ ture Reserve. The prior flux indicated the pixel to be a slight carbon sink of $\mathrm{CO}_{2}$ whereas the inversion adjusted the flux to be a slight $\mathrm{CO}_{2}$ source. With respect to the rest of the domain, excluding the crude oil refinery, the most substantial innovations were made over the central business district (CBD) area to the south-east of Robben Island. These innovations were positive, indicating that the fossil fuel fluxes were overestimated by the prior estimates. 
Robben Island
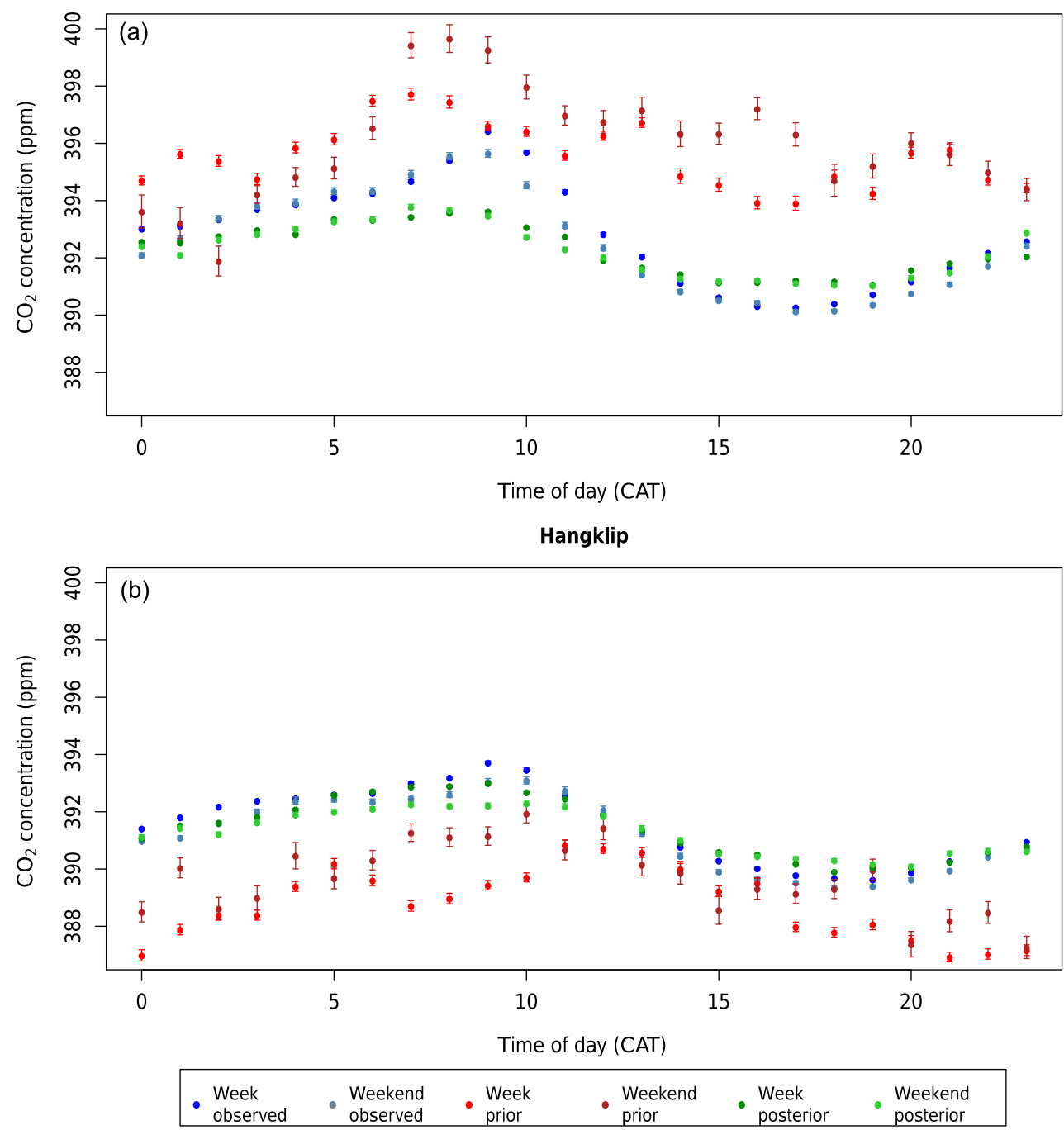

Figure 8. The hourly diurnal cycle (mean concentrations for each hour with $95 \%$ confidence interval) in the observed, prior, and posterior modelled $\mathrm{CO}_{2}$ concentrations (ppm) over the full measurement period from March 2012 until June 2013, separated by working week and weekend and plotted separately for Robben Island (a) and Hangklip (b) measurement sites. The diurnal plots are separated into working week and weekend observed concentrations (blue and light blue), working week and weekend prior modelled concentrations (red and dark red), and working week and weekend posterior modelled concentrations (green and light green).

The percentage change in the fossil fuel estimates, from prior to posterior, indicate the changes tended to be small except on Robben Island itself, where percentage changes were up to $75 \%$, indicating that the emissions on the island were significantly reduced by the inversion (Fig. 12). There were a few pixels which had negative change, indicating that the inversion increased fossil fuel emissions, just north of the island. Located on the north-eastern shore of Robben Island is a diesel-fuelled power generation plant, as well as a desalination plant which is powered by this station. Increases in the fossil fuel fluxes may be due to emissions arising from these activities which have not been accounted for in the inventory analysis. In the inventory analysis there was no fuel informa- tion available for any industrial sources on Robben Island, but fossil fuel emissions were included due to domestic and transport activities; therefore these could have been adjusted by the inversion. The inventory analysis does not take into account explicitly the shipping routes going into CT harbour or into Robben Island harbour, but rather all the emissions are concentrated within CT harbour, where the shipping information is available. This could also result in the inversion adjusting emissions on the island to deal with near shipping related emissions. There was a region in the Western Cape interior to the east of Robben Island which had slightly increased fossil fuel emissions. The inversion had the effect of mainly reducing fossil fuel emissions along the south- 

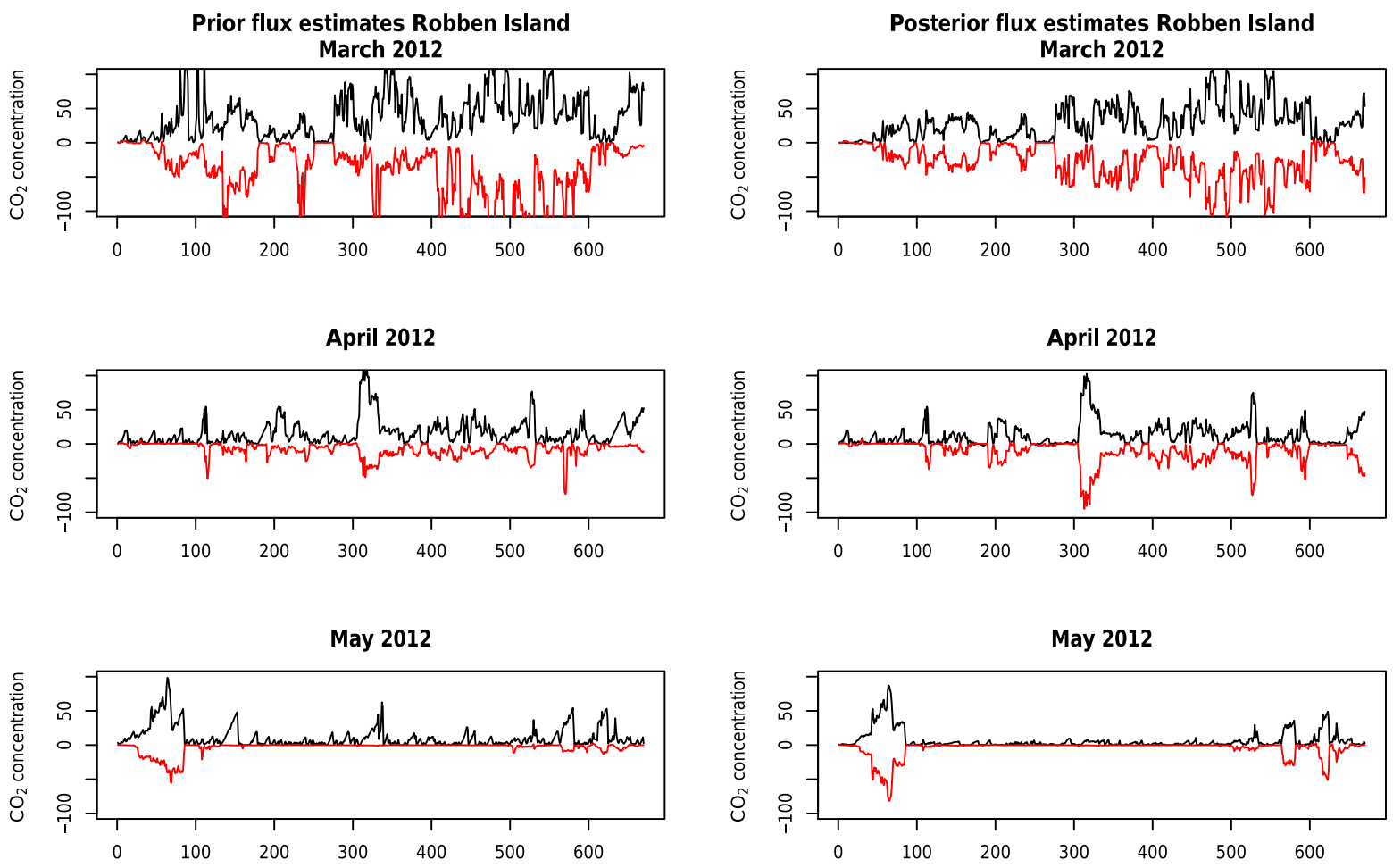

J une 2012
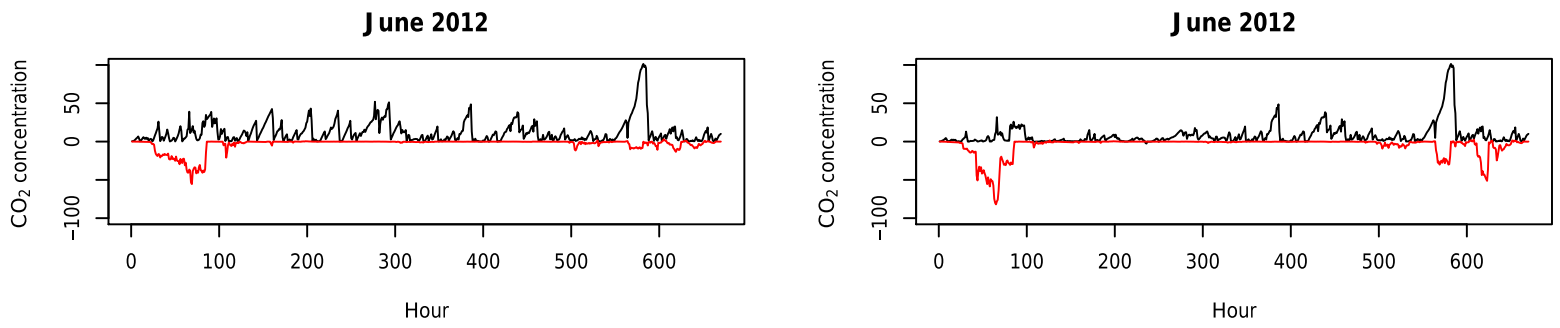

- Fossil fuel
- Net ecosystem exchange

Figure 9. Prior and posterior contributions of the fossil fuel and NEE surface fluxes to the modelled $\mathrm{CO}_{2}$ concentrations (ppm) at Robben Island from March 2012 until June 2012.

east transect extending from Robben Island over the CBD towards Hangklip or leaving the emission unchanged.

The inversion had a much larger impact on the terrestrial NEE fluxes (Fig. 12). This is unsurprising, as the relative uncertainties of the prior NEE fluxes were much larger compared with those of the prior fossil fuel fluxes. The area of the domain experiencing innovation from the inversion was also much more widespread compared with the innovations made to the fossil fuel fluxes. This is in part due to the correlation specified between the NEE fluxes of adjacent pixels, but not between their fossil fuel fluxes. The majority of the innovation over the domain was close to zero, between -0.02 and $0.02 \mathrm{~kg} \mathrm{CO}_{2} \mathrm{~m}^{-2}$ week ${ }^{-1}$, indicating that the inversion was making small absolute adjustments to the NEE flux estimates. Over the $\mathrm{CBD}$ region, the adjustments were the largest, up to $0.32 \mathrm{~kg} \mathrm{CO}_{2} \mathrm{~m}^{-2}$ week ${ }^{-1}$ and these differences were positive, indicating that the posterior fluxes were more in the negative direction and therefore the inversion was acting to reduce total emissions of $\mathrm{CO}_{2}$ over the $\mathrm{CBD}$ region relative to the prior estimates, through changes to the NEE fluxes. The natural region around Cape Point and within the Kogelberg Nature Reserve north of Hangklip showed slight negative changes in the NEE fluxes, indicating that the uptake of $\mathrm{CO}_{2}$ was reduced by the inversion, making the total flux in these regions more positive towards the atmosphere.

In terms of the percentage standard deviation reduction (Fig. 12), the largest reductions occurred over the natural areas, particularly Cape Point to the south of Robben Island, 

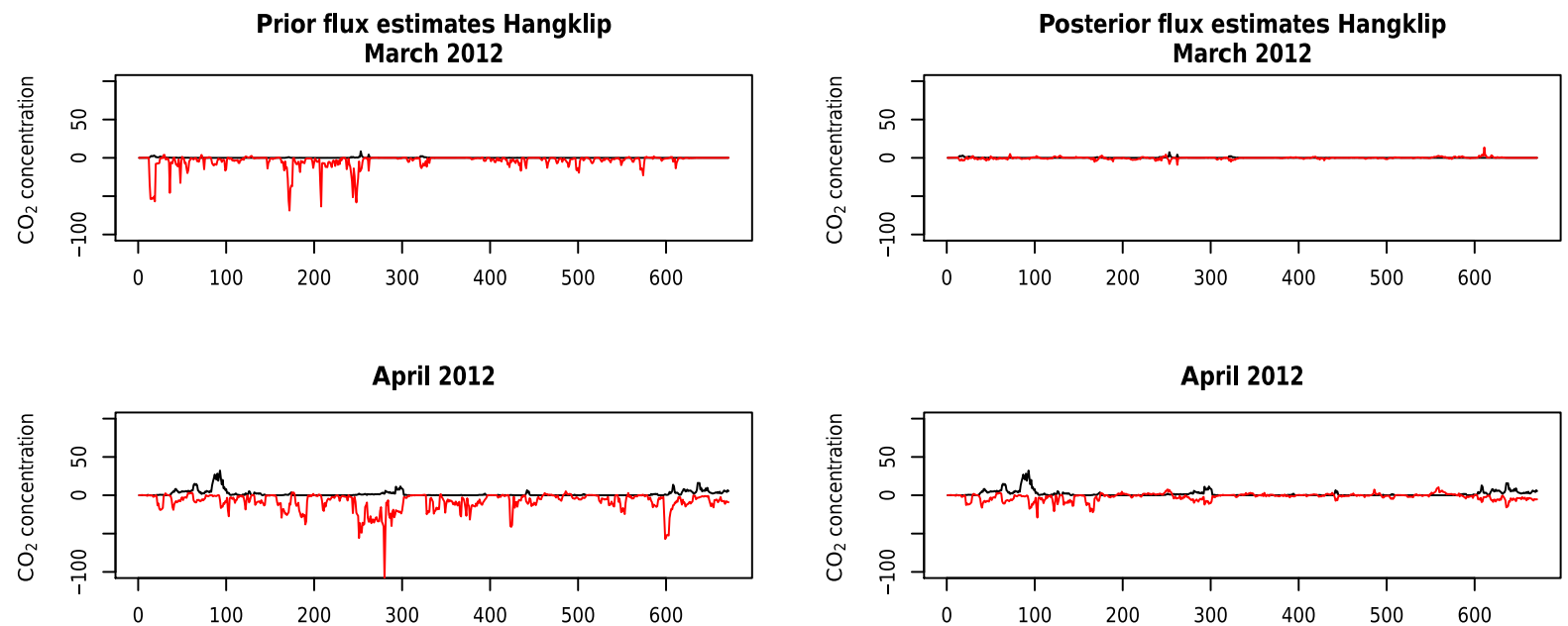

May 2012

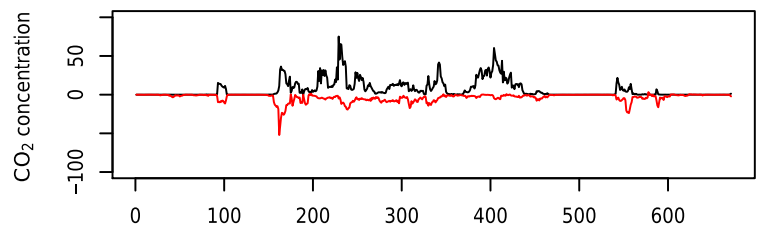

May 2012

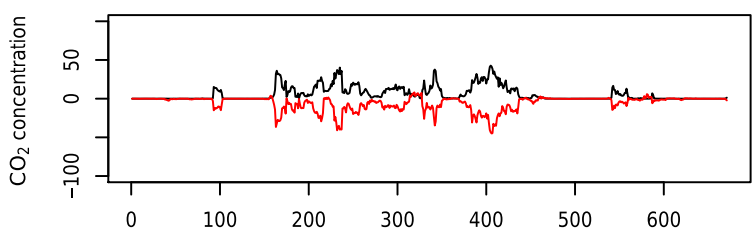

J une 2012

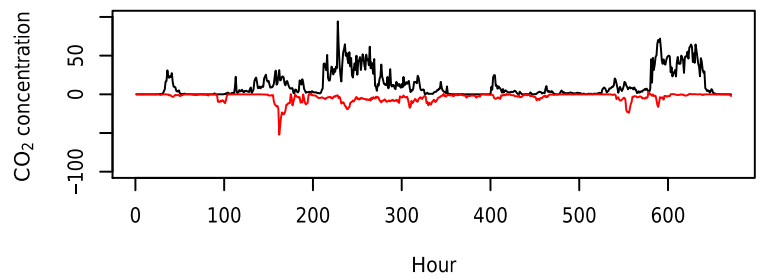

J une 2012

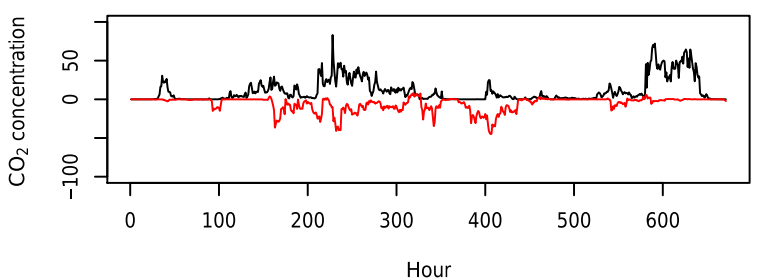

- Fossil fuel

- Net ecosystem exchange

Figure 10. Prior and posterior contributions of the fossil fuel and NEE surface fluxes to the modelled $\mathrm{CO}_{2}$ concentrations (ppm) at Hangklip from March 2012 until June 2012.

where the posterior uncertainty over the area was significantly lower, by over $50 \%$, compared with the prior uncertainties. Significant reductions are also shown over largely agricultural areas to the north of the CBD region. Over the $\mathrm{CBD}$ area itself, the reductions were present, reaching values of close to $60 \%$ over a few central CBD pixels, but generally smaller compared with the uncertainty reductions over natural areas in the domain which reached levels as high as $92 \%$.

September is the beginning of the summer months in the Western Cape region, when temperatures start to rise and the mean monthly rainfall reduces. The innovations across the region during this month were dominated by negative values with the majority ranging between -0.03 and $-0.01 \mathrm{~kg} \mathrm{CO}_{2} \mathrm{~m}^{-2}$ week $^{-1}$, indicating that the inversion increased emissions of $\mathrm{CO}_{2}$ over the majority of the domain. The maximum increase in $\mathrm{CO}_{2}$ fluxes of $0.2 \mathrm{~kg} \mathrm{CO}_{2} \mathrm{~m}^{-2}$ week $^{-1}$ occurred over an agricultural region north-east of the CBD region, from -0.10 up to $0.08 \mathrm{~kg} \mathrm{CO}_{2} \mathrm{~m}^{-2}$ week $^{-1}$, where mainly vineyards are located (Fig. 13). The inversion increased the total fluxes by an amount close to $0.2 \mathrm{~kg} \mathrm{CO}_{2} \mathrm{~m}^{-2}$ week ${ }^{-1}$ over a further five areas. One of these areas, also over agricultural land, lies further inland to the east of the area with largest increase in $\mathrm{CO}_{2}$ fluxes. Three more regions lie to the north, north-east, and east of the Hangklip site. These three regions are all within the Hottentots Holland Mountain catchment area, which is largely dominated by vineyard agricul- 


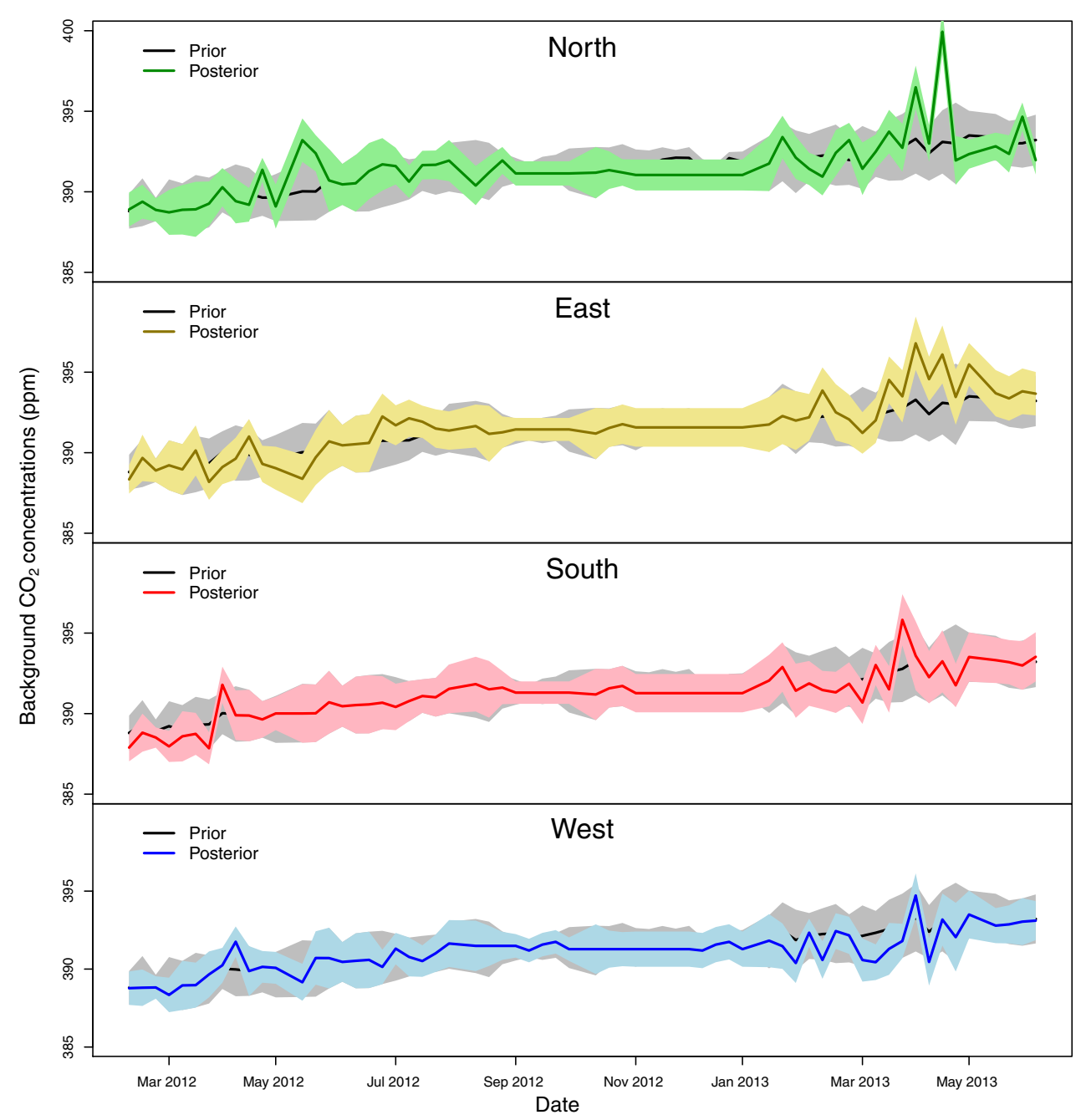

Figure 11. Time series with $95 \%$ confidence interval (represented by the shaded area) of the prior (black line) and posterior estimates of the $\mathrm{CO}_{2}$ concentrations (ppm) at the domain boundaries (north - green, east - yellow, south - red, west - blue). The prior estimates are the same for each cardinal direction and are obtained from the Cape Point percentile-filtered observations. The posterior estimates for the concentrations are solved for as additional unknowns in the reference inversion.

ture. The fifth area is located within the Kogelberg Nature Reserve near the Hangklip site. The maximum reduction of $2.1 \mathrm{~kg} \mathrm{CO}_{2} \mathrm{~m}^{-2}$ week $^{-1}$ occurred over the crude oil refinery site, from 9.4 down to $7.2 \mathrm{~kg} \mathrm{CO}_{2} \mathrm{~m}^{-2}$ week $^{-1}$ (Fig. 13). The inversion made small reductions to the fluxes near the CBD area of CT or left the posterior fluxes to be similar to the priors.

Innovations made to the fossil fuel fluxes were mainly made on the transect of the city running between Robben Island and Hangklip, as well as to fossil fuel emissions on Robben Island itself, similar to the month of May. The maximum percentage adjustment to the fossil fuel fluxes was $51.1 \%$ and the mean innovation was close to zero, with almost all innovations positive, indicating that the posterior estimates were smaller relative to the priors. Robben Island itself showed a mix of positive and negative innovations, with posterior fluxes larger than the priors on the west of the island but smaller than the priors on the east of the island.

The effect of the inversion on the NEE fluxes was to make these fluxes more negative over the CBD region and made $\mathrm{CO}_{2}$ fluxes more positive relative to the priors over the Table Mountain region, over the agricultural area to the north of the CBD, and over the natural regions near Hangklip. The fluxes over the CBD were made more negative by up to $0.21 \mathrm{~kg} \mathrm{CO}_{2} \mathrm{~m}^{-2}$ week $^{-1}$ through adjustments to the NEE fluxes. The areas to the north of the domain which had prior NEE estimates between -0.20 and $-0.10 \mathrm{~kg} \mathrm{CO}_{2} \mathrm{~m}^{-2}$ week $^{-1}$ were made more positive, with posterior estimates ranging between -0.10 and $0.10 \mathrm{~kg} \mathrm{CO}_{2} \mathrm{~m}^{-2}$ week $^{-1}$, where the largest changes were over the vineyard agricultural areas. The natural area surrounding Hangklip site showed negative innovations between 

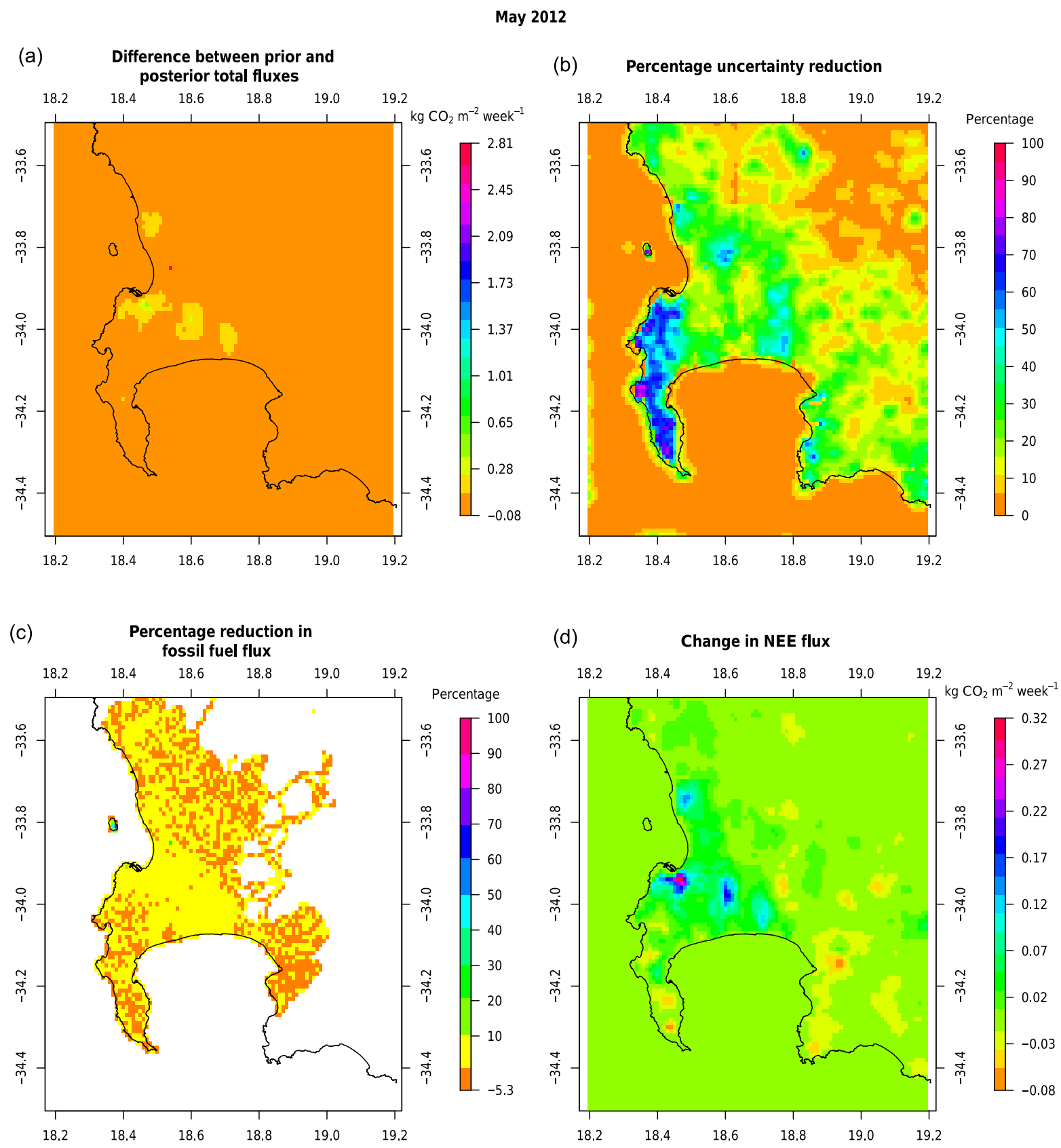

Figure 12. (a) Differences between the prior and posterior total flux estimates $\left(\mathrm{kg} \mathrm{CO}_{2} \mathrm{~m}^{-2} \mathrm{week}^{-1}\right)$ for May 2012 (prior - posterior). (b) Percentage reduction in the standard deviation of the flux estimate from prior to posterior. (c) Percentage reduction in the fossil fuel flux estimates from prior to posterior. (d) Differences in the biogenic flux estimates between prior and posterior estimates (prior - posterior) $\left(\mathrm{kg} \mathrm{CO}_{2} \mathrm{~m}^{-2}\right.$ week $\left.{ }^{-1}\right)$, with negative values indicating posterior $\mathrm{CO}_{2}$ fluxes were made more positive by the inversion compared with the prior estimates. Extent: between 34.5 and $33.5^{\circ} \mathrm{S}$ and between 18.2 and $19.2^{\circ} \mathrm{E}$.

the prior and posterior fluxes, indicating that the inversion adjusted the negative prior NEE fluxes by making these more positive. Therefore the CABLE model appears to have overestimated the amount of $\mathrm{CO}_{2}$ uptake during this period.

Most reductions in the total flux uncertainty ranged between 2.3 and $18.6 \%$, with a maximum reduction of $88.5 \%$
(Fig. 13). The largest uncertainty reductions induced by the inversion occurred over the natural areas bordering on the CBD, particularly over the Table Mountain National Park, as well as the natural areas surrounding the Hangklip site. The areas to the east of Robben Island over the Durbanville and Bellville townships, comprised of a mix of residential sub- 
urbs, vineyard agricultural areas, and industrial areas, also showed reductions in the uncertainties of the fluxes.

Figure 14 presents box plots of the pixel-level weekly fluxes over the domain for each month, and Sect. 1.7 in the Supplement displays the spatial extent of the adjustments made to prior flux estimates by the inversion, as well as the uncertainty reductions, for each month. The limits of the range for the posterior pixel-level weekly fluxes are more negative compared with those of the prior estimates, indicating that the inversion tended to reduce the emission of $\mathrm{CO}_{2}$ for all the months. This is also evident from the maps of differences in total flux estimates between the prior and posterior estimates. Specifically, the inversion tended to reduce the fossil fuel emissions, evident from the shift downwards in the distribution of the posterior pixel-level fossil fuel fluxes compared with the prior fluxes. The variability in the posterior fluxes across pixels was slightly reduced compared with the variability in the prior fluxes. The pixel-level NEE fluxes, although generally smaller in magnitude and range, were the most altered by the inversion, where these changes were related to the season in which the month fell. For most months, the overall mean in the NEE fluxes became more positive, indicating less uptake of $\mathrm{CO}_{2}$ than predicted by the CABLE model. But for the months of June and July, which occur mid-winter, the mean NEE was made more negative. The minimum values were also at least twice the minimum value of the prior estimates for all months, and this is also evident from the maps of change in NEE from prior to posterior, which show that the inversion reduced the $\mathrm{CO}_{2}$ flux towards the atmosphere over the CBD region by altering the NEE fluxes within those pixels.

For most months the percentage uncertainty reduction for the pixel-level total flux reached over $90 \%$ for at least some of the pixels, with a maximum uncertainty reduction over a pixel of $97.7 \%$ in March 2012. The lowest maximum reduction in the uncertainty of the total flux in a pixel in a month was $68.2 \%$ in June 2012.

An example pixel, located near the CBD sources, was selected in order to investigate posterior uncertainty spatial covariances in the fluxes resulting from the inversion. For a given week, the total $\mathrm{CO}_{2}$ flux is composed of six sources: working week and weekend fossil fuel sources, both day and night, and the day and night biogenic sources. Each of these sources could have a non-zero covariance term between itself and the same source but from surrounding pixels or with one of the other five sources from the same pixel or from surrounding pixels.

The posterior uncertainty covariances between the daytime working week flux of the selected pixel and other sources are only notably different from zero for working week daytime fossil fuel fluxes, working week night-time fossil fuel fluxes, and the daytime biogenic fluxes. The uncertainty covariances between the daytime working week fluxes reveal that non-zero covariances do not necessarily have to be close in proximity to the selected pixel, and negative and pos- itive covariances can cluster in space. The uncertainty covariances with the night-time fossil fuel fluxes were larger than those during the day, but were limited to a few pixels close to the selected pixel. These covariances ranged between -0.15 and $0.09 \mathrm{~g}^{2} \mathrm{CO}_{2} \mathrm{~m}^{-4}$ week ${ }^{-2}$. The non-zero uncertainty covariances with NEE fluxes were larger (between -1.50 and $0.88 \mathrm{~g}^{2} \mathrm{CO}_{2} \mathrm{~m}^{-4}$ week $^{-2}$ ) and fluctuated between patches of positive and negative values. Closer to the $\mathrm{CBD}$ area there was a distinct region of positive uncertainty covariance between the fossil fuel source of the selected pixel and the NEE fluxes from a region over the Table Mountain area and a negative covariance patch south of the CBD. The eastern terrestrial part of the domain had patches of positive and negative covariances. When converting these covariances into correlations, correlations are small - no bigger than 0.001 in either direction.

The covariances between fossil fuel and NEE flux uncertainties are small because the uncertainties in the prior modelled concentrations that are attributed to the flux contributions $\left(\mathbf{H C}_{\boldsymbol{s}_{0}} \mathbf{H}^{T}\right)$ are small relative to the uncertainties specified for the modelled concentration errors $\left(\mathbf{C}_{c}\right)$. This is not because our prior uncertainty is small but because the transport Jacobian only projects fluxes from individual pixels weakly into modelled concentrations. As the uncertainty in the modelled concentration errors is decreased, the size of the posterior off-diagonal covariance elements between the fossil fuel and NEE flux uncertainties from the same pixel increases. This can easily be confirmed through the use of a toy inversion system using typical values for $\mathbf{H}, \mathbf{C}_{\boldsymbol{s}_{0}}$ and $\mathbf{C}_{c}$ from our inversion system. This is presented in Sect. 1.8 in the Supplement.

The sum of the covariances in the uncertainties between the selected fossil fuel flux and all other fluxes equals $-25.8 \mathrm{~g}^{2} \mathrm{CO}_{2} \mathrm{~m}^{-4}$ week $^{-2}$. Therefore the covariances associated with this pixel's fossil fuel flux would reduce the variance associated with the total pixel-level flux by 51.7, where the total uncertainty of the fossil fuel flux, as a variance, was $233.7 \mathrm{~g}^{2} \mathrm{CO}_{2} \mathrm{~m}^{-4}$ week $^{-2}$.

\subsection{Weekly totals}

Three time series plots of the total weekly estimates of $\mathrm{CO}_{2}$ flux over the full spatial domain (i.e. all fluxes aggregated over all pixels) are presented in Fig. 16. The total flux estimate for a week represents the sum of all the fossil fuel and NEE fluxes for that week. For the prior total flux uncertainties, the only non-zero covariances are those imposed between the uncertainties in NEE fluxes of neighbouring pixels. These positive covariance terms increase the total uncertainty. The uncertainties in the posterior total fluxes include the posterior covariance terms between the uncertainties in the fossil fuel and NEE fluxes, which are generally negative and have the overall effect when summed of reducing the uncertainty in the total flux estimate. 
September 2012
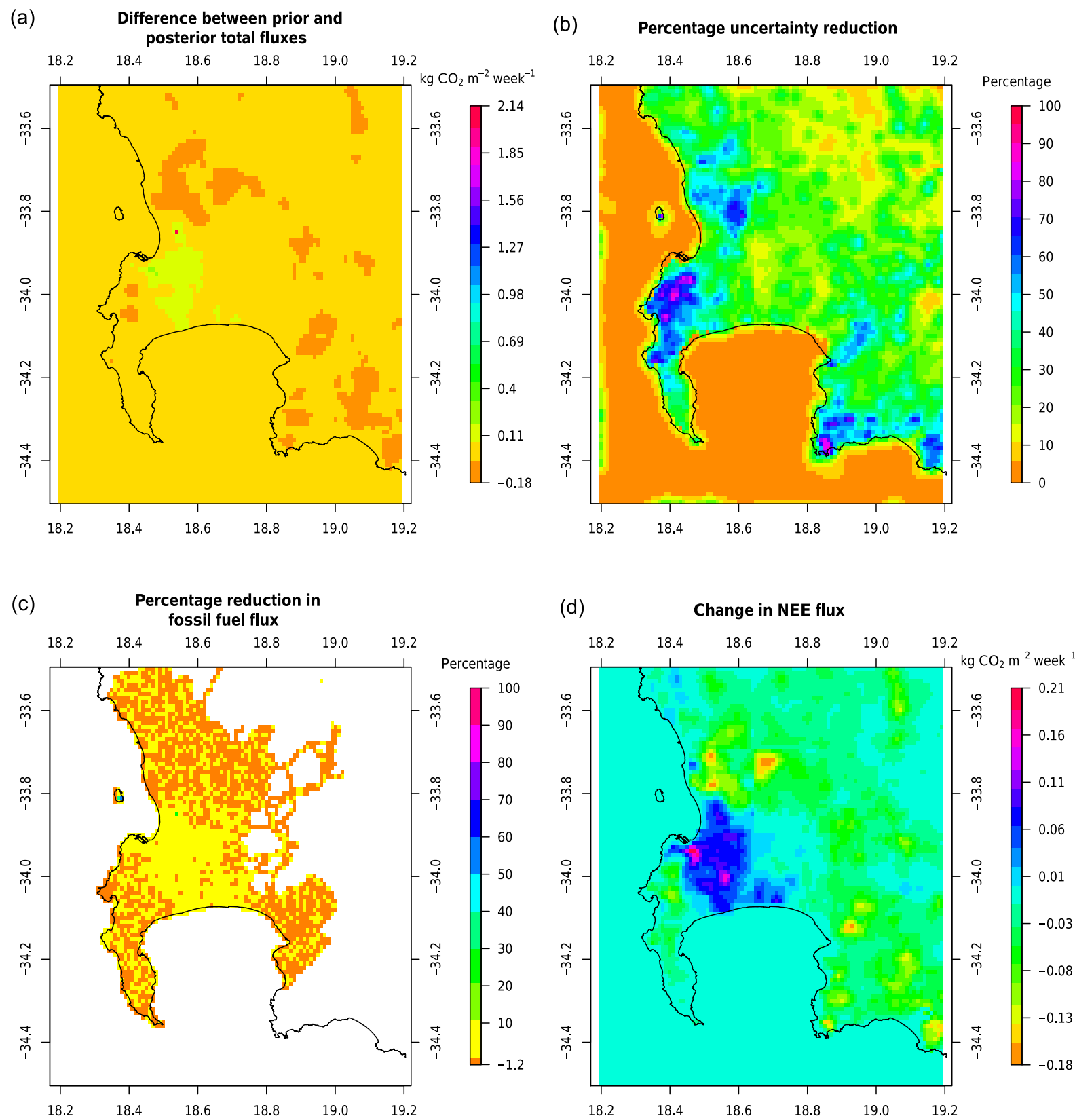

Figure 13. (a) Differences between the prior and posterior total flux estimates $\left(\mathrm{kg} \mathrm{CO}_{2} \mathrm{~m}^{-2}\right.$ week $\left.{ }^{-1}\right)$ for September 2012 (prior - posterior). (b) Percentage reduction in the standard deviation of the flux estimate from prior to posterior. (c) Percentage reduction in the fossil fuel flux estimates from prior to posterior. (d) Differences in the biogenic flux estimates between prior and posterior estimates (prior - posterior) $\left(\mathrm{kg} \mathrm{CO}_{2} \mathrm{~m}^{-2}\right.$ week ${ }^{-1}$ ), with negative values indicating posterior $\mathrm{CO}_{2}$ fluxes were made more positive by the inversion compared with the prior estimates. Extent: between 34.5 and $33.5^{\circ} \mathrm{S}$ and between 18.2 and $19.2^{\circ} \mathrm{E}$.

Uncertainties in the prior total fossil fuel fluxes ranged between 1.3 and $1.5 \mathrm{kt} \mathrm{CO}_{2}$ week $^{-1}$, whereas the posterior uncertainties ranged between 0.9 and $1.5 \mathrm{kt} \mathrm{CO}_{2}$ week $^{-1}$. For the NEE fluxes the uncertainties ranged between 23.6 and $57.3 \mathrm{kt} \mathrm{CO}_{2}$ week $^{-1}$ before the inversion and between 15.8 and $47.1 \mathrm{kt} \mathrm{CO}_{2}$ week $^{-1}$ after the inversion. Uncertain- ties in the total fluxes were similar to those of the NEE fluxes, with prior uncertainties ranging between 23.6 and 57.3 and posterior uncertainties ranging between 15.8 and $47.1 \mathrm{kt} \mathrm{CO}_{2}$ week $^{-1}$. The median percentage uncertainty reduction in the total weekly flux was $28.0 \%$ and ranged be- 

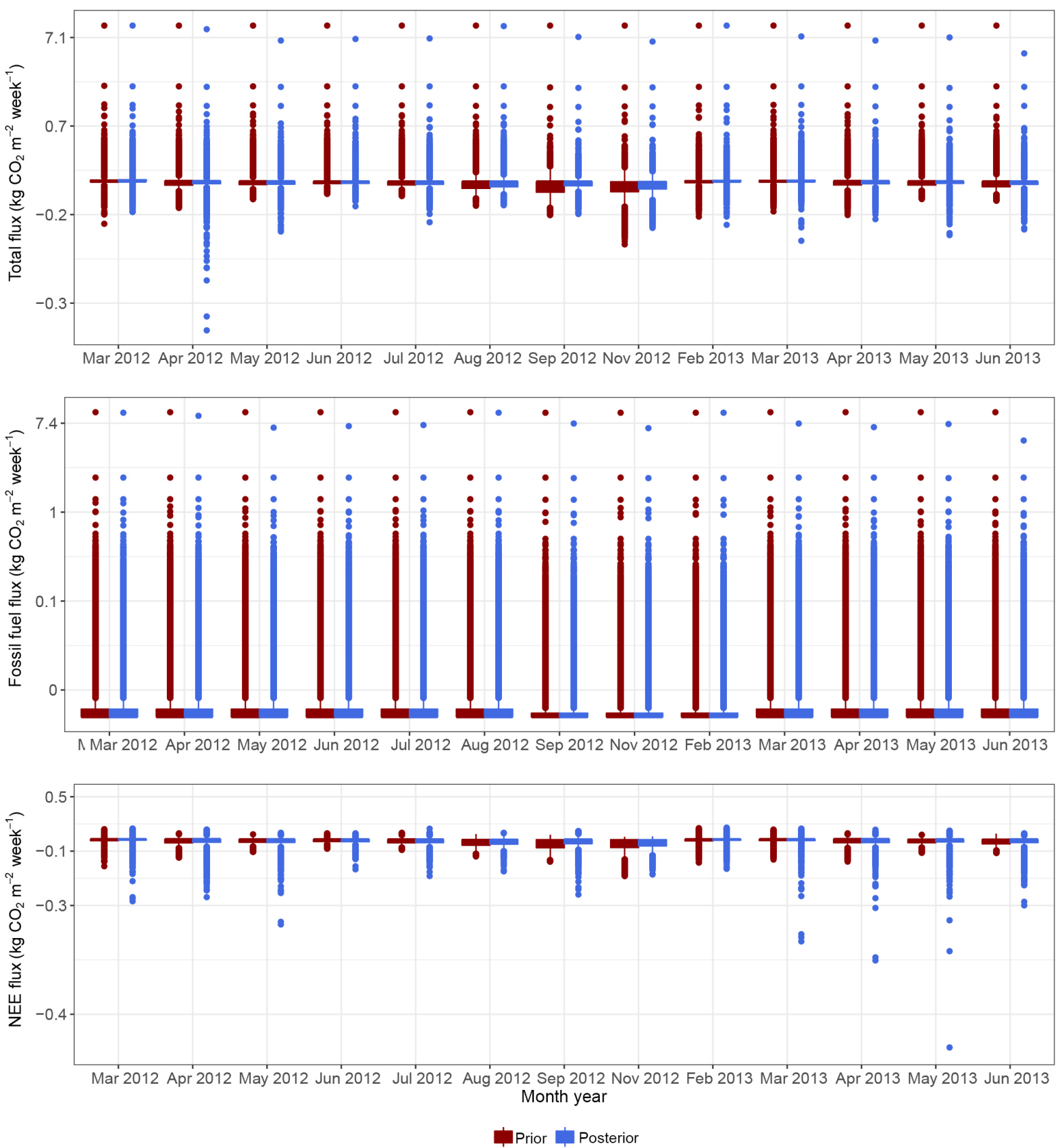

Figure 14. Box plots of the pixel-level weekly prior and posterior flux estimates $\left(\mathrm{kg} \mathrm{CO}_{2} \mathrm{~m}^{-2} \mathrm{week}^{-1}\right)$ for each month. These plots present summary statistics calculated over all pixels in the domain of the pixel-level mean weekly fluxes. The $y$ axis is presented on a log scale.

tween 2.3 and $50.5 \%$, with the largest reduction occurring in March 2012.

The posterior total estimate for the emission of $\mathrm{CO}_{2}$ from the domain was within the confidence bounds of the prior total estimate for the majority of the period from March 2012 until June 2013. The confidence bounds of the posterior total estimates were narrower compared with those of the prior total estimates. Total prior flux estimates ranged between
139.5 and $-386.8 \mathrm{kt} \mathrm{CO}_{2}$ week $^{-1}$, with the maximum total during March 2013 and the minimum total flux occurring in November 2012. The posterior totals ranged between 149.5 and $-375.1 \mathrm{kt} \mathrm{CO}_{2}$ week $^{-1}$, with the maximum occurring in March 2013 and the minimum in October 2012. During the winter months, from March to July, the posterior fluxes fell within the uncertainty limits of the prior fluxes. The posterior total flux moved outside of the prior's confidence limits 
(a) Fossil fuel week day

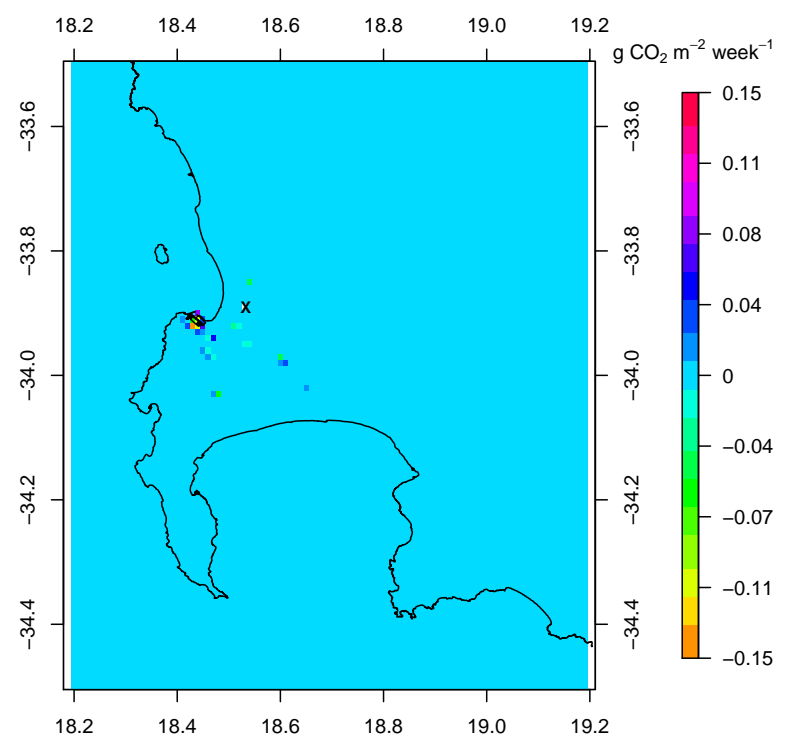

(c) NEE day

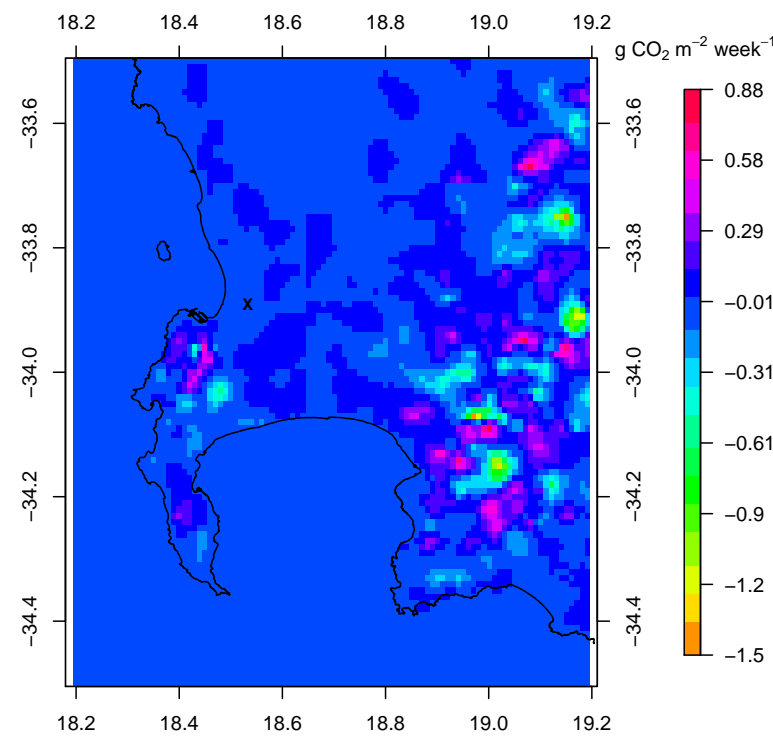

(b) Fossil fuel week night

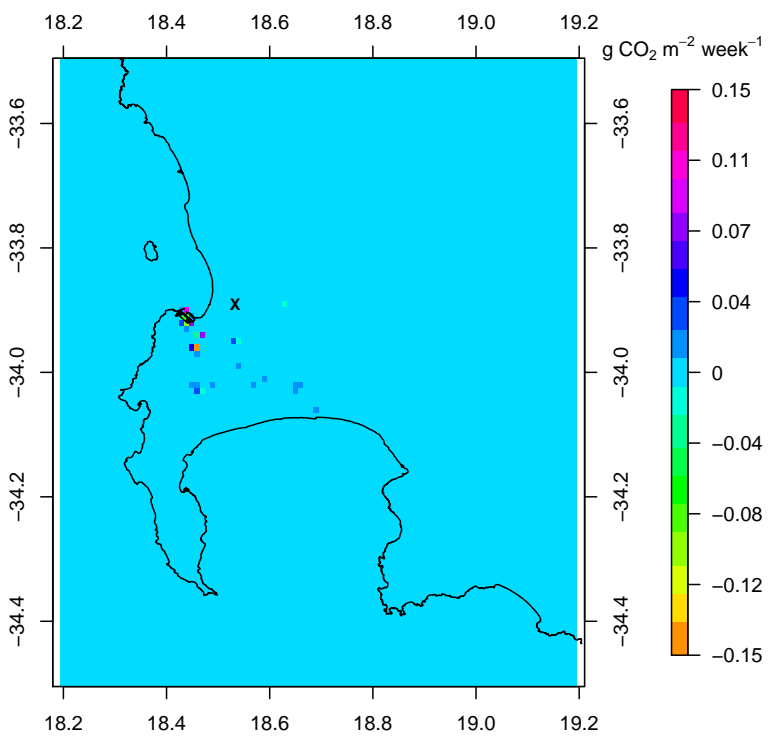

(d) NEE night

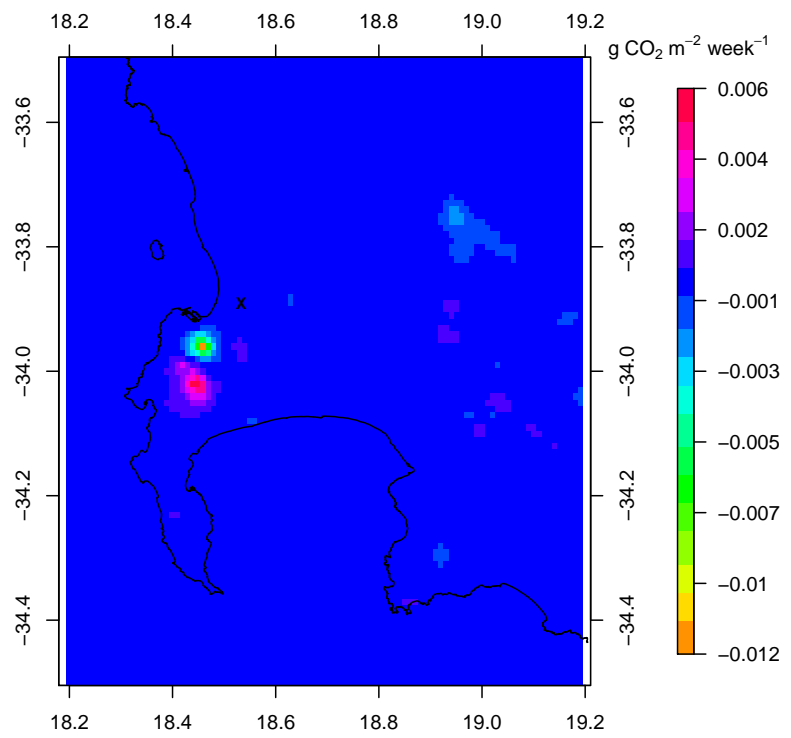

Figure 15. Posterior covariances $\left(\mathrm{g}^{2} \mathrm{CO}_{2} \mathrm{~m}^{-4}\right.$ week $\left.{ }^{-2}\right)$ between the uncertainty in the fossil fuel working week daytime flux during the first week of March 2012 in the selected pixel (marked by X) and (a) all other fossil fuel working week daytime fluxes; (b) fossil fuel working week night-time fluxes within this pixel and all other pixels; (c) NEE daytime fluxes within this pixel and all other pixels; (d) NEE night-time fluxes within this pixel and all other pixels. Extent: between 34.5 and $33.5^{\circ} \mathrm{S}$ and between 18.2 and $19.2^{\circ} \mathrm{E}$.

during August and September 2012, which was during the South African spring period. Posterior estimates were larger compared with the prior estimates. Data were missing during October 2012 and from December 2012 to January 2013, and therefore the estimates are completely overlapping during these periods. When observations were available during the summer months in November 2012 and February 2013 the posterior fluxes were more positive compared with the prior estimates.

The total prior fossil fuel flux was flat and close to $150 \mathrm{kt} \mathrm{CO}_{2}$ week $^{-1}$ during the winter months and close to $110 \mathrm{kt} \mathrm{CO}_{2}$ week $^{-1}$ during the summer months. This stepped effect in the fossil fuel fluxes is due to the simple representation of the domestic emissions in the fossil fuel inventory. It is unlikely that fossil fuel emissions would have a 
Total flux
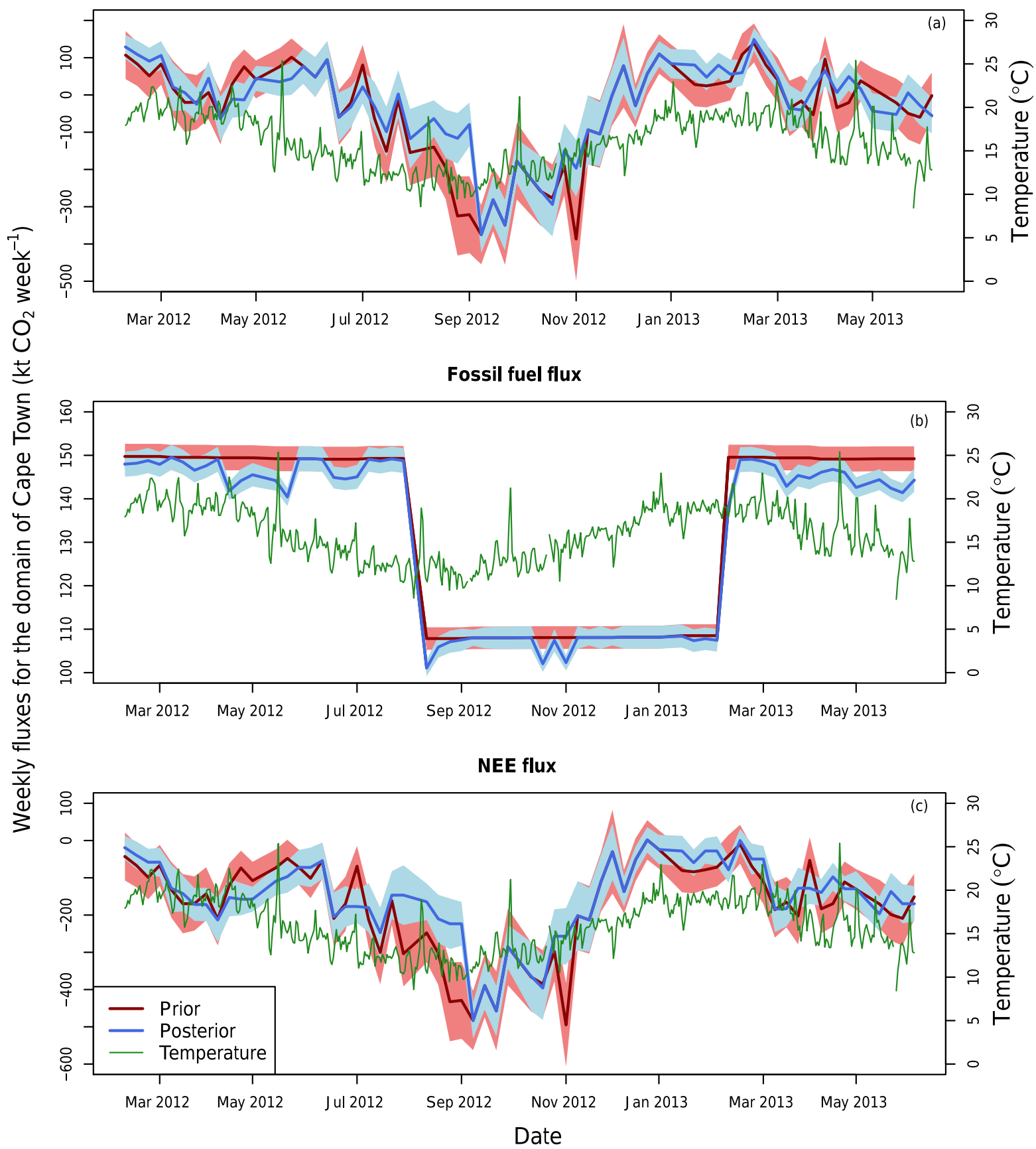

Figure 16. Prior (red) and posterior (blue) total weekly $\mathrm{CO}_{2}$ flux estimates $\left(\mathrm{kt} \mathrm{CO}_{2}\right.$ week ${ }^{-1}$ ) (left axis) and uncertainty limits (shaded area), represented as a $95 \%$ confidence interval, across the full domain of Cape Town, shown as (a) the total flux, (b) the fossil fuel flux, and (c) the NEE flux. The daily temperature $\left({ }^{\circ} \mathrm{C}\right)$ as recorded at the Cape Point GAW station is provided by the lower green line (right axis).

sharp change between summer and winter. As a separate sensitivity analysis presented in a follow-up paper (Nickless et al., 2018) we adjusted the assumption of domestic emissions such that domestic emissions were distributed uniformly during the year. The inversion had the effect of reducing the total estimate, particularly during May 2012 and between March 2013 and June 2013, to a value of as low as $138 \mathrm{kt} \mathrm{CO}_{2}$ week $^{-1}$ during the winter months and to a value of $107 \mathrm{kt} \mathrm{CO}_{2}$ week ${ }^{-1}$ during the summer months and early winter 2013. The posterior total fossil fluxes and confidence bounds for June 2013 were outside of those for the prior estimates for the full month. Compared with the total 
flux, the range of the total fossil fuel fluxes was much narrower (between 100 and $160 \mathrm{kt} \mathrm{CO}_{2}$ week $^{-1}$ ), and the confidence bounds around the estimates were also narrower. This is not immediately apparent from the plot, but the range of the $y$ axis needed to be adjusted for the fossil fuel fluxes; otherwise it would appear as a thin line if plotted on the same range as the total fluxes.

Total prior NEE fluxes ranged between values close to zero and $-494.9 \mathrm{kt} \mathrm{CO}_{2}$ week $^{-1}$ and between zero and $-483.1 \mathrm{kt} \mathrm{CO}_{2}$ week $^{-1}$ for the posterior estimates. During the winter months posterior estimates were generally contained within the limits of the prior estimates, except for May 2012, when the total NEE flux was slightly lower compared with the prior. From August 2012 to September 2012, the posterior total NEE fluxes were well above the total prior estimates, indicating that the total uptake of $\mathrm{CO}_{2}$ by the domain was reduced by the inversion during this period.

Comparisons of the NEE and fossil fuel fluxes to the total estimates show that the variability in the total flux estimates was driven by variability in the NEE fluxes, and differences between the posterior and prior total estimates were mainly driven by adjustments to the NEE fluxes induced by inversion. As would be expected, due to the large uncertainty around the NEE prior fluxes, the inversion was not strongly constrained by these priors and therefore mainly adjusted the NEE fluxes, rather than the fossil fuel fluxes, so that the modelled concentrations better matched the observed concentrations. This is unsurprising as we provided no information regarding what proportion of the observed $\mathrm{CO}_{2}$ concentration was attributable to fossil fuel contributions and what proportion was due to NEE fluxes.

Temperatures are at their highest between January and March. This is also the region's dry period. Both the prior and posterior NEE fluxes were most positive during this period, with NEE fluxes close to zero. The posterior NEE fluxes were more positive than the prior fluxes during these periods, i.e. the posterior estimates indicated less uptake of $\mathrm{CO}_{2}$ by biogenic processes compared with the prior estimates. The minimum temperatures occurred between July and October, and during this period the NEE estimates were negative, indicating $\mathrm{CO}_{2}$ uptake. The peak in the uptake by biogenic processes occurred in September to early November. This was during the spring period, after the winter rainfall period, and when the temperatures in the region begin to increase. The posterior estimates were less negative than the prior NEE fluxes, indicating that the NEE fluxes estimated by CABLE may have overestimated the amount of $\mathrm{CO}_{2}$ uptake.

\section{Discussion and conclusions}

\subsection{Inversion innovation}

The inversion was able to substantially improve the agreement between the prior and posterior modelled concentrations, with posterior modelled concentrations tracking most of the local events observed in the measurements. The most notable corrections to the pixel-level fluxes by the inversion were made to those with the largest industrial point sources, to pixels located on Robben Island where activities unaccounted for in the inventory were taking place, and to the areas dominated by NEE fluxes and located relatively close to the measurement sites. This evidence suggests that the inversion framework used here has had some success in capturing information regarding the $\mathrm{CO}_{2}$ fluxes in the $\mathrm{CT}$ domain and has applied reasonable corrections to the sources considered.

This is clear from Figs. 12 and 13. Posterior fossil fuel fluxes for the vast majority of the pixels were 5 to $10 \%$, either larger or smaller than the prior estimates, and therefore the posterior fluxes were not unreasonable when related to what we believed about these emissions before performing the inversion. The corrections to the NEE fluxes were small in absolute terms: no smaller or larger than $0.02 \mathrm{~kg} \mathrm{CO}_{2} \mathrm{~m}^{-2}$ week $^{-1}$. The most notable changes were to pixels within the CBD area where the posterior fluxes were made more negative than the prior fluxes. This could be due to the inversion attempting to reduce the overall flux by making the NEE fluxes more negative as the inversion had less freedom to make changes to the fossil fuel fluxes, or it could be that the NEE productivity predicted by CABLE in this location was underpredicting the amount of $\mathrm{CO}_{2}$ uptake by the vegetation on the fringes of the CBD. Therefore, these posterior fluxes may be reasonable representations of the truth. In the natural areas of the domain, the inversion has made the NEE fluxes slightly more positive, by at most $0.08 \mathrm{~kg} \mathrm{CO}_{2} \mathrm{~m}^{-2}$ week $^{-1}$. Therefore, these estimates are not very different from those we specified for the prior estimates.

The inversion was able to reduce uncertainty of the total flux within a pixel by up to $97.7 \%$ and was able to reduce the uncertainty in the total weekly flux over the whole domain by up to $50.5 \%$. The largest innovation to a fossil fuel flux was applied to a pixel which contained an important point source in the domain - a crude oil refinery. This facility can process up to 100000 barrels of crude oil per day. Unlike most industrial sources in the area which would be expected to have fairly consistent activity from day to day, activity at the crude oil refinery depends on oil supply and on the global oil prices. During the period of March 2012 to June 2013, the global monthly oil price deviated between USD 117.29 in March 2012 and USD 90.73 in June 2012, ending at USD 99.74 in June 2013 (World Bank commodity prices). In addition, the consumption of liquid petroleum gas and heavy furnace oils may have decreased during this period (City of Cape Town, 2015). As this is a source with a large amount of expected variability, it is unlikely that the inversion method with distant measurement sites will be able to adequately estimate the flux in this pixel. In order for this to occur, the measurement site would have to consistently view the source during periods of both high and low activity in order to provide an unbiased estimate. An inversion could be used to estimate this particular source if a ring of instruments were placed 
around the site in order to capture information from the site at all times, regardless of the prevailing wind direction, such as suggested for the Otway $\mathrm{CO}_{2} \mathrm{CRC}$ carbon capture project (Cook, 2012).

Sensitivity tests show that these large uncertainty reductions are mainly due to the small error correlation length specified for the NEE prior fluxes. If these covariances are made zero in the prior uncertainty covariance matrix, then the ability of the observations to correct the fluxes across the domain is largely reduced. The uncertainty reduction achieved in the aggregated flux, when no error correlation was specified, was less than $12 \%$ for all months. When we used a prior product for the NEE fluxes that specified smaller NEE and NPP fluxes, the inversion attempted to correct the fluxes in the same direction as the posterior estimates obtained for this reference inversion.

Compared with the fossil fuel emissions, relative innovations to the NEE fluxes were much larger due to the large uncertainty prescribed to these fluxes. The largest innovations were made to natural areas near the CBD of CT as well as to agricultural regions within the domain, particularly those close to the measurement sites. The prior estimates are dependent on the CABLE land-atmosphere interaction model, which, although driven by the CCAM regional climate model, which in turn was driven by reliable reanalysed observations of the climate from NCEP, is still under ongoing development for use over South Africa. There is a great deal of uncertainty in its ability to simulate fluxes over the fynbos biome, as there is for most dynamic vegetation models (Moncrieff et al., 2015). In general, the inversion tended to increase the NEE fluxes so that the total flux was less negative compared with the priors, indicating that the amount of productivity may have been overestimated by CABLE.

\subsection{Distinguishing fossil fuel and biogenic emissions}

The spatial distribution and magnitude of the posterior fluxes and their uncertainties is strongly dependent on the prior spatial assignment of sources. In a city like CT, fossil fuel and NEE fluxes are usually co-occurring in the same pixel, with vegetation within the city representing a significant and large sink of $\mathrm{CO}_{2}$. Under the current framework, if no fossil fuel source were prescribed to occur in a particular pixel, the inversion would only be able to adjust the NEE flux in this pixel, as the fossil fuel flux and its uncertainty are set to zero. If there is an unknown fossil fuel source in a pixel the inversion would lead to a better match between the modelled and observed concentrations, but a worse NEE flux estimate. Therefore the success of the inversion is largely dependent on how well the spatial extent of fossil fuel and biogenic sources are prescribed in the prior information.

In Bréon et al. (2015) NEE fluxes were aggregated to a larger grid size than the fossil fuel emissions. Effectively this means that perfect correlation was applied between the NEE fluxes for all pixels which fall within the same larger NEE pixel. By distinguishing the biogenic and fossil fuel sources in this way, it may allow the inversion to correctly allocate corrections between the fossil fuel and biogenic sources. We attempted to implement a similar idea by allowing correlation between NEE fluxes of neighbouring pixels and not prescribing correlations between fossil fuel sources. As the model tended to reduce fossil fuel emissions and increase NEE fluxes in the same pixel, it appears that the inversion is unlikely to adequately adjust the individual fluxes making up the total flux from a pixel. With the large coverage of vegetation within the domain, it is unlikely that a measurement network with only two sites could accurately estimate a given industrial point source, but there is still potential to monitor the overall city emissions, and assess the feasibility of inventory information. This is evident from the large uncertainty reductions attained by the inversion for the total weekly flux estimates aggregated over the domain.

The posterior uncertainty of any linear combination of terms from the control vector of the fluxes (including the difference between two fluxes from the same pixel) will always be reduced or (at worst) left unchanged relative to the prior uncertainty of the same linear combination of elements (Jackson, 1979; Jackson and Matsu'ura, 1985). This means that although negative correlation between the flux components may be introduced through the inversion as observations are made of the sum of these components, the uncertainty in both the difference between fluxes from the same pixel and the total flux within a pixel will be reduced.

If we define the distinction between the fossil fuel flux and NEE flux within the same pixel $i$ as the variance of the difference between the fossil fuel and NEE fluxes $s_{\mathrm{f}, i}-s_{\mathrm{NEE}, i}$, this will be equal to the sum of the variances of these two fluxes minus twice the covariance between them: $C_{s(\mathrm{f}, i ; \mathrm{f}, i)}+$

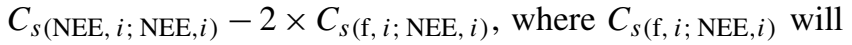
be negative. Therefore, although the posterior uncertainty of the difference in these fluxes will always be larger than the sum of the individual posterior flux uncertainties, it will be smaller than the prior uncertainty of this linear combination of terms. The ability of the inversion under the current framework to distinguish between NEE and fossil fuel fluxes is limited as the posterior uncertainties are still large, and therefore the uncertainty of $s_{\mathrm{f}, i}-s_{\mathrm{NEE}, i}$ is large.

However, when we aggregate these fluxes from the same pixel to get the total flux within a pixel $s_{\mathrm{f}, i}+$ $s_{\mathrm{NEE}, i}$, the uncertainty of this term is equal to $C_{s(\mathrm{f}, i ; \mathrm{f}, i)}+$ $C_{s(\mathrm{NEE}, i ; \mathrm{NEE}, i)}+2 \times C_{s(\mathrm{f}, i ; \mathrm{NEE} i)}$, where $C_{s(\mathrm{f}, i ; \mathrm{NEE} i)}$ is negative. When we aggregate fluxes from the same pixel, the uncertainty of this total is smaller due to the both the smaller posterior uncertainties of the individual fluxes and also because the covariances are negative. This demonstrates that the value of the inversion is to reduce the uncertainty on each of the individual fluxes and to additionally reduce the uncertainty of the aggregation of the NEE and fossil fuel flux within the same pixel. In this case, the reduction in the uncertainty of the sum of fluxes within the same pixel is strongly 


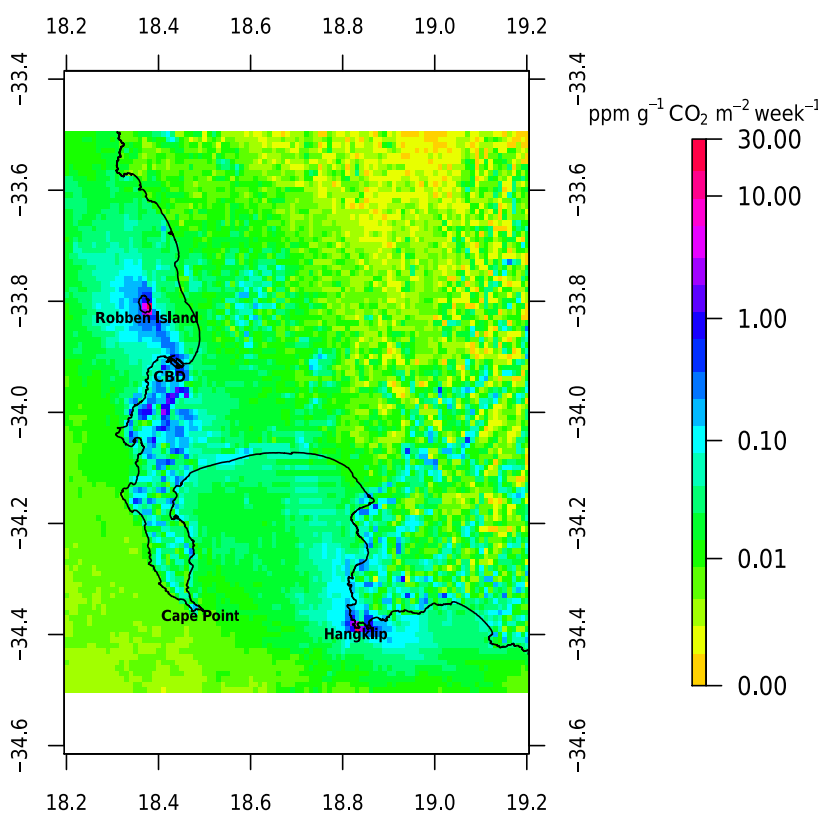

Figure 17. Mean weekly sensitivities $\left(\mathrm{ppm} \mathrm{kg}^{-1} \mathrm{CO}_{2} \mathrm{~m}^{-2}\right.$ week $^{-1}$ ) of the measurement sites at Robben Island and Hangklip to each surface source pixel, plotted on a $\log$ scale.

dependent on the size of the uncertainty of the NEE flux, which is usually the larger uncertainty.

We have shown in Sect. 1.8 in the Supplement that if we reduce the uncertainty in the modelled concentrations, the negative off-diagonal covariance terms of $\mathbf{C}_{s}$ become larger in magnitude. To improve the ability of the inversion to estimate the total flux within a pixel, we need to improve the skill of the atmospheric transport model, and we need to reduce the uncertainty in the estimates of the NEE. As it stands, with a large prior uncertainty in the estimation of the NEE fluxes from the CABLE model, which remains a large posterior estimate after the inversion, the distinction between the fossil fuel and NEE flux from the same pixel, $C_{S(\mathrm{f}, i ; \mathrm{f}, i)}+C_{S(\mathrm{NEE}, i ; \mathrm{NEE}, i)}-2 \times C_{S(\mathrm{f}, i ; \mathrm{NEE} i)}$, is not very different from the prior estimate, $C_{S_{0}(\mathrm{f}, i ; \mathrm{f}, i)}+C_{S_{0}(\mathrm{NEE}, i ; \mathrm{NEE}, i)}$.

\subsection{Strengths and limitations}

This paper represents a first attempt at estimating $\mathrm{CO}_{2}$ fluxes at the high resolution of $1 \mathrm{~km}$ by $1 \mathrm{~km}$ over CT, solving for individual fossil fuel, terrestrial, and oceanic biogenic sources. A previous network design study for South Africa (Nickless et al., 2015b), which aggregated the NEE and fossil fuel fluxes up to a $15 \mathrm{~km} \times 15 \mathrm{~km}$ resolution, showed the aggregation errors could be high at the regional level. By avoiding this aggregation, and maintaining the $1 \mathrm{~km}$ by $1 \mathrm{~km}$ resolution of the atmospheric transport model throughout the inversion process, we attempted to minimise these aggregation errors. Maintaining this resolution is computationally expen- sive, but possible due to the relatively small domain size of $100 \mathrm{~km}$ by $100 \mathrm{~km}$.

A limitation of this study is that human respiration was not explicitly accounted for. With a population of over 3 million, this flux could represent up to $26 \mathrm{kt} \mathrm{CO}_{2}$ week $^{-1}$, if we attribute $1 \mathrm{~kg} \mathrm{CO}_{2}$ per day to each person (Bréon et al., 2015). This represents between a fifth and a quarter of the total fossil fuel flux estimated for the domain, and therefore is by no means a negligible quantity. Including this fossil fuel flux in the inventory information would most likely lead to confounding between the domestic emissions and the human respiration, as these two sources would have been calculated based on population data. Domestic emissions were heavily dependent on the assumption regarding how domestic heating emissions were distributed during the year. This had a large impact on the temporal profile of fossil fuel emissions, resulting in a lower average emission in summer compared with winter, which persisted in the posterior estimates of the fossil fuel fluxes. Consequently the prior uncertainties in the domestic emissions were larger compared with other fossil fuel sources. We have included sensitivity analyses on the specification of the fossil fuel emissions and their uncertainties in a follow-up paper (Nickless et al, 2018).

This inversion was performed by solving for the total observed concentrations rather than solving for the gradient in concentration measurements between two sites (Bréon et al., 2015). There are several reasons why the gradient method would not have been suitable in these circumstances. Firstly, we had the advantage of a background site which viewed background levels over $70 \%$ of the time. As our city is located within the Southern Hemisphere, far less variability is expected between the hourly measurements or from week to week compared with the Northern Hemisphere, and we would expect the $\mathrm{CO}_{2}$ concentration at the oceanic boundaries of our domain to be similar to background levels of $\mathrm{CO}_{2}$. This was confirmed by the results of the inversion, which made almost no adjustments to the oceanic boundary concentrations but made slightly larger adjustments to the boundary concentrations at the north and east terrestrial boundaries. This implies that the adjustments made by the inversion were largely due to the surface flux sources within the domain. In addition, there are no large expected sources located anywhere near the boundaries of the domain. The next major city in the proximity of CT is Port Elizabeth, which is over $600 \mathrm{~km}$ away. For this reason, it is unnecessary to solve for the gradients between the two sites, as we did not require the removal of unknown outside sources from the observation dataset. This allowed us to use the entire measurement record, which is an advantage as we only had two $\mathrm{CO}_{2}$ measurement sites available.

Secondly, the gradient method would likely have performed poorly here, as the direction of travel of an air parcel between the two sites would not necessarily be in a straight line due to the topography of the site and demonstrated by the plot of the sensitivities at the two sites to the domain 
(Fig. 17), as well as the modelled wind fields provided in Sect. 1.3 in the Supplement. Therefore extracting observations based on the prevailing wind speed and directions at the sites would have not represented true gradients in the $\mathrm{CO}_{2}$ concentrations between the two measurements sites.

These sensitivities of the sites to the surface fluxes also reveal that the sites are often viewing oceanic sources (Fig. 17). A limitation of this study is that a single time series of ocean biogenic emissions was used as the prior estimate for all oceanic pixels in the domain. The fluxes from the nearcoastal oceanic pixels are likely to have significant spatial heterogeneity, although smaller compared with the terrestrial biogenic fluxes. A way of improving this would be to use the output of a model representing atmosphere-land-ocean biogeochemical exchanges to provide prior fluxes over both the land and ocean. The CSIR's Variable Resolution Earth System Model (VRESM) is such a model currently under development, which aims to couple CCAM, CABLE, and CSIR's Variable-Cubic Ocean Model (VCOM) and Pelagic Interactions Scheme for Carbon and Ecosystem Studies (PISCES) to model ocean transport and biogeochemistry (Engelbrecht et al., 2016). Due to the amount of shipping activity around the CT harbour and within the ocean domain viewed by the Robben Island site, the inventory analysis could be improved by the inclusion of information on shipping routes so that the inversion can adjust fossil fuel fluxes in these ocean pixels as well.

The uncertainty in the NEE fluxes played an important role in the outcome of the inversion. If tighter uncertainty limits could be placed on the NEE flux estimates from the land-atmosphere exchange model, it would allow the inversion to better distinguish between the fossil fuel and NEE fluxes. This could be attained by validation work through eddy-covariance flux measurements over dominant vegetation types within the domain, for example. The use of a landatmosphere exchange model well suited to the vegetation within the domain of a city-scale inversion is essential for improving the ability of the inversion to adjust the fossil fuel sources which are of foremost interest. The dependence on knowing the NEE fluxes well in order to estimate the fossil fuel fluxes could be reduced if there were additional measurements of $\Delta^{14} \mathrm{C}$ and $\delta^{13} \mathrm{C}$ isotope measurements at each of the sites, including at the background site (Turnbull et al., 2015; Newman et al., 2016).

\section{Conclusions}

We have presented the results of a city-scale atmospheric inversion for Cape Town, South Africa. We have shown that the current inversion framework was able to reduce the misfit between the observed and modelled concentrations by making reasonable adjustments to the fossil fuel and NEE fluxes. We were able to reduce the total uncertainty in $\mathrm{CO}_{2}$ weekly flux from the domain by up to $50 \%$. We have demonstrated the ability of an inversion to obtain an improved estimate of an aggregated flux, even when the uncertainty in one component is large. To realistically use this framework for an operational inversion system for use in MRV, the uncertainty around the NEE estimates for Cape Town needs to be reduced. Further qualifying concentration observations according to the contributions from anthropogenic sources and those from the biosphere will help the inversion to disentangle the corrections to these two fluxes and will reduce the dependency of the fossil fuel flux corrections on the uncertainty of the NEE flux estimates.

Code and data availability. Data and code related to the Bayesian inversion procedure can be made available upon request.

\section{The Supplement related to this article is available online at https://doi.org/10.5194/acp-18-4765-2018-supplement.}

Author contributions. AN installed and maintained all the instrumentation at Robben Island and Hangklip, obtained the measurements and processed these into hourly concentrations, ran and processed the result of the LPDM in Fortran, produced all code and ran the inversion in Python, processed all the inversion results using R Statistical Software, produced all graphics and tables, and was responsible for the development of the manuscript which forms part of her PhD. PJR was the main scientific supervisor, oversaw all implementation of the inversion, and provided guidance on the presentation of results. EGB provided the Cape Point concentration and meteorological data and provided assistance and guidance in the installation and maintenance of the Picarro instrumentation. FE provided the CCAM and CABLE data. BE provided guidance on statistical issues. RJS provided guidance on the location of the sites and provided advice on the interpretation of the biogenic fluxes. All authors had the opportunity to comment on the manuscript.

Competing interests. The authors declare that they have no conflict of interest.

Acknowledgements. We would like to acknowledge and thank Casper Labuschagne and Danie van der Spuy of the South African Weather Service for their assistance in maintaining the instruments at Robben Island and Hangklip, and Casper Labuschagne for his guidance on processing the instantaneous $\mathrm{CO}_{2}$ concentration data; Martin Steinbacher for providing guidance and schematics on the calibration system used on the Picarro instruments; Robin Poggenpoel and Jacobus Smith of Transnet for allowing us access to the lighthouses; Peter Saaise of Transnet, the Robben Island lighthouse keeper (and his daughter), for assisting when the instrument was not responding; Marek Uliasz for providing us access to the code for his LPDM model; Thomas Lauvaux for providing guidance on processing the LPDM results and useful 
discussion on the boundary contribution in the inversion; Keith Moir in Rooi Els, for providing wind data near Hangklip. Use was made of the University of Cape Town ICTS-HPC cluster. Please see http://hpc.uct.ac.za/ for details. We would like to thank Andrew Lewis of the University of Cape Town HPC facility for providing useful advice on improving the efficiency of the Python runs. This research was funded by competitive parliamentary grant funding from the Council of Scientific and Industrial Research awarded to the Global Change Competency Area towards the development of the VRESM (grants EEGC030 and EECM066). Additional funding was obtained from the South African National Research Foundation for the Picarro instrumentation.

Edited by: Martin Heimann

Reviewed by: three anonymous referees

\section{References}

Andres, R. J., Boden, T. A., Bréon, F.-M., Ciais, P., Davis, S., Erickson, D., Gregg, J. S., Jacobson, A., Marland, G., Miller, J., Oda, T., Olivier, J. G. J., Raupach, M. R., Rayner, P., and Treanton, K.: A synthesis of carbon dioxide emissions from fossil-fuel combustion, Biogeosciences, 9, 1845-1871, https://doi.org/10.5194/bg-9-1845-2012, 2012.

Andres, R. J., Boden, T. A., and Higdon, D.: A new evaluation of the uncertainty associated with CDIAC estimates of fossil fuel carbon dioxide emission, Tellus B, 66, 23616, https://doi.org/10.3402/tellusb.v66.23616, 2014.

Baker, D. F., Law, R. M., Gurney, K. R., Rayner, P., Peylin, P., Denning, A. S., Bourquet, P., Bruhwiler, L., Chen, Y., Ciais, P., Fung, I. Y., Heimann, M., John, J., Maki, T., Maksyutov, S., Masarie, K., Prather, M., Pak, B., Taguchi, S., Zhu, Z.: TransCom 3 inversion intercomparison: impact of transport model errors on the interannual variability of regional $\mathrm{CO}_{2}$ fluxes, 1988-2003, Global Biogeochem. Cy., 20, GB1002, https://doi.org/10.1029/2004GB002439, 2006.

Bellassen, V. and Stephan, N.: Accounting for carbon: Monitoring, reporting and verifying emissions in the climate economy, Cambridge University Press, Cambridge, UK, 2015.

Boden, T. A., Marland, G., and Andres, R. J.: Global, regional, and national fossil fuel $\mathrm{CO}_{2}$ emissions, Carbon Dioxide Information Analysis Center, Oak Ridge National Laboratory, US Department of Energy, Oak Ridge, TN, USA., https://doi.org/10.3334/CDIAC/00001_V2011, 2011.

Boon, A., Broquet, G., Clifford, D. J., Chevallier, F., Butterfield, D. M., Pison, I., Ramonet, M., Paris, J.-D., and Ciais, P.: Analysis of the potential of near-ground measurements of $\mathrm{CO}_{2}$ and $\mathrm{CH}_{4}$ in London, UK, for the monitoring of city-scale emissions using an atmospheric transport model, Atmos. Chem. Phys., 16, 67356756, https://doi.org/10.5194/acp-16-6735-2016, 2016.

Bousquet, P., Ciais, P., Peylin, P., Ramonet, M., and Monfray, P.: Inverse modeling of annual atmospheric $\mathrm{CO}_{2}$ sources and sinks: 1. Method and control inversion, J. Geophys. Res., 104, 2616126178, 1999.

Bréon, F. M., Broquet, G., Puygrenier, V., Chevallier, F., XuerefRemy, I., Ramonet, M., Dieudonné, E., Lopez, M., Schmidt, M., Perrussel, O., and Ciais, P.: An attempt at estimating Paris area $\mathrm{CO}_{2}$ emissions from atmospheric concentra- tion measurements, Atmos. Chem. Phys., 15, 1707-1724, https://doi.org/10.5194/acp-15-1707-2015, 2015.

Brioude, J., Angevine, W. M., Ahmadov, R., Kim, S.-W., Evan, S., McKeen, S. A., Hsie, E.-Y., Frost, G. J., Neuman, J. A., Pollack, I. B., Peischl, J., Ryerson, T. B., Holloway, J., Brown, S. S., Nowak, J. B., Roberts, J. M., Wofsy, S. C., Santoni, G. W., Oda, T., and Trainer, M.: Top-down estimate of surface flux in the Los Angeles Basin using a mesoscale inverse modeling technique: assessing anthropogenic emissions of $\mathrm{CO}, \mathrm{NO}_{\mathrm{x}}$ and $\mathrm{CO}_{2}$ and their impacts, Atmos. Chem. Phys., 13, 3661-3677, https://doi.org/10.5194/acp-13-3661-2013, 2013.

Brunke, E.-G., Labuschagne, C., Parker, B., Scheel, H. E, and Wittlestone, S.: Baseline air mass selection at Cape Point,South Africa: application of ${ }^{222} \mathrm{Rn}$ and other filter criteria to $\mathrm{CO}_{2}$, Atmos. Environ., 38, 5693-5702, https://doi.org/10.1016/j.atmosenv.2004.04.024, 2004.

Buyantuyev, A. and Wu, J.: Urbanization diversifies land surface phenology in arid environments: Interactions among vegetation, climatic variation, and land use pattern in the Phoenix metropolitan region, USA, Landscape Urban Plan, 105, 149159, https://doi.org/10.1016/j.landurbplan.2011.12.013, 2012.

Carslaw, D. C. and Ropkins, K.: openair - an R package for air quality data analysis, Environ. Model. Softw., 27-28, 52-61, https://doi.org/10.1016/j.envsoft.2011.09.008, 2012.

Chevallier, F., Ciais, P., Conway, T. J., Aalto, T., Anderson, B. E., Bousquet, P., Brunke, E. G., Ciattaglia, L., Esaki, Y., Fröhlich, M., Gomez, A., Gomez-Pelaez, A. J., Haszpra, L., Krummel, P. B., Langenfelds, R. L., Leuenberger, M., Machida, T., Maignan, F., Matsueda, H., Morgui, J. A., Mukai, H., Nakazawa, T., Peylin, P., Ramonet, M., Rivier, L., Sawa, Y., Schmidt, M., Steele, L. P., Vay, S. A., Vermeulen, A. T., Wofsy, S., and Worthy, D.: $\mathrm{CO}_{2}$ surface fluxes at grid point scale estimated from a global 21 year reanalysis of atmospheric measurements, J. Geophys. Res., 115, D21307, https://doi.org/10.1029/2010JD013887, 2010.

Chouinard, C., Béland, M., McFarlane, N.: A simple gravity wave drag parameterization for use in medium-range weather forecast models, Atmos. Ocean, 24, 91-110, 1986.

Ciais, P., Rayner, P., Chevallier, F., Bousquet, P., Logan, M., Peylin, P., and Ramonet, M.: Atmospheric inversions for estimating $\mathrm{CO}_{2}$ fluxes: methods and perspectives, Climatic Change, 103, 69-92, 2010.

City of Cape Town: State of energy and energy futures report, Cape Town: City of Cape Town, available at: http://www.capetown. gov.za/en/EnvironmentalResourceManagement/publications/ Documents/State_of_Energy_+_Energy_Futures_Report_2011_ revised_2012-01.pdf (last access: 15 January 2014), 2011.

City of Cape Town: State of energy report 2015, Cape Town: City of Cape Town, availablet at: https://africancityenergy.org/getfile. php?id=22\&category=0 (last access: 10 July 2016), 2015.

Cook, P.: Geologically storing carbon: The CO2CRC Otway Project: Learning from the Otway Project experience, CSIRO Press, Melbourne, Australia, 408 pp., 2014.

Crosson, E.: A cavity ring-down analyzer for measuring atmospheric levels of methane, carbon dioxide, and water vapor, Appl. Phys. B, 92, 403-408, https://doi.org/10.1007/s00340-008-3135y, 2008.

Davis, K. J., Deng, A., Lauvaux, T., Miles, N. L., Richardson, S. J., Sarmiento, D. P., Gurney, K. R., Hardesty, R. M., 
Bonin, T. A., Brewer, W. A., Lamb, B. K., Shepson, P. B., Harvey, R. M., Cambaliza, M. O., Sweeney, C., Turnbull, J. C., Whetstone, J., and Karion, A.: The Indianapolis Flux Experiment (INFLUX): A test-bed for developing urban greenhouse gas emission measurements, Elem. Sci. Anth., 5, https://doi.org/10.1525/elementa.188, 2017.

UK Department for Environment, Food and Rural Affairs (Defra): UK ship emissions inventory. Final report, London: Crown, available at: http://uk-air.defra.gov.uk/assets/documents/reports/ cat15/1012131459_21897_Final_Report_291110.pdf (last access: 12 January 2014), 2010.

UK Department for Environment, Food and Rural Affairs (Defra): Government GHG conversion factors for company reporting: Methodology paper for emission factors, London: Crown, available at: https://www.gov.uk/government/ uploads/system/uploads/attachment_data/file/224437/

pb13988-emission-factor-methodology-130719.pdf

(last access: 23 March 2014), 2013.

UK Department for Environment, Food and Rural Affairs (Defra): Treatment of uncertainties for national estimates of greenhouse gas emissions, available at: http://uk-air.defra.gov.uk/ reports/empire/naei/ipcc/uncertainty/contents.html (last access: 23 March 2014), 2013.

Dlugokencky, E. and Tans, P.: Trends in atmospheric carbon dioxide, National Oceanic and Atmospheric Administration, Earth System Research Laboratory (NOAA/ESRL), available at: http:// www.esrl.noaa.gov/gmd/ccgg/trends/global.html, last access: 29 September 2016.

Duren, R. M. and Miller, C. E.: Measuring the carbon emissions of megacities, Nat. Clim. Change, 2, 560-562, https://doi.org/10.1038/nclimate1629, 2012.

Engelbrecht, F. A., McGregor, J. L. and Engelbrecht, C. J.: Dynamics of the conformal-cubic atmospheric model projected climatechange signal over southern Africa, Int. J. Climatol., 29, 10131033, doi:10/1002/joc.1742.29., 2009.

Engelbrecht, F. A., Landman, W. A., Engelbrecht, C. J., Landman, S., Bopane, M. M., Roux, B., McGregor, J. L., and Thatcher, M.: Multi-scale climate modelling over Southern Africa using variable-resolution global model, Water Research Commission 40-Year Celebration Conference, Kempton Park, South Africa, 31 August-1 September 2011, https://doi.org/10.4314/wsa.v37i5.2, 2011.

Engelbrecht, C. J., Engelbrecht, F. A. and Dyson, L. L.: Highresolution model-projected changes in mid-tropospheric closedlows and extreme rainfall events over southern Africa, Int. J. Climatol., 33, 173-187, doi:10/1002/joc.3420, 2013.

Engelbrecht, F., Adegoke, J., Bopape, M-J., Naidoo, M., Garland, R., Thatcher, M., McGregor, J., Katzfey, J., Werner, M., Ichoku, C. and Gatebe, C.: Projections of rapidly rising surface temperatures over Africa, Environ. Res. Lett., 10, 085004, https://doi.org/10.1088/1748-9326/10/8/085004, 2015.

Engelbrecht, F. A., McGregor, J. L., Thatcher, M., Garland, R., Sovara, M., Bopane, M. M., and van der Merwe, J.: The VariableResolution Earth System Model and its simulations of the Benguela upwelling system. The International Conference on Regional Climate CORDEX 2016, 17-20 May 2016, Stockholm, Sweden, 2016.

Enting, I. G.: Inverse Problems in Atmospheric Constituent Transport, Cambridge Univ. Press, New York, USA, 2002.
Erickson, P. and Tempest, K.: Advancing climate ambition: How city-scale actions can contribute to global climate goals, in: SEI Working Paper No. 2014-06, edited by: Davis, M., Stockholm Environment Institute, Stockholm, Sweden, 2014.

Exbrayat, J.-F., Pitman, A. J. Abramowitz, G. and Wang, Y.-P.: Sensitivity of net ecosystem exchange and heterotrophic respiration to parameterization uncertainty, J. Geophys. Res.-Atmos., 118, 1640-1651, https://doi.org/10.1029/2012JD018122, 2013.

Fawcett, R. A., Pitcher, G., Bernard, S., Cembella, A., and Kudela, R.: Contrasting wind patterns and toxigenic phytoplankton in the southern Benguela upwelling system, Mar. Ecol. Prog. Ser., 348, 19-31, https://doi.org/10.3354/meps07027, 2007.

Feng, S., Lauvaux, T., Newman, S., Rao, P., Ahmadov, R., Deng, A., Díaz-Isaac, L. I., Duren, R. M., Fischer, M. L., Gerbig, C., Gurney, K. R., Huang, J., Jeong, S., Li, Z., Miller, C. E., O'Keeffe, D., Patarasuk, R., Sander, S. P., Song, Y., Wong, K. W., and Yung, Y. L.: Los Angeles megacity: a high-resolution landatmosphere modelling system for urban $\mathrm{CO}_{2}$ emissions, Atmos. Chem. Phys., 16, 9019-9045, https://doi.org/10.5194/acp16-9019-2016, 2016.

Ganesan, A. L., Rigby, M., Zammit-Mangion, A., Manning, A. J., Prinn, R. G., Fraser, P. J., Harth, C. M., Kim, K.-R., Krummel, P. B., Li, S., Mühle, J., O’Doherty, S. J., Park, S., Salameh, P. K., Steele, L. P., and Weiss, R. F.: Characterization of uncertainties in atmospheric trace gas inversions using hierarchical Bayesian methods, Atmos. Chem. Phys., 14, 3855-3864, https://doi.org/10.5194/acp-14-3855-2014, 2014.

Geels, C., Gloor, M., Ciais, P., Bousquet, P., Peylin, P., Vermeulen, A. T., Dargaville, R., Aalto, T., Brandt, J., Christensen, J. H., Frohn, L. M., Haszpra, L., Karstens, U., Rödenbeck, C., Ramonet, M., Carboni, G., and Santaguida, R.: Comparing atmospheric transport models for future regional inversions over $\mathrm{Eu}-$ rope - Part 1: mapping the atmospheric $\mathrm{CO}_{2}$ signals, Atmos. Chem. Phys., 7, 3461-3479, https://doi.org/10.5194/acp-7-34612007, 2007.

Gerbig, C., Lin, J. C., Wofsy, S. C., Daube, B. C., Andrews, A. E., Stephens, B. B., Bakwin, P. S., and Grainger, C. A.: Toward constraining regional-scale fluxes of $\mathrm{CO}_{2}$ with atmospheric observations over a continent: 1 . Observed spatial variability from airborne platforms, J. Geophys. Res., 108, 4756, https://doi.org/10.1029/2002JD003018, 2003.

Gregor, L. and Monteiro P. M. S.: Is the southern Benguela a significant regional sink of $\mathrm{CO}_{2}$ ?, S. Afr. J. Sci., 109, 0094, https://doi.org/10.1590/sajs.2013/20120094, 2013.

Gurney. K. R., Law, R. M., Denning, A. S., Rayner, P. J., Baker, D., Bousquet, P., Bruhwiler, L., Chen, Y., Ciais, P., Fan, S., Fung, I. Y., Gloor, M., Heimann, M., Higuchi, K., John, J., Maki, T., Maksyutov, S., Masarie, K., Peylin, P., Prather, M., Pak, B. C., Randerson, J., Sarmiento, J., Taguchi, S., Takahashi, T., and Yuen, C.: Towards robust regional estimates of $\mathrm{CO}_{2}$ sources and sinks using atmospheric transport models, Nature, 405, 626-630, 2002.

Gurney, K. R., Law, R. M., Denning, A. S., Rayner, P. J., Baker, D., Bousquet, P., Bruhwiler, L., Chen, Y., Ciais, P., Fan, S., Fung, I. Y., Gloor, M., Heimann, M., Higuchi, K., John, J., Kowalczyk, E., Maki, T., Maksyutov, S., Peylin, P., Prather, M., Pak, B. C., Sarmiento, J., Taguchi, S., Takahashi, T., and Yuen, C.: TransCom $3 \mathrm{CO}_{2}$ inversion intercomparison: 1 . 
Annual mean control results and sensitivity to transport and prior flux information, Tellus B, 55, 555-579, 2003.

Gurney, K. R., Mendoza, D. L., Zhou, Y. Y., Fischer, M. L., Miller, C. C., Geethakumar, S., and Du Can, S. D.: High resolution fossil fuel combustion $\mathrm{CO}_{2}$ emission fluxes for the United States, Environ. Sci. Technol., 43, 5535-5541, https://doi.org/10.1021/es900806c, 2009.

Gurney, K. R., Razlivanov, I., Song, Y., Zhou, Y., Benes, B., and Abdul-Massih, M.: Quantification of fossil fuel $\mathrm{CO}_{2}$ emissions on the building/street scale for a large U.S. city, Environ. Sci. Technol., 46, 12194-12202, https://doi.org/10.1021/es3011282, 2012.

Holtslag, A. A. M. and Boville, B. A.: Local versus nonlocal boundary layer diffusion in a global climate model, J. Clim., 6, 1825-1842, https://doi.org/10.1175/15200442(1993)006<1825:LVNBLD>2.0.CO;2, 1993.

Hutyra, L., Duren, R., Gurney, K. R., Grimm, N., Kort, E. A., Larson, E., Shrestha, G.: Urbanization and the carbon cycle: Current capabilities and research outlook from the natural sciences perspective, Earth's Future, 2, 473-495, https://doi.org/10.1002/2014EF000255, 2014.

Intergovernmental Panel on Climate Change (IPCC): Good practice guidance and uncertainty management in national greenhouse gas inventories, Montreal: IPCC, 93-102, http://www. ipcc-nggip.iges.or.jp/public/gp/english/, 2000.

IPCC: Climate Change 2014: Synthesis Report. Contribution of Working Groups I, II and III to the Fifth Assessment Report of the Intergovernmental Panel on Climate Change, edited by: Core Writing Team, Pachauri, R. K. and Meyer, L. A., IPCC, Geneva, Switzerland, 151 pp., 2014.

Jackson, D. D.: The use of a priori data to resolve non-uniqueness in linear inversion, Geophys. J. Roy. Astr. S., 57, 137-157, 1979.

Jackson, D. D and Matsu'ura, M.: A Bayesian approach to nonlinear inversion, J. Geophys. Res, 90, 581-591, 1985.

Janssens-Maenhout, G., Pagliari, V., Guizzardi, D., and Muntean, M.: Global emission inventories in the Emission Database for Global Atmospheric Research (EDGAR) - Manual (I). Gridding: EDGAR emissions distribution on global gridmaps, Joint Research Centre, Luxembourg: European Union, 33 pp., https://doi.org/10.2788/81454, 2012.

Kalnay, E., Kanamitsu, M., Kistler, R., Collins, W., Deaven, D., Gandin, L., Iredell, M., Saha, S., White, G., Woollen, J., Zhu, Y., Chelliah, M., Ebisuzaki, W., Higgins, W., Janowiak, J., Mo, K., C., Ropelewski, C., Wang, J., Leetmaa, A., Reynolds R., Jenne, R., and Joseph, D.: The NCEP/NCAR 40-year reanalysis project, B. Am. Meteorol. Soc., 77, 437-472, 1996.

Kaminski, T., Heimann, M., and Giering, R.: A coarse grid three dimensional global inverse model of the atmospheric transport, 2. Inversion of the transport of $\mathrm{CO}_{2}$ in the $1980 \mathrm{~s}, \mathrm{~J}$. Geophys. Res., 104, 18555-18581, 1999.

Kaminski, T., Rayner, P .J., Heimann, M., and Enting, I. G.: On aggregation errors in atmospheric transport inversions, J. Geophys. Res., 106, 4705-4715, 2001.

Kort, E. A., Angevine, W. M., Duren, R., and Miller, C. E.: Surface observations for monitoring urban fossil fuel $\mathrm{CO}_{2}$ emissions: minimum site location requirements for the Los Angeles megacity, J. Geophys. Res., 118, 1-8, https://doi.org/10.1002/jgrd.50135, 2013.
Kowalczyk, E. A., Garratt, J. R. and Krummel, P. B.: Implementation of a soil-canopy scheme into the CSIRO GCM - regional aspects of the model response, CSIRO Div. Atmospheric Research, Melbourne, Australia, Tech Paper No. 32, 59 pp., 1994.

Kowalczyk, E. A., Wang, Y. P. and Law, R. M.: CSIRO Atmosphere Biosphere Land Exchange model for use in climate models and as an offline model, CSIRO Marine and Atmospheric Research technical paper xxV, ISBN 192123239 0, 2006.

Lacis, A. A. and Hansen, J. E.: A parameterization for the absorption of solar radiation in the earth's atmosphere, J. Atmos. Sci., 31, 118-133, https://doi.org/10.1175/15200469(1974)031<0118:APFTAO>2.0.CO;2, 1974.

Landman, S., Engelbrecht, F. A, Dyson, L., Engelbrecht, C., J., and Landman, W., A.: A short-range ensemble prediction system for South Africa, Water SA, 38, 765-774, https://doi.org/10.4314/wsa.v38i5.16, 2012.

Lauvaux, T., Uliasz, M., Sarrat, C., Chevallier, F., Bousquet, P., Lac, C., Davis, K. J., Ciais, P., Denning, A. S., and Rayner, P. J.: Mesoscale inversion: first results from the CERES campaign with synthetic data, Atmos. Chem. Phys., 8, 3459-3471, https://doi.org/10.5194/acp-8-3459-2008, 2008.

Lauvaux, T., Pannekoucke, O., Sarrat, C., Chevallier, F., Ciais, P., Noilhan, J., and Rayner, P. J.: Structure of the transport uncertainty in mesoscale inversions of $\mathrm{CO}_{2}$ sources and sinks using ensemble model simulations, Biogeosciences, 6, 1089-1102, https://doi.org/10.5194/bg-6-1089-2009, 2009.

Lauvaux, T., Schuh, A. E., Uliasz, M., Richardson, S., Miles, N., Andrews, A. E., Sweeney, C., Diaz, L. I., Martins, D., Shepson, P. B., and Davis, K. J.: Constraining the $\mathrm{CO}_{2}$ budget of the corn belt: exploring uncertainties from the assumptions in a mesoscale inverse system, Atmos. Chem. Phys., 12, 337-354, https://doi.org/10.5194/acp-12-337-2012, 2012.

Lauvaux, T., Miles, N. L., Richardson, S. J., Deng, A., Stauffer, D. R., Davis, K. J., Jacobson, G., Rella, C., Calonder, G.P., and DeCola, P. L.: Urban emissions of $\mathrm{CO}_{2}$ from Davos, Switzerland: the first real-time monitoring system using atmospheric inversion technique, J. Appl. Meteorol. Clim., 52, 2654 2668, https://doi.org/10.1175/JAMC-D-13-038.1, 2013.

Lauvaux, T., Miles, N. L., Deng, A. Richardson, S. J., Cambaliza, M. O., Davis, K. J., Gaudet, B., Gurney, K. R., Huang, J., O’Keefe, D., Song, Y., Karion, A., Oda, T., Patarasuk, R., Razlivanov, I., Sarmiento, D., Shepson, P., Sweeney, C., Turnbull, J., and $\mathrm{Wu}, \mathrm{K}$.: High-resolution atmospheric inversion of urban $\mathrm{CO}_{2}$ emissions during the dormant season of the Indianapolis Flux Experiment (INFLUX), J. Geophys. Res.-Atmos., 121, 52135236, https://doi.org/10.1002/2015JD024473, 2016.

Law, R. M., Chen, Y., Gurney, K. R., and Transcom 3 Modellers: TransCom $3 \mathrm{CO}_{2}$ inversion intercomparison: 2. Sensitivity of annual mean results to data choices, Tellus B, 55, 580-595, 2003.

Law, R. M., Raupach, M. R., Abramowitz, G., Dharssi, I., Haverd, V., Pitman, A. J., Renzullo, L., Van Dijk, A., and Wang, Y.-P.: The Community Atmosphere Biosphere Land Exchange (CABLE) model Roadmap for 2012-2017, CAWCR Technical Report No. 057, 2012.

Le Quéré, C., Andres, R. J., Boden, T., Conway, T., Houghton, R. A., House, J. I., Marland, G., Peters, G. P., van der Werf, G. R., Ahlström, A., Andrew, R. M., Bopp, L., Canadell, J. G., Ciais, P., Doney, S. C., Enright, C., Friedlingstein, P., Huntingford, C., Jain, A. K., Jourdain, C., Kato, E., Keeling, R. F., Klein Gold- 
ewijk, K., Levis, S., Levy, P., Lomas, M., Poulter, B., Raupach, M. R., Schwinger, J., Sitch, S., Stocker, B. D., Viovy, N., Zaehle, S., and Zeng, N.: The global carbon budget 1959-2011, Earth Syst. Sci. Data, 5, 165-185, https://doi.org/10.5194/essd-5-1652013, 2013.

McGregor, J. L., Gordon, H. B., Watterson, I. G., Dix, M. R., and Rotstayn, L. D.: The CSIRO 9-level atmospheric general circulation model, CSIRO Div. Atmospheric Research Tech, Paper No. 26, 89 pp., 1993.

McGregor, J. L.: Semi-Lagrangian advection on conformal-cubic grids. Mon. Weather Rev., 124, 1311-1322, https://doi.org/10.1175/15200493(1996)124<1311:SLAOCC>2.0.CO;2, 1996.

McGregor, J. L. and Dix, M. R.: The CSIRO conformal-cubic atmospheric GCM, in: IUTAM Symposium on Advances in Mathematical Modelling of Atmosphere and Ocean Dynamics, Limerick, Ireland, 2-7 July 2000, edited by: Hodnett, P. F., Kluwer, Dordrecht, the Netherlands, 197-202, 2001.

McGregor, J. L.: A new convection scheme using a simple closure, in: Current issues in the parameterization of convection, BMRC, Melbourne, Australia, Research Report 93, 33-36, 2003.

McGregor, J. L.: Geostrophic adjustment for reversibly staggered grids. Mon. Weather Rev., 133, 1119-1128, https://doi.org/10.1175/MWR2908.1, 2005a.

McGregor, J. L.: C-CAM: Geometric aspects and dynamical formulation. CSIRO Atmospheric Research Technical Paper, No. 70, $41,2005 \mathrm{~b}$.

McGregor, J. L. and Dix, M. R.: An updated description of the Conformal-Cubic Atmospheric Model, in: High Resolution Numerical Modelling of the Atmosphere and Ocean, edited by: Hamilton, K. and Ohfuchi, W., Springer, New York, USA, 5176, 2008.

McKain, K., Wofsy, S. C., Nehrkorn, T., Eluszkiewicz, J., Ehleringer, J. R., and Stephens, B. B.: Assessment of groundbased atmospheric observations for verification of greenhouse gas emissions from an urban region, P. Natl. Acad. Sci. USA, 109, 8423-8428, https://doi.org/10.1073/pnas.1116645109, 2012.

Michalak, A. M., Hirsch, A., Bruhwiler, L., Gurney, K. R., Peters, W., and Tans, P. P.: Maximum likelihood estimation of covariance parameters for Bayesian atmospheric trace gas surface flux inversions, J. Geophys. Res., 110, D24107, https://doi.org/10.1029/2005JD005970, 2005.

Moncrieff, G. R., Scheiter, S. Slingsby, J. A., and Higgins, S. I.: Understanding global change impacts on South African biomes using Dynamic Vegetation Models, S. Afr. J. Bot., 101, 16-23, https://doi.org/10.1016/j.sajb.2015.02.004, 2015.

Newman, S., Xu, X., Gurney, K. R., Hsu, Y. K., Li, K. F., Jiang, X., Keeling, R., Feng, S., O'Keefe, D., Patarasuk, R., Wong, K. W., Rao, P., Fischer, M. L., and Yung, Y. L.: Toward consistency between trends in bottom-up $\mathrm{CO}_{2}$ emissions and top-down atmospheric measurements in the Los Angeles megacity, Atmos. Chem. Phys., 16, 3843-3863, https://doi.org/10.5194/acp16-3843-2016, 2016.

Nickless, A., Scholes, R. J., and Filby, E.: Spatial and temporal disaggregation of anthropogenic $\mathrm{CO}_{2}$ emissions from the City of Cape Town, S. Afr. J. Sci., 111, 2014-0387, https://doi.org/10.17159/sajs.2015/20140387, 2015.
Nickless, A., Ziehn, T., Rayner, P. J., Scholes, R. J., and Engelbrecht, F.: Greenhouse gas network design using backward Lagrangian particle dispersion modelling - Part 2: Sensitivity analyses and South African test case, Atmos. Chem. Phys., 15, 20512069, https://doi.org/10.5194/acp-15-2051-2015, 2015.

Nickless, A., Rayner, P. J., Engelbrecht, F., Erni, B., and Scholes, R. J.: An atmospheric inversion over the city of Cape Town: sensitivity analyses, Atmos. Chem. Phys., in prep., 2018.

NRC (Committee on Methods for Estimating Greenhouse Gas Emissions): Verifying greenhouse gas emissions: methods to support international climate agreements (9780309152112), The National Academies Press, Washington, DC, USA, 2010.

Oda, T., Lauvaux, T., Lu, D., Rao, P., Miles, N. L., Richardson, S. J., and Gurney, K. R.: On the impact of granularity of space-based urban $\mathrm{CO}_{2}$ emissions in urban atmospheric inversions: A case study for Indianapolis, IN, Elem. Sci. Anth., 5, 28, https://doi.org/10.1525/elementa.146, 2017.

Peylin, P., Baker, D., Sarmiento, J., Ciais, P., and Bousquet, P.: Influence of transport uncertainty on annual mean and seasonal inversions of atmospheric $\mathrm{CO}_{2}$ data, J. Geophys. Res., 107, 4385, https://doi.org/10.1029/2001JD000857, 2002.

Rayner, P. J., Enting, I. G., Francey, R. J., and Langenfelds, R. L.: Reconstructing the recent carbon cycle from atmospheric $\mathrm{CO}_{2}$, $\delta^{13} \mathrm{C}$ and $\mathrm{O}_{2} / \mathrm{N}_{2}$ observations, Tellus B, 51, 213-232, 1999.

Rayner, P. J., Law, R. M, Allison, C. E., Francey, R. J., Trudinger, C. M., Pickett-Heaps, C.: Interannual variability of the global carbon cycle (1992-2005) inferred by inversion of atmospheric $\mathrm{CO}_{2}$ and $\delta^{13} \mathrm{C}$ measurements, Global Biogeochem. Cy., 22, GB3008, https://doi.org/10.1029/2007GB003068, 2008.

Rotstayn, L. D.: A physically based scheme for the treatment of stratiform clouds and precipitation in large-scale models. I: Description and evaluation of the microphysical processes, Q. J. Roy. Meteor. Soc., 123, 1227-1282, 1997.

Roux, B.: Ultra high-resolution climate simulations over the Stellenbosch wine producing region using a variable-resolution model, MSc Thesis, Faculty of Natural and Agricultural Sciences, University of Pretoria, South Africa, 106 pp., 2009.

Schmidt, F.: Variable fine mesh in spectral global model, Beitr. Phys. Atmos., 50, 211-217, 1977.

Schuh, A. E., Lauvaux, T., West, T. O., Denning, A. S., Davis, K., J., Miles, N., Richardson, S., Uliasz, M., Lokupitiya, E., Cooley, D., Andrews, A., and Ogle, S.: Evaluating atmospheric $\mathrm{CO}_{2}$ inversions at multiple scales over a highly inventoried agricultural landscape, Glob. Change Biol., 19, 1424-1439, https://doi.org/10.1111/gcb.12141, 2013.

Schwarzkopf, M. D. and Fels, S. B.: The simplified exchange method revisited: An accurate, rapid method for computation of infrared cooling rates and fluxes, J. Geophys. Res., 96, 90759096, 1991.

Shiga, Y. P., Michalak, A. M., Gourdji, S. M., Mueller, K. L., and Yadav, V.: Detecting fossil fuel emissions patterns from subcontinental regions using North American in situ $\mathrm{CO}_{2}$ measurements, Geophys. Res. Lett., 41, 4381-4388, https://doi.org/10.1002/2014GL059684, 2014.

Shrout, P. E. and Fleiss, J. L.: Intraclass correlations: uses in assessing rater reliability, Psychol. Bull., 2, 420-428, 1979.

Seibert, P. and Frank, A.: Source-receptor matrix calculation with a Lagrangian particle dispersion model in backward mode, At- 
mos. Chem. Phys., 4, 51-63, https://doi.org/10.5194/acp-4-512004, 2004.

Seto, K. C., Dhakal, S., Bigio, A., Blanco, H., Delgado, G. C., Dewar, D., Huang, L., Inaba, A., Kansal, A., Lwasa, S., McMahon, J. E., Müller, D. B., Murakami, J., Nagendra, H., and Ramaswami, A.: Human settlements, infrastructure and spatial planning, in: Climate Change 2014: Mitigation of Climate Change. Contribution of Working Group III to the Fifth Assessment Report of the Intergovernmental Panel on Climate Change, edited by: Edenhofer, O., Pichs-Madruga, R., Sokona, Y., Farahani, E., Kadner, S., Seyboth, K., Adler, A., Baum, I., Brunner, S., Eickemeier, P., Kriemann, B., Savolainen, J., Schlömer, S., von Stechow, C., Zwickel, T., and Minx, J. C., Cambridge, UK and New York, NY, USA, 2014.

South African Department of Energy: Digest of South African energy statistics, Pretoria: Department of Energy, available at: http://www.energy.gov.za/files/media/explained/ 2009DigestPDFversion.pdf (last access: 10 July 2014), 2009.

South African Weather Service: Cape Point $\mathrm{CO}_{2}$ record, available at: https://ds.data.jma.go.jp/gmd/wdcgg/ (last access: 29 September 2016), 2014

Statistics South Africa: Census 2011 statistical release, P0301.4., Pretoria: Statistics South Africa, 2011.

Staufer, J., Broquet, G., Bréon, F.-M., Puygrenier, V., Chevallier, F., Xueref-Rémy, I., Dieudonné, E., Lopez, M., Schmidt, M., Ramonet, M., Perrussel, O., Lac, C., Wu, L., and Ciais, P.: The first 1-year-long estimate of the Paris region fossil fuel $\mathrm{CO}_{2}$ emissions based on atmospheric inversion, Atmos. Chem. Phys., 16, 14703-14726, https://doi.org/10.5194/acp-16-147032016, 2016.

Strong, C., Stwertka, C., Bowling, D. R., Stephens, B. B., and Ehleringer, J. R.: Urban carbon dioxide cycles within the Salt Lake Valley: A multiple-box model validated by observations, J. Geophys. Res., 116, D15307, https://doi.org/10.1029/2011JD015693, 2011.

Sugar, L. and Kennedy, C.: A low carbon infrastructure plan for Toronto, Canada, Can. J. Civil Eng., 40, 86-96, https://doi.org/10.1139/cjce-2011-0523, 2013.

Tans, P. and Keeling, R.: Mauna Loa $\mathrm{CO}_{2}$ monthly mean data, NOAA/ESRL (www.esrl.noaa.gov/gmd/ccgg/trends/) and Scripps Institution of Oceanography, available at: scrippsco2. ucsd.edu/, last access: 13 June 2016.

Tarantola, A.: Inverse Problem Theory and Methods for Model Parameter Estimation, Society for Industrial and Applied Mathematics, Philadelphia, PA, USA, 2005.

Thatcher, M. and McGregor, J. L.: Using a scale-selective filter for dynamical downscaling with the conformal cubic atmospheric model, Mon. Weather Rev., 137, 1742-1752, 2009.

Thatcher, M. and McGregor, J. L.: A technique for dynamically downscaling daily-averaged GCM datasets over Australia using the Conformal Cubic Atmospheric Model, Mon. Weather Rev., 139, 79-95, 2010.
Turnbull, J. C., Sweeney, C., Karion, A., Newberger, T., Lehman, S. J., Tans, P. P., Davis, K. J., Lauvaux, T., Miles, N. L., Richardson, S. J., Cambaliza, M. O., Shepson, P. B., Gurney, K., and Patarasuk, P.: Toward quantification and source sector identification of fossil fuel $\mathrm{CO}_{2}$ emissions from an urban area: Results from the INFLUX experiment, J. Geophys. Res.-Atmos., 120, 292-312, https://doi.org/10.1002/2014JD022555, 2015.

Uliasz, M.: The atmospheric mesoscale dispersion modeling system, J. Appl. Meteorol., 31, 139-149, 1993.

Uliasz, M.: Lagrangian particle modeling in mesoscale applications, in: Environmental Modelling II, Computational Mechanics Publications, Southampton, UK, 71-102, 1994.

UN-Habitat: Cities and climate change: global report on human settlements 2011, Earthscan, United Nations Human Settlements Programme (UN-Habitat), 2011.

Wang, Y. P., Kowalczyk, E., Leuning, R., Abramowitz, G., Raupach, M. R., Pak, B., van Gorsel, E., and Luhar, A.: Diagnosing errors in a land surface model (CABLE) in the time and frequency domains, J. Geophys. Res., 116, G01034, https://doi.org/10.1029/2010JG001385, 2011.

Whittlestone, S., Kowalczyk, E., Brunke, E. G., and Labuschagne, C.: Source Regions for $\mathrm{CO}_{2}$ at Cape Point Assessed by Modelling 222Rn and Meteorological Data, Technical Report for the South African Weather Service, Pretoria, South Africa, 2009.

Wu, L., Bocquet, M., Chevallier, F., Lauvaux, T., and Davis, K.: Hyperparameter estimation for uncertainty quantification in mesoscale carbon dioxide inversions, Tellus B, 65, 20894, https://doi.org/10.3402/tellusb.v65i0.20894, 2013.

Wu, L., Broquet, G., Ciais, P., Bellassen, V., Vogel, F., Chevallier, F., Xueref-Remy, I., and Wang, Y.: What would dense atmospheric observation networks bring to the quantification of city $\mathrm{CO}_{2}$ emissions?, Atmos. Chem. Phys., 16, 7743-7771, https://doi.org/10.5194/acp-16-7743-2016, 2016.

Zhang, L., Zhang, H., and Li, Y.: Surface energy, water and carbon cycle in China simulated by the Australian community land surface model (CABLE), Theor. Appl. Climatol., 96, 375-394, https://doi.org/10.1007/s00704-008-0047-z, 2009.

Zhang, H., Pak, B., Wang, Y. P., Zhou, X., Zhang, Y., and Zhang, L.: Evaluating surface water cycles simulated by the Australian community land surface model (CABLE) across different spatial and temporal domains, J. Hydrometeorol, 14, 1119-1138, 2013.

Ziehn, T., Nickless, A., Rayner, P. J., Law, R. M., Roff, G., and Fraser, P.: Greenhouse gas network design using backward Lagrangian particle dispersion modelling - Part 1: Methodology and Australian test case, Atmos. Chem. Phys., 14, 9363-9378, https://doi.org/10.5194/acp-14-9363-2014, 2014. 